\title{
Informed shared decision making and medical education
}

Citation for published version (APA):

Thistlethwaite, J. E. (2004). Informed shared decision making and medical education. [Doctoral Thesis, Maastricht University]. Universiteit Maastricht. https://doi.org/10.26481/dis.20041217jt

Document status and date:

Published: 01/01/2004

DOI:

10.26481/dis.20041217jt

Document Version:

Publisher's PDF, also known as Version of record

\section{Please check the document version of this publication:}

- A submitted manuscript is the version of the article upon submission and before peer-review. There can be important differences between the submitted version and the official published version of record.

People interested in the research are advised to contact the author for the final version of the publication, or visit the DOI to the publisher's website.

- The final author version and the galley proof are versions of the publication after peer review.

- The final published version features the final layout of the paper including the volume, issue and page numbers.

Link to publication

\footnotetext{
General rights rights.

- You may freely distribute the URL identifying the publication in the public portal. please follow below link for the End User Agreement:

www.umlib.nl/taverne-license

Take down policy

If you believe that this document breaches copyright please contact us at:

repository@maastrichtuniversity.nl

providing details and we will investigate your claim.
}

Copyright and moral rights for the publications made accessible in the public portal are retained by the authors and/or other copyright owners and it is a condition of accessing publications that users recognise and abide by the legal requirements associated with these

- Users may download and print one copy of any publication from the public portal for the purpose of private study or research.

- You may not further distribute the material or use it for any profit-making activity or commercial gain

If the publication is distributed under the terms of Article $25 \mathrm{fa}$ of the Dutch Copyright Act, indicated by the "Taverne" license above, 
Informed shared decision making and medical education 


\section{Acknowledgements}

My co-authors, Elizabeth Cockayne, George Ridgway.

I am grateful to the following journals for permission to publish the studies in this thesis:

- Medical Education

- Education for Primary Care

- Medical Teacher

- Education for Health

- International Journal of Pharmacy Practice

(C) Blackwell Science Ltd, Chapters $2 \& 7$

(C) Radcliffe Medical Press, Chapters 3, 8 \& 9

(C) Taylor \& Francis Ltd, Chapters 4 \& 6 (www.tandf.co.uk/journals)

(C) RPSGB, Chapter 5: Reproduced by permission of International Journal of Pharmacy

Practice published by Pharmaceutical Press, the Publications Division of the Royal Pharmaceutical Society of Great Britain.

(C) Jill E Thistlethwaite, Other chapters 


\title{
Informed shared decision making and medical education
}

\author{
PROEFSCHRIFT
}

Ter verkrijging van de graad van doctor aan de Universiteit Maastricht, op gezag van de Rector Magnificus, Prof. mr. G.P.M.F. Mols volgens het besluit van het College van Decanen, in het openbaar te verdedigen

Op vrijdag 17 december 2004 om 12.00uur

door

Jill Elizabeth Thistlethwaite 


\section{Promotor:}

Prof.dr. C.P.M. van der Vleuten

Copromotor:

Dr. J. van Dalen

Beoordelingscommissie:

Prof.dr. A.J.J.A. Scherpbier (voorzitter)

Dr. R. Lulofs

Prof.dr. J.C.M. Metz (UMCN, Nijmegen)

Prof. J. Morrison (University of Glasgow, United Kingdom)

Dr. P. Ram 


\section{Contents}

Introduction. Aim of the research

Chapter 1

Introduction and literature review

Chapter 2

Patient-centred consultations: a comparison of student experience and understanding in two clinical environments.

Published in: Medical Education 1999; 33: 678-685.

Chapter 3

The views of general practitioner tutors on developing medical students' communication and management skills.

Published in: Education for Primary Care 2004; 15: 370-377.

Chapter 4

An assessment of medical students' experiences of learning about the psychosocial enquiry during their introductory clinical course.

Published as: Medical Teacher 2001; 23: 65-70

Chapter 5

Are health professionals ready for the new philosophy of concordance in medicine taking?

Published in: International Journal of Pharmacy Practice 2001; 9: 81-89.

Chapter 6

Medical students' attitudes towards concordance in medicine taking: exploring the impact of an educational intervention.

Published in: Education for Health 2003; 16: 307-317. 
Making and sharing decisions about management with patients: the views and experiences of pre-registration house officers in general practice and hospital. Published in: Medical Education 2002; 36: 49-55.

Chapter 8

The use of incognito simulated patients in general practice: a feasibility study. Published in: Education for Primary Care 2003; 14: 419-425.

\section{Chapter 9}

Informed shared decision making: views and competencies of pre-registration house officers in hospital and general practice.

Published in: Education for Primary Care 2004; 15: 83-92.

Chapter 10

Discussion: conclusions, implications and recommendations

Summary

Curriculum vitae 
Introduction

Aim of the research 


\section{Aim of the research}

This thesis defines the concept of informed shared decision making (ISDM) between doctor and patient, and explores its current status in the undergraduate medical education curriculum and pre-registration year. The relevance of ISDM to modern medical practice is demonstrated by means of a literature review (chapter 1), which also provides a framework for the research in chapters 2 to 9 . These chapters explore whether ISDM is currently being learnt and practised by undergraduate medical students and doctors in their first year after graduation (pre-registration year), and ways in which the concept may be taught, fostered and assessed. Based on the results of this exploration, recommendations are made for changes to undergraduate medical curricula in chapter 10 .

This research has been stimulated by increasing interest in the principle of patient partnership as a way of practising medicine in the twenty-first century. In the United Kingdom the National Health Service (NHS) Executive has defined 'patient partnership' as encompassing two areas at the level of individual patient care'.

- Patients' involvement in their own care, as active partners with professionals

- Information being given to patients about their treatment so they may make informed decisions about this as they wish.

The NHS Executive is promoting the concept of patient partnership with the need to 'put patients first' and to develop 'health services and care that are truly responsive to the needs of users and patients'. The two areas of patient partnership are similar to the four stages of the shared decision making model as defined by Charles et al in 1997, though this latter model has a greater emphasis on doctor and patient building a consensus and agreeing on management ${ }^{2}$. The terms 'shared decision making', 'informed decision making' and 'informed shared decision making' are all used in the literature and need to be defined and differentiated. In the United States of America informed shared decision making has been suggested as the future of health care ${ }^{3}$, while the American Urological Association recommends shared decision making for prostate cancer screening ${ }^{4}$ and treatment.

However the 2002 Commonwealth Health Fund International Health Policy Survey of Sicker Adults found that about $50 \%$ of patients in the five countries surveyed felt that their regular doctor did not ask for their ideas and opinions about treatment and care (figures ranged from $47 \%$ in the USA and New Zealand to $67 \%$ in the UK) ${ }^{5}$. There are many possible reasons for these figures including lack of time, pressure of work, attitudes to patient care and lack of training. It is therefore timely to investigate whether today's medical students are being prepared for patient partnership and informed shared decision making in consultations in the future. 
'NHS Executive. Patient partnership: building a collaborative strategy' Leeds: NHS E; 1996.

${ }^{2}$ Charles C, Gafni A, Whelan T. Shared decision-making in the medical encounter: what does it mean? (or it takes two to tango). Social Science and Medicine 1997; 44: 681-692.

${ }^{3}$ Rockefeller R. Informed shared decision making: is this the future of health care? Health Forum Journal 1999; 42: 54-56.

${ }^{4}$ American Urological Association. Prostate-specific antigen (PSA) best practice policy. Oncology 2000; 14: 267.

${ }^{5}$ Blendon RJ, Schoen C, Des Roches C, Osborn R, Zapert K. Common concerns amid diverse systems: Health care experiences in five countries. Health Affairs 2003; 22: 106121. 
Chapter 1

Literature review and research questions 
This chapter reviews the literature in order to answer the following questions and to provide a conceptual framework for the research questions and the research itself contained in the chapters that follow.

- What is informed shared decision making (ISDM) and how has the concept evolved?

- Why is ISDM important?

- What is the relationship between ISDM and the concepts of patient partnership, the patient centred approach and concordance?

- Why should ISDM be taught and what should be learnt?

- Where should ISDM be learnt in the medical undergraduate curriculum?

- How may performance of ISDM be measured for formative and summative assessment purposes?

\section{WHAT is informed shared decision making?}

The notion of ISDM is not new; similar ideas were a feature of doctor-patient relationships two centuries ago. Patient involvement begins with the medical history and continues into discussion about treatment. Thus it is helpful to look the changes in medical history taking and management discussion over time.

\section{The medical history and early patient involvement}

The medical history was and is the mainstay of any attempt at diagnosis and subsequent management. As Roy Porter, an expert on the eighteenth and nineteenth century history of medicine wrote: "The reliance upon taking the history was a positive mark of the confidence felt by the expert clinician in his personal ability to assess a case solely from the patient's story and gross physical signs'" Taking a full history could take well over half an hour ${ }^{2}$ and often considered events over considerable periods of time ${ }^{3}$. Indeed, such was the confidence in history taking, and the contemporary lack of expertise in examination, that consultations were often conducted by mail ${ }^{4}$. In 1752 the clinician, John Rutherford, wrote: 'We must learn the nature of a disease by an accurate and distinct account of it from the patients...to discover its causes and the part affected" 5 .

Physicians had to take into account the beliefs of their patients, many of who had a wealth of concepts and remedies on which to draw. Moral, emotional and social factors were discussed in consultations as well as the physical details of the ailment. Medical knowledge was a part of the popular culture of the eighteenth century and patients expected to have a say in their treatment, in fact the consultation could be viewed as a negotiation about diagnosis and treatment between physician and patient as partners ${ }^{6}$.

\section{Erosion of patient partnership and the rise of paternalism}

This partnership was beginning to be eroded by the mid-eighteenth century because of increasing use of the hospital as a site to treat the sick, particularly the sick lower classes. Thomas Percival (1740-1804) advocated reinforcing paternalism, especially as regards these poorer and charity patients, though he admitted that adopting an authoritarian stance towards paying patients might be more difficult. However his book on medical ethics has little to say on how a consultation should be properly conducted ${ }^{6}$.

As doctors assumed control in hospitals with a subsequent increase in medical autonomy, the patient's narrative of illness became redundant. The nineteenth century saw a swing 
towards a more scientific basis for medicine with the establishment of scientific method and experiments ${ }^{7}$, which further eroded the doctor-patient partnership of the previous century. With the rise of scientific medicine the 'sick man' disappeared and the 'patient', a pathological body studded with lesions, made an appearance 8 . What went on in the consultation in these centuries is difficult to establish as the only evidence that remains is in the form of anecdotes relating doctor-patient encounters that tend to be about rich patients. As science advanced, and doctors became more diagnostically and therapeutically powerful, the bedside manner was often forgotten, though bedside tools such as the stethoscope and ophthalmoscope meant that examining a patient became important. The physical examination became a bridge between the doctor's scientific knowledge and the patient's symptoms'.

Primary care, established in the middle of the nineteenth century in the United Kingdom, gave everyone the opportunity to see a doctor. The concept of the family doctor, with its overtones of a strong personal bond between doctor and patient, did not exist before the early part of the nineteenth century 9 . In contrast with the movement towards laboratory science in medicine and the increasing use of hospitals by physicians and patients, in the nineteenth century the general practitioner still continued to visit patients at home and to treat the 'whole person', with the patient retaining a degree of control over the consultation".

\section{The biomedical model: the disease-centred approach}

In modern times the history is still the cornerstone of the medical encounter, though the reliance on laboratory tests may further shorten doctor-patient interaction at this point. The process of 'taking a history' differs depending on the patient and the nature of the presenting complaint or symptoms that have prompted the patient to seek medical help. Taking a history in a formal and structured way, though in a truncated form compared to that learnt and practised at medical school, tends to make the consultation disease or doctor-centred ${ }^{10}$. The components of the traditional medical history were defined in the first edition of Clinical Methods in 1887. This textbook, which became Hutchison's Clinical Methods and a favourite of medical students, defined history taking as the interrogation of the patient'." But by 1929 the text advised letting the patient 'tell (the) story in his own words' and suggested that 'the use of leading questions is only occasionally allowable...it may also be necessary in dealing with patients who are stupid by nature or as the result of disease ${ }^{12}$. Another late nineteenth century text advised student or physician 'to listen attentively and as far as possible without interruption to the patient's own statement of his case' but suggested that the histories of the rich were reliable while those of the poor were not and that to distrust or disregard the word of paying patients was professional suicide ${ }^{13}$.

After an initial query from the doctor as to the nature of the problem and the patient's opening description of the symptoms, the doctor sets the agenda by asking questions in order to formulate a list of differential diagnoses or the most likely nature of the patient's problem. In 1993 the sociologists Fisher and Todd suggested that the structure of the consultation reflects a mechanistic view focused on disease rather than health or prevention, arising from the germ theory of illness and the division of mind and body ${ }^{14}$. 
The biomedical model, in which illness is explained in terms of pathophysiology and the resulting disease, is limited because it does not take into account that health and illness are also shaped by personal and social as well as biological factors. This model leads to a disease-centred approach where the main tasks of the doctor are to diagnose illness from a biological perspective and to treat it, hopefully affecting a cure. The drive to make a diagnosis is extremely strong. This biomedical model disconnects medicine from the social fabric of patients' lives ${ }^{15}$. The traditional history-taking format has also been criticised as being unproven in its effectiveness in improving medical conditions ${ }^{16}$.

Disease-centred, or doctor-centred ${ }^{17}$, consultations usually end with the doctor making a diagnosis and prescribing treatment. The patient is not involved in any management decisions and thus may not take the prescribed treatment correctly, if at all, or may seek another opinion. The prescribing of medicines is the most common intervention in health care, yet it is estimated that around $50 \%$ of patients do not take their medicines as intended $^{18.19}$. Misunderstandings about prescriptions between doctor and patient often relate to failure of communication about the doctor's decisions, leading to non-adherence to treatment ${ }^{20}$. Doctor-centred consultations hinder compliance with treatment ${ }^{21}$, the term compliance in itself suggesting the power base of the transaction.

Doctor-centred behaviour also stems from the idea that there is a competence gap between the doctor and patient, ie the difference in the level of knowledge between doctor and patient, a gap that is bridged by trust. In 1951 Parsons, a functionalist sociologist and professor at Harvard, wrote that illness is not strictly a pathophysiological process but is also a social phenomenon. When people become ill they adopt a sick role, behaviour that may be seen as a form of deviance. The doctor then acts as an agent of social control, allowing or not the patient's continuation of this role by the doctor's power of sick certification. In Parson's analysis, the doctor-patient relationship is a formal and distant one. The doctor is concerned only with the patient's health and less interested in matters that are not health-related ${ }^{22}$. The doctor expects the patient 'to obey' the doctor without question while the doctor gives the minimum amount of information to the patient.

\section{Integrating content and process}

Early work on involving patients in the consultation process, beyond merely answering a list of generally closed questions and then being 'prescribed' what to do, include that of Balint, a psychoanalyst who worked with groups of general practitioners in the UK from the late 1950s. He focussed on exploring the nature of the doctor-patient relationship and practical ways of reaching understanding of patients' illnesses ${ }^{23}$.

In the 1970s and 1980s doctors and sociologists began to dissect the nature of the consultation in more detail, looking at how doctors communicate with patients, in an attempt to define the tasks and behaviours of the consultation. Tasks are those areas that should be explored or discussed (content) while behaviours are how the doctor achieves them (process). Content and process have all too often been treated as separate entities. At an undergraduate medical education level for instance communication skills (process) have often been learnt separately from history taking (content). Integration of the two in clinical skills teaching marries the task-orientated consultation with the patient-centred behavioural approach ${ }^{24}$. 


\section{Involving the patient: the biopsychosocial model \& patient-centred care}

Balint and his co-workers first used the term 'patient-centred medicine' in 1970, a reference to the client-centred therapy expounded by the psychologist Carl Rogers ${ }^{25}$. The term was contrasted with 'illness-centred'. Byrne and Long compared the patient-centred style with what they called the doctor-centred style of consulting ${ }^{17}$. In the latter the manner of consulting is based only on the doctor's knowledge and questioning of the patient in order to formulate a diagnosis whereas the former incorporates the patient's experiences and health beliefs. In a patient-centred consultation the doctor and patient consider the patient's condition and diagnosis in partnership and the management or treatment plan is negotiated between the doctor and patient.

Stott and Davis emphasised the need within the consultation to combine clinical acumen with an insight into human behaviour ${ }^{26}$. They suggested that doctors need to develop skills in order to make a comprehensive assessment of the patient's problems: 'the integrated physical and psychosocial formulation is relevant to every speciality'. This formulation helps to widen the diagnostic process. They concluded that the tasks of the consultation encompass modification of health-seeking behaviour and opportunistic health promotion as well as the diagnosis and management of new and continuing problems.

In 1983 the psychologist Pendleton wrote that '...it would seem that satisfaction of the patient is more likely when the doctor discovers and deals with the patient's concerns and expectations; when the doctor's manner communicates warmth, interest and concern about the patients, when the doctor volunteers a lot of information and explains things to the patient in terms that are understood, 27 .

The patient-centred approach to the consultation recognises that a patient's problem may be defined in terms of its physical, psychological and social components (the biopsychosocial model ${ }^{28.29}$ ). The cause of the problem, how the patient handles it and its course are determined by the patient's 'understanding of and emotional response to what is happening'30. Bensing has defined psychosocial care as 'receptiveness for and treatment of the (aetiological and consequential) non-somatic aspects of the presented health problem ${ }^{31}$. Thus, ultimately, a diagnosis may encompass more than a medical problem. The doctor needs to be aware of the nature and cause of the problem, the reason for the patient seeking medical advice at the time and should try to discover the patient's ideas, concerns and expectations.

\section{The patient-centred clinical method}

In Ontario Canada in 1986, a group of doctors (including IR McWhinney) working within the Department of Family Medicine described a model for the consultation that they also called 'the patient-centred clinical method'32. This method was defined and refined following an analysis of one thousand audiotaped consultations in South Africa. They divided the consultations into 'effective' and 'less effective'. One of the defining characteristics of the effective consultations was the doctor eliciting the patient's concerns and expectations. In less effective consultations the doctor failed to recognise or ignored the patient's agenda. 
Most patients come to the consultation with a particular agenda and this needs to be explored, this agenda is often not the 'presenting complaint' mentioned first by the patient $^{33}$. The patient's social circumstances and the effect these have on the problem are also areas that should be elicited during the consultation. Conversely the doctor should explore what effects the patient's problem is having on the patient's social and family life. This line of inquiry is referred to as the psychosocial history or perspective and is one of five components of patient-centredness as defined in the literature ${ }^{34}$, the others being the 'patient-as-person', sharing power and responsibility in the consultation, the therapeutic alliance and the 'doctor-as-person'.

\section{Evidence for the patient-centred approach}

Learning and practising the patient-centred model should help doctors improve healthcare outcomes $^{35}$. Effective information gathering using a patient-centred approach has been shown to improve such outcomes ${ }^{36}$. If the doctor asks many questions about the patient's understanding of the problem, explores concerns and expectations and discusses the impact of the problem on daily life, there is better resolution of anxiety ${ }^{37}$ and symptoms ${ }^{38}$. If the patient is able to express him or herself and feels that there has been a full discussion of the problem, physical limitation is reduced ${ }^{39}$ and health status improves $^{40}$. Patients, particularly those with psychosocial problems, want a patientcentred approach with a doctor who communicates well ${ }^{4}$.

\section{Sharing information and ideas}

Having elicited the patients' concerns and ideas, doctors are still in the position of deciding how much information to give patients. The quantity and quality of this information affects how patients make decisions relating to their own health care and may limit their choice of treatment depending on the number of options they are given. Fletcher $^{42}$ and Walton et $\mathrm{al}^{43}$ gave similar recommendations as to what doctors should routinely tell patients in consultations. These include

- The possible diagnosis

- Necessary investigations and what they involve

- What the investigations might show

- The treatment

- The likely outcome of treatment

An eloquent account of the tension between minimal sharing of information and absolute disclosure of all possible adverse effects by doctors is given in Jay Katz's book 'The Silent World of Doctor and Patient' published in $1984^{44}$. Katz is a physician and law professor at Yale University. His thesis is that doctors wish to preserve the mystique of their profession and believe that lay incompetence in relation to medical matters means that only a limited amount of explanation is needed for patient agreement to treatment. Katz feels that 'the affirmation of physician's commitment to patients' physical needs...had failed to address physicians' lack of commitment to patients' decision making needs ${ }^{, 44}$.

Eliot Freidson, an American sociologist and notable critic of the medical profession, suggested in 1970 that doctors purposefully withhold information from patients in order to maintain their professional dominance and power ${ }^{45}$. This stems from their 'splendid isolation' from society at large and leads to the exertion of an unreasonable level of social 
control $^{46}$. While many may disagree with this motive, doctors have been shown frequently to be poor at giving information, whether this is information about the illness ${ }^{47}$ or information following a procedure. It is not only an inability to communicate to patients in the appropriate language and detail that causes problems, but doctors' value judgements about what patients should be told. For example, patients expect to receive more detailed information about adverse events during operations than doctors are happy to deliver ${ }^{48}$. This may be partly due to the fact that doctors want to spare patients from information that the patients might find upsetting. However doctors also fail to communicate because of pressures on time and the difficulty of the task. They are also reluctant to risk losing a patient's trust and possibly being sued, yet poor communication itself has been shown to increase the likelihood of malpractice suits ${ }^{49}$.

In 1989 Roter suggested that the skill of a doctor in information giving is paramount for patient compliance and recall. 'Information-giving may be viewed as enhancing patient power and increasing the patient's ability to participate actively in the therapeutic process ${ }^{, 50}$.

\section{The patient as expert}

In 1985 a group of social scientists at the Health Education Studies Unit in Cambridge published the results of their research study into medical consultations. The aim of the work was to study the extent to which ideas are shared between doctors and patients, in particular to look at what is said or done in consultations to help patients understand what is happening to them. The patient was defined as an expert about his or her illness. By asking about a patient's ideas about the illness or problem, the doctor would tap into this expertise and then share his or her own professional diagnosis of the problem in turn with the patient ${ }^{51}$. Thus, while not mentioning patient-centredness specifically, the approach is similar to that of the other workers already mentioned.

In conclusion Tuckett and colleagues argued that patients should be treated as experts. They defined that successful shared understanding has taken place if, following a consultation, a patient can remember the key points of what the doctor said and be aware of points of conflict and difference between himself and his doctor. They make recommendations for future training of general practitioners, but do not extend this to hospital-based doctors ${ }^{5 !}$.

\section{Models of the doctor-patient relationship: affecting management}

The need to address the issue of poor compliance has led to research on why patients do not always do as their doctor advises and on ways in which to improve compliance. According to the patient-centred model, the doctor and patient should make management decisions in partnership ${ }^{32}$, thus aiding compliance with treatment and improving the outcome for the patient ${ }^{52}$. Management decisions will be affected by the patient's concerns and expectations as elicited during the history taking.

This partnership between doctor and patient is only one model of the doctor-patient relationship. There are a number of descriptions of the relationship based on the locus of control within it. Szasz and Hollander in 1956 provided an early discussion of three theoretical models of doctor-patient relationship and suggest that which one of these is uppermost at any particular time depends on the nature of the patient's problem and the setting of the consultation ${ }^{53}$. The models are graded from the doctor being active while 
the patient is passive (activity-passivity) via the patient having limited power while being expected to co-operate with the doctor's advice (guidance-co-operation) to there being a state of mutual participation. This last model is the most difficult to sustain. Doctor and patient must be aware of the other's needs, wishes and individuality.

Over thirty years later Roter and Hall wrote about the spectrum of high and low control ${ }^{54}$. There are four possible combinations of such control between physician and patient. High physician control combined with low patient control leads to a consultation in which the doctor dominates and makes decisions. 'This is the traditional form of the doctor-patient relationship and is still the most common.' The patient should co-operate with medical advice and do what he or she is told. This traditional form, also classified as paternalism, is described as patients drawing comfort and support from the doctor as a 'parent figure'.

At the other end of the spectrum from paternalism, there is a danger in the physician adopting a completely neutral stance and giving the patient a range of options without expressing any preference, the "informed model" been seen as a move towards increased patient autonomy but has been criticised as sacrificing competence for control as physicians withhold their own experience and recommendations to avoid overly influencing patients ${ }^{56}$. Therefore the shared model (the patient as partner; management by negotiation) is now in the ascendancy. It has also become part of UK national policy as defined by the NHS Executive ${ }^{57}$. However it should be noted that there is often difficulty in distinguishing between shared decision making and informed choice and that separating the two models is not actually justified ${ }^{58}$, hence my use of the term ISDM. Quill \& Brody in the USA refer to ISDM as 'enhanced autonomy ${ }^{56^{\circ}}$, which allows the doctor to support and guide the patient's decision making without surrendering the medical power on which the patient depends.

This growing consensus that patients should be more involved in decisions about their care has arisen from various powerful ideas including political trends, ethics and health service research ${ }^{59}$. It has been suggested that the model is of particular benefit for clinicians intervening to reduce the risk of disease in their patients, where individualised calculations of risks and benefits are used and where choices about treatment are being made ${ }^{60}$. The doctor-patient relationship is important in effective risk communication; patients prefer doctors who know them well and for sometime to discuss risks as the doctors then understand the patients' preferences and need for information ${ }^{6 !}$. Doctors also find it easier to share decision making with patients they know well ${ }^{62}$, which has implications for the current trend away from personal lists for GPs to multidisciplinary care and lack of continuity due to patients not being able to stick to seeing one doctor.

\section{Informed shared decision making}

Sharing decisions is not simply sharing information. While courses in communication skills are now commonplace in undergraduate and postgraduate medical curricula, particularly for GP registrars on vocational training schemes, these mainly concentrate on the first part of the consultation (achieving rapport, matching agendas, problem-solving) rather than management and negotiation ${ }^{63}$. 
Charles et al have defined one model of shared decision making that has four main characteristics:

- Both the patient and the doctor are involved

- Both parties share information

- Both parties take steps to build a consensus about the preferred treatment

- Doctor and patient reach an agreement on the treatment to implement ${ }^{64}$.

For such shared decision making to be carried out in practice the commitment of both doctor and patient to engage in the process is crucial although the extent of involvement may vary.

Towle has suggested a series of steps that should occur in consultations that would enable doctors and patients to share in the decision-making process:

- Establishing a context in which patients' views about treatment options are valued and necessary.

- Eliciting patients' preferences so that appropriate treatment options are discussed.

- Transferring technical information to the patient on the treatment options, risks and their probable benefits in an unbiased, clear and simple way.

- Physician participation includes helping the patient conceptualize the weighing process of risks versus benefits and ensuring that their preferences are based on fact and not misconception.

- Shared decision making involves the physician in sharing the treatment recommendation with the patient and/or affirming the patient's treatment preference ${ }^{65}$.

Towle labels the process of decision-making in this way as ISDM, ie informed shared decision-making. From the above steps a list of ISDM competencies for doctors is derived:

1. Develop a partnership with the patient.

2. Establish or review the patient's preferences for information (eg amount, format).

3. Establish or review the patient's preferences for role in decision-making (eg risk taking; degree of involvement of self and others) and the existence/nature/degree of decisional conflict (where decisional conflict is defined as the state of uncertainty about the course of action to take).

4. Ascertain and respond to patient's ideas, concerns and expectations (eg about disease management options).

5. Identify choices (including ideas and information patient may have) and evaluate the research evidence in relation to the individual patient.

6. Present (or direct to) evidence taking into account \#1 and \#2 above, framing effects etc (where framing effects are when the presentation of the same information in different formats changes the decisions that people make) and help patient to reflect upon and assess the impact of alternative decisions vis a vis his/her values and lifestyles.

7. Make or negotiate a decision in partnership and resolve conflict.

8. Agree upon an action plan and complete arrangements for follow-up ${ }^{66}$.

Towle \& Godolphin discuss three recurring objections they have encountered in the course of their work ${ }^{67}$. These include the amount of time that ISDM would take in consultations; doctors stating that they already involve patients in management decisions; 
and the likelihood that not all patients would want to be involved in deciding on their treatment. They suggest that if ISDM does take longer it may still be more efficient in terms of health outcomes; that the evidence shows that many doctors do not involve patients; and that patients need experience in sharing and doctors need to encourage patient autonomy.

Greenhalgh $^{68}$ and Gambrill ${ }^{69}$ in commentaries on ISDM have criticised the above competencies particularly in relation to the task of developing a partnership with the patient. The process of developing a partnership, suggesting a suitable doctor-patient relationship, is complex and involves several skills of its own. Moreover such doctorpatient relationships implying continuity are difficult to develop and maintain in today's health service, particularly where teams of doctors and health professionals look after many patients with complex problems in both primary and secondary care.

A fundamental step in the informed shared decision making process is the decision by the doctor as to which management options should be described. The ideas of the doctor as to the correct course of action will obviously colour his or her choice of which options to present to the patient. Doctors choose the amount and type of information they give in order to influence patients' choices ${ }^{70}$. The options may be limited by the doctor's lack of knowledge in a particular field, or by previous experience of a treatment causing an adverse reaction in a patient. Even when a menu of options is presented, the doctor may already have decided on his or her personal recommendation, and thus how the choices are presented is affected by this opinion. However there will be times when the approaches to management are completely open with the doctor having no firm opinions as to which is preferable. Elwyn and colleagues have named this situation clinical 'equipoise', defining it as when the doctor admits there are two or more approaches to management and he or she does not have a strong view towards any of them ${ }^{71}$. It is at moments like these that the patient is truly involved in the decision making process.

It is important to remember that patient centred care does not necessarily mean sharing all information and decisions about care, rather it means taking into account the patient's wish for information and preference for sharing decisions or not ${ }^{72}$. Of course some patients will not wish to share decisions ${ }^{73}$, preferring the doctor to choose the management. However it is difficult for doctors to guess which patients prefer a nonparticipatory role ${ }^{74}$ and therefore it is important for the doctor to explore patient preferences, even if the patient does not wish to make the final decision ${ }^{75}$, and not assume or make value judgements as to whether a particular patient wishes to share in the decision making process.

Elwyn, working with a team of researchers into ISDM in clinical practice at the University of Wales, has suggested that ISDM needs to be 'adequately defined, developed and implemented in practice and exposed to accurate means of measurement ${ }^{76}$. From the literature discussed above a working definition of ISDM is proposed as a process linked to the patient-centred clinical method, which involves doctors and patients sharing information in order to negotiate a management plan based on a set of appropriate options. 


\section{WHY is informed shared decision making important? \\ Improving 'compliance'}

We know that about 50 per cent of patients with chronic diseases do not take their medication as prescribed in fully therapeutic doses ${ }^{77}$. Bensing and colleagues in 2003 have defined non-compliance as the best-hidden taboo in medical encounters ${ }^{78}$ though research on its antecedents and ways to improve compliance has been carried out for many years. Compliance has been defined as the extent to which a patient's actual history of drug taking corresponds to the prescribed regimen ${ }^{79}$. That eliciting patients' worries and expectations (patient-centred approach) and giving clear, jargon-free, explanations of the diagnosis and its causes improve satisfaction and compliance has been documented over thirty years ago by in the USA ${ }^{80}$. 'Adherence' is another term that has been used to describe patient behaviour in regards to medicine taking ${ }^{81}$.

As not all doctor-patient interactions end with the giving and receiving of a prescription, it is important to look at ISDM in the context of other outcomes as well as adherence to medicine taking. Improved quality of diabetes care through change in patients' risk factor behaviour has been shown to result from GPs being supported to negotiate realistic individual goals with their patients ${ }^{82}$. Supporting patients to negotiate decisions also improves patient satisfaction and diabetes control ${ }^{83}$. While important physician attributes according to women with breast cancer are: expertise, being able to develop and maintain a personal relationship and showing respect for patients as autonomous individuals ${ }^{84}$. The amount of information was not perceived to be as important as the nature of that information and the way in which it was presented.

\section{Informed shared decision making aids concordance}

A group of researchers funded in part by the Department of Health Prescribing Research Initiative in the UK have focused on the first two of the four characteristics as defined by Charles et $\mathrm{al}^{64}$ listed above. Their research looks at issues relating to doctor-patient communication and prescribing, in particular misunderstandings about prescriptions ${ }^{85}$ and patients' unvoiced agendas regarding treatment ${ }^{86}$. Overall they came to the conclusion that there is little evidence that at present doctors and patients do share information and views about medicines, leading to the prescription of drugs that patients do not want and do not take ${ }^{87}$. This work is part of a larger project looking at the concept of concordance, a concept that encompasses the role of both doctor and patient as regards medicine taking. The term concordance is preferred to compliance, the latter with its overtones of paternalism and 'doctor knows best ${ }^{88}$. The consensus in this field is that improved communication between doctor and patient and informed shared decision making in the consultation will improve concordance, leading eventually to a reduction in the number of unwanted drugs prescribed and improved patient satisfaction" ${ }^{21}$. 'The aim of concordance is to optimise health gain from the best use of medicines, compatible with what the patient desires and is capable of achieving. ${ }^{21}$ While concordance has been defined in relation to the use of medicines, it is a word that also encompasses the process of informed shared decision making. The optimum consultation is thus a concordant one, though perhaps this is not the most elegant way of defining the outcome. 


\section{What is the relationship between ISDM and the concepts of patient partnership, the patient centred approach and concordance?}

A comparison between the terms, explored above, used to describe aspects of the four concepts: patient partnership, ISDM, patient-centred and concordance is made below, demonstrating the relationships between them.

Patient partnership ${ }^{57}$

Patient's involvement

Information sharing

Informed decisions

\section{ISDM $^{64}$}

Both the patient and the doctor are involved Both parties share information

Both parties...build a consensus about the preferred treatment

Doctor and patient reach an agreement on the treatment to implement

Concordance
Encompasses the role of both doctor and
patient as regards medicine taking
Decisions about medicine-taking being a
negotiation between partners
Therapeutic alliance

\section{WHY should ISDM be taught and WHAT should be learnt? Implications for medical education}

The literature suggests that informed shared decision making is an important component in modern doctor-patient interactions and consultations. However in a systematic review of health care provider consulting style on health outcomes in diabetes, van Dam and colleagues conclude that attempting to change providers to a more patient-centred style is difficult. The change is hard to sustain and intensive support is required ${ }^{89}$. Introducing the concept of the patient-centred approach and ISDM as topics in the early years of medical training at undergraduate and early postgraduate stages may help medical students and doctors adopt this consultation style and reduce the need for such change later in their careers.

Consideration needs to be given as to how these topics may be taught at the undergraduate level as evidence suggests that many doctors do not have the requisite skills required at present. The director of the King's Fund in the UK wrote in the British Medical Journal towards the end of 1999 that 'paternalism is endemic in the NHS',90. A patient-centred approach in the first half of an interview may still become paternalism in the second, as consultations where both the doctor and patient are involved in management decisions are $\operatorname{rare}^{91}$. GP registrars, following undergraduate and postgraduate training, and during vocational training for general practice, report that they are not receiving the necessary training in the skills needed for successful involvement of patients in decision making ${ }^{22}$. Candidates in the MRCGP examination in the UK, whose consulting skills are assessed by submission of a videotape of seven consultations, have been shown to have only limited ability to achieve patient-centred outcomes including involving patients in decision making ${ }^{93}$. An assessment of interns' skills in 2000 found 
that while the interns felt competent in history taking and clinical examination, they felt they were less skilled in clinical management and giving information sensitively ${ }^{94}$. A 2002 survey of patients in five countries (USA, Canada, UK, Australia and New Zealand) found that about half the respondents did not feel that their regular doctor asked for their ideas and opinions about treatment and care ${ }^{95}$. These results relate to doctors who started their undergraduate training more than seven years ago since when there have been changes in undergraduate curricula.

There are no international guidelines for medical education but some countries have published recommendations for undergraduate curricula that include consultations skills and ISDM, for example the UK and the USA.

\section{Tomorrow's doctors (United Kingdom perspective)}

This is the title of a document produced by the General Medical Council (GMC) of the United Kingdom in 1993 and is a set of recommendations on undergraduate medical education for British universities ${ }^{96}$ (revised in $2002^{97}$ ). When considering how ISDM should be taught and the implications of the consultation model considered above for medical education, these recommendations are a good guide to what the medical establishment in the United Kingdom expects the knowledge, skills and attitudes of the modern graduating doctor to be in broad terms.

The recommendations that are of interest to this thesis are:

Expectations have risen and patients are concerned to understand the nature of their problems and the consequences of their treatment. The relationship between doctor and patient has changed and there is a clear duty on the doctor to be able and willing to communicate effectively, an attribute that must be developed throughout the undergraduate course. (Introduction, $\mathrm{p} 4$ )

By the end of the undergraduate course the student will have acquired a knowledge and understanding of....

(j) The importance of communication, both with patients and their relatives...(Objectives, pl3)

At the end of the course of undergraduate education the student will have acquired ...the ability to

(i) Obtain and record a comprehensive history

(iv) Reach a provisional assessment of patients' problems and formulate with them plans for investigation and management (Skills, p14)

Doctors must be good listeners if they are to understand the problems of their patients and they must be able to provide advice and explanations that are comprehensible to patients... (Communication skills, pl7)

Annex $A$ to the document lists the attributes of the independent practitioner. This person is not defined as any particular level of doctor, pre-registration, post-registration, specialist trained. The independent practitioner is the person to offer advice.

\section{Attitudes of the independent practitioner}

3. Possession of consultation skills which include: 
(c)...the ability to exercise sound clinical judgement to analyse symptoms and physical signs in pathophysiological terms, to establish diagnoses, and to offer advice to the patient taking account of physical, psychological, social and cultural factors.

(Annex A, p25)

But the patient may choose to decline such advice.

8. The maintenance of attitudes and conduct appropriate to a high level of professional practice, which includes:

(b) Recognition that good medical practice depends on partnership between doctor and patient, based upon mutual understanding and trust; the doctor may give advice but the patient must decide whether or not to accept it. (Annex A, p26)

\section{Learning objectives for medical student education (United States of America perspective)}

A shift towards more patient-centred care has been occurring in the USA ${ }^{98}$. As early as 1984 Lipkin et al proposed a core curriculum for teaching medical interviewing to internists that included patient-centred interviewing and treatment as well as an integrated (biopsychosocial) approach to patient care ${ }^{99}$. However such a curriculum should be covered during undergraduate training. The Association of American Medical Colleges produced a set of guidelines for medical schools in $1998^{100}$. The aim of this document was 'to stimulate changes in medical education to create a better alignment of educational content and goals with evolving societal needs, practice patterns and scientific developments'.

The guidelines state that: In all of their (physicians') interactions with patients they must seek to understand the meaning of the patients' stories in the context of the patients' beliefs, and family and cultural values. (p4).

There is direct reference to sharing options with patients:

(Physicians) nulust understand the scientific basis and evidence of effectiveness for each of the therapeutic options that are available for patients at different times in the course of the patients' conditions and be prepared to discuss those options with patients in an honest and objective fashion. (p6)

The report goes on to suggest that not all the recommended learning objectives have outcomes that can be measured and that further work in needed in this area. However the passages above demonstrate that the AAMC is in line with the GMC in recommending that medical students learn shared decision making.

Informed shared decision making and undergraduate education.

The competencies defined by Towle et $a l^{66}$ listed above are currently being used as the basis for developing several different types of educational programmes aimed at faculty staff who serve as role models for medical students at the University of British Columbia. Questions are still being asked as to how such competencies may be taught to medical students, particularly as they learn clinical medicine in a predominantly hospital setting. In particular medical students are unlikely to have the opportunity to develop partnerships with patients that are ongoing over time. 
Towle et al in their work on defining the competencies interviewed practising physicians who had not learnt the competencies in medical school nor in formal educational programmes. However many of them had, during the years since qualification, begun to consult in a patient-centred way including involving patients in management decisions. They identified a variety of influences that had led them to this approach:

- trial and error (including mistakes)

- observing colleagues

- clinical experience in different settings

- teaching medical students

- self reflection on consultations

- role models

- long held attitudes about relationships with patients ${ }^{66}$.

Biomedical sciences are still the predominant subjects in the undergraduate medical curricula of the UK, though they are now integrated and usually taught as systems-based courses. However, the revised curricula of the post Tomorrow's Doctors world contain modules including communication skills, ethics, personal and professional development with a slant towards producing reflective practitioners. It might be expected that medical students and recent graduates of such programmes would demonstrate patient-centred and ISDM skills in contrast to doctors who qualified before the changes were in place.

Medical students tend to have a concrete view of their chosen profession. Doctors treat sick people in order to make them better though this is not always possible. The hospitalbased nature of much of their study stresses the importance of high technology medicine, investigations and treatment often at the expense of the personal touch of the caring physician. The effect of communication skills training on qualified doctors is variable and ongoing performance feedback is an important feature of such courses ${ }^{101}$. Feedback is also important at the undergraduate level where communication skills modules, often being taught as a special stand-alone subject rather than being integrated into basic history taking and examination skills, are not always successful at providing a clear framework within which to practise. Certainly such teaching is often only taken seriously if rounded off with an examination that must be passed; students' learning behaviour being strongly influenced by assessment procedures ${ }^{102}$. Silverman et al ${ }^{103}$ have proposed a programme of what to teach and learn in a communication skills curriculum based on their Calgary-Cambridge observation guide ${ }^{104}$. This guide includes shared decision making.

\section{Teaching and learning ISDM}

An integrated approach to teaching communication and consultation skills throughout the undergraduate programme extending into the postgraduate years has been suggested as the optimum way to train students in such skills ${ }^{105}$. In the early undergraduate years the communication skills syllabus would include developing the skills of starting an interview and information gathering, moving onto more formal history taking in parallel with an increase in clinical exposure and later to explanation, planning and shared decision making ${ }^{103}$.

Well-established methods of teaching communication and consultation skills are delineated and described in great detail in medical education literature. The skills-based 
approach $^{103}$ recognises that communication is a series of learned skills and that practice with observation and feedback is required to achieve acquisition of new skills and a change in learners' behaviour. Appropriate teaching methods include a mixture of didactic, eg lectures and presentations; experiential methods, eg role-play ${ }^{106}$, exercises; consultations with simulated patients ${ }^{10 \%},{ }^{108}$; observation and feedback of real consultations either with the teacher 'sitting in' with the learner or via video taping and subsequent analysis ${ }^{109,110}$. Each method has its advantages and disadvantages.

\section{WHERE should ISDM be learnt?}

\section{Differences in approach: primary, secondary and tertiary care}

Work on the nature and facilitating of patient autonomy has been carried out in both hospital and general practice settings. In 1987 Brodky postulated that a difference in the relationship between primary care physicians and tertiary care physicians affects the degree to which patient autonomy may be facilitated in the different settings ${ }^{111}$. He suggests that the tertiary care setting is characterized by what he calls a 'decisional ethic', that doctors and patients in such settings tend to have no prior relationship with each other and are likely to part company in the future. In contrast, the relationship between the primary care physician or GP and the patient is likely to be a long-term one and this relationship is characterized by a 'relational ethic'.

The decisional ethic leads to questions such as 'what degree of autonomous choice is this patient capable of with regard to this immediate pressing medical decision?' whereas the relational ethic leads to the doctor asking 'what can I do to enhance this patient's autonomy for the future?' The GP recognises that the patient's ability to decide or negotiate management may vary over time and thus his or her approach to particular consultations with this patient need to be adjusted to take this into account. Decisionmaking is helped by being preceded by a process of social dialogue in which the patient and doctor bounce ideas off each other and work through the options together. As Brodky wrote: 'we can be helped both by those who know us well as individuals and recognize our core values and projects and also by those who have technical expertise relating to the decision at hand. Within the relational ethic, the primary care physician can offer at least one and sometimes both these types of assistance.'111

Thus when thinking of the training that doctors require, it appears to be important that they are exposed to a variety of learning experiences in different settings, hospital and community. In hospital settings students will observe clinicians seeking informed consent from patients for procedures, a process that must include explanation and discussion of risk ${ }^{1 / 2}$, components of shared decision making.

\section{Community-based and primary care education}

The traditional focus for undergraduate learning has been the hospital and increasingly the tertiary care setting attached to the university and medical school. But a higher proportion of medical education is now taking place in community and primary care settings. The impetus for this change arose first in the developing world ${ }^{113}$, with Europe and the USA also adopting a move towards a higher proportion of such education ${ }^{114}$. The reasons for this are well documented and include: changing patterns of healthcare 
delivery with reduced numbers of hospital in-patients ${ }^{115}$, recognition that patients in teaching hospitals are not representative of the general population ${ }^{116}$ and an emphasis on community management of chronic disease ${ }^{117}$.

Due to similar changes in how patient care is delivered, with an emphasis on a primarycare led NHS, and the subsequent decrease in hospital beds in the United Kingdom ${ }^{118}$, the role of primary care in the delivery of undergraduate medical education has been scrutinised $^{119}$. From work done in the UK it appears that clinical skills and internal medicine may be learnt as effectively in primary as secondary care settings ${ }^{120}$. The challenge now is to distinguish which learning outcomes are best pursued in which setting. As undergraduate education in primary care is no cheaper, and indeed likely to be more expensive, than that provided in secondary settings, it is imperative that educators decide what should be learnt and where to be most cost-effective. Patients in primary care have been shown to want a patient-centred approach and partnership ${ }^{121}$, and thus the primary care setting may be more important for students in terms of role models and practising the skills required. However informed decision making by physicians, surgeons and primary care physicians has been shown to be often incomplete in both outpatient and community clinics settings ${ }^{122}$, so that it cannot be assumed that ideal role models will exist in any setting. However a pilot study of a community-based teaching initiative involving third year medical students showed that they are more likely to adopt a patient-centred approach to history taking than students exposed solely to hospital practice $^{123}$.

Towle and colleagues believe that the mainly hospital-based nature of undergraduate medical education does little to support notions of patient autonomy and choice ${ }^{65}$. They suggest that the practice of informed shared decision making requires a good knowledge of treatment options, critical appraisal skills and sophisticated communication skills such as an ability to elicit patients' preferences, present evidence-based choices and negotiate conflict. They also identify role models and clinical experience in different settings as important ways to help learn such skills ${ }^{66}$. There is also an emphasis on providing longer term patient follow-up in primary care, as continuity of care is a feature of that framework ${ }^{124}$, and this may be important for students' skills development, a factor that needs to be explored when comparing settings and deciding where ISDM could be taught.

\section{HOW may the performance of ISDM be measured for formative and summative assessment purposes?}

The inclusion of ISDM within the undergraduate curriculum will necessitate consideration of how it may be assessed. Assessment is a strong motivating factor guiding students' learning ${ }^{125}$ but is also important in checking that examinees have reached a satisfactory standard for professional practice. Miller's pyramid ${ }^{126}$ represents a hierarchy of performance and is helpful in thinking about the assessment of ISDM. Knowledge or 'knows' may be assessed by written tests and the application of such knowledge by assessment of consultation behaviour. With regards to consultation skills encompassing ISDM the optimum assessment is of 'shows how' (competence) and 'does' (performance). Competence-based assessment involves measuring what students or doctors do in controlled circumstances, eg in an OSCE, while performance-based assessment measures what they do in the workplace in everyday practice ${ }^{127}$. This 
difference needs to be taken into account when planning assessments as a gap between competence and performance has been shown ${ }^{128}$.

The important features to consider when planning assessment, as well as validity and reliability, are its feasibility, ie whether it can be delivered within the constraints of resources and time; its acceptability to candidates, assessors, patients and society; and its educational impact, ie the degree to which it helps candidates improve performance through preparation and feedback ${ }^{129}$. To assess 'shows how' with respect to ISDM some type of mock or simulated consultation scenario should be set up. The most common format for such assessment of medical students is the OSCE developed by Harden and Gleeson in $1979^{130}$.

\section{Assessing 'does' by clinical examinations}

But ultimately the most valid assessment of consultation skills and clinical competence is by testing what the doctor or medical students does from day-to-day in the workplace. This is an assessment of 'does', the doctor's actual performance. There are six main ways in which 'does' may be assessed, all of which have advantages and disadvantages:

- Rating of videotapes of consultations ${ }^{131}$

- Medical observer sits in with the student/doctor on consultations ${ }^{132}$

- Incognito (covert) simulated patient assesses doctor ${ }^{133.134}$

- Asking patients for feedback on a student's/doctor's performance ${ }^{104,135}$

- Reflective portfolios ${ }^{136}$

- Multisource assessment including 360 degree appraisal ${ }^{137}$

\section{Rating the consultation}

All of the methods of assessment for 'shows how' and 'does' need to be combined with a marking /assessment instrument or rating scale in order to determine the student's or doctor's competence and/or performance. The scale may be completed by the patient (real or simulated), a medically trained observer or assessor (usually senior to the candidate) or by a peer.

The literature contains references to many scales designed for measuring consultation skills in various settings and times in a doctor's career. Assessment may be at the level of looking at behaviour, eg the use of open questions, eye contact, and measuring pauses. One way of characterizing a consultation as patient-centred is by analysing the verbal exchange structure of the interview as outlined by Stiles \& Putnam ${ }^{138}$. Consultations consisting of mainly closed questions and instructions by the doctor tend to be doctorcentred, whereas exposition (patient describing the illness), checking and explanation by the physician tend to be patient-centred. More usually for examinations, measurement is focussed at the level of outcomes, eg the extent to which patient health beliefs are explored, the extent to which the patient is involved in decision making. Examples of consultation rating scales include the Maastricht history-taking and advice checklist ${ }^{139}$, ${ }^{140}$, assessment of videotapes of general practitioners' performance ${ }^{141}$ and scales of patient-centredness $^{142}$. More recently Elwyn and colleagues have devised the OPTION scale as an instrument to evaluate specifically shared decision making within a 
consultation ${ }^{143}$ having concluded that existing scales did not identify and measure patient involvement ${ }^{144}$.

In order to gain the patient's voice and opinion on the doctor's performance simulated patients may be trained to assess ${ }^{107}$, and give valuable feedback from the patient's perspective $^{109}$. Simulated patients may be overt or covert (incognito). The covert method is important as it measures consultation behaviours in the workplace rather than behaviours that may be performed solely for the purpose of an examination and it allows feedback from the patient. Care must be taken when assessment is carried out solely by simulated patients that they are adequately trained and prepared, and that the purpose of the assessment is clear. Simulated and real patients cannot make judgements about the medical content and knowledge of a doctor in most cases, ie physician defined measures of care $^{145}$, unless they have well devised check lists ${ }^{140}$.

\section{Assessment of attitudes}

Having positive attitudes to ISDM and related concepts are also important if students and doctors are to practise in this way. Brown et al in a review of the assessment of attitudes offer a 'rough and ready' description of the term as 'a mixture of beliefs, thoughts and feclings that predispose a person to respond, in a positive or negative way, to objects, people, processes or institutions ${ }^{3146}$. The General Medical Council in the UK has defined one of the goals of undergraduate medical education as 'the student should acquire and demonstrate attitudes necessary for the achievement of high standards of medical practice...in relation to the provision of care of individuals, ${ }^{95}$.

The assessment of attitudes is a relatively new area in medical education but is recognised as a key aspect of competence for the future doctor ${ }^{132}$. Attitudes may be inferred from behaviour but in practice the correlation between observed behaviour and attitudes is not always high ${ }^{147}$. Methods that may be used to assess attitudes are interviews $^{146}$, direct observation ${ }^{148}$, written tests and portfolios ${ }^{133}$, and self-report methods such as questionnaires ${ }^{146}$. As attitudes of medical students do change during their education, sometimes in the direction of a decrease in humanistic values ${ }^{149}$, it is important to develop instruments to assess attitudes in response to changes in curricula, such as the introduction of learning sessions relating to ISDM and related concepts.

The need to measure ISDM will become more important as and when the concept becomes a learning outcome within medical education and more methods will be developed to do this.

\section{Summary}

The purpose of this literature review is to answer a set of questions posed at its start in order to outline a framework for this thesis.

- It has defined ISDM as a process linked to the patient-centred clinical method, which involves doctors and patients sharing information in order to negotiate a management plan based on a set of appropriate options. Such doctor-patient partnership was a feature of consultations prior to the rise of the scientific method, after which a biomedical model was adopted. In contrast a biopsychosocial approach, incorporating the doctor eliciting the patient's psychosocial history, is integral to the ISDM process. 
- ISDM is important as it improves patient adherence and health outcomes. The concept of concordance has been proposed as a new way of looking at the issue of patient compliance and is linked to ISDM.

- Evidence suggests that ISDM is not a feature of many consultations at present. Possible reasons for this include lack of training particularly relating to the second (management) half of consultations, lack of opportunity to observe the process and lack of role models, attitudes to patients and resistance to change, plus lack of patient autonomy in hospital settings.

- Recommendations for undergraduate medical education incorporating patientcentred care and ISDM have been produced in both the UK and USA. Competencies for ISDM have been defined. The literature proposes that these should be incorporated into an integrated, curriculum spanning communication skills programme in order to prepare medical graduates for modern medical practice. ISDM should be learnt and practised in all healthcare settings where students are placed. Hospital-based education has been criticised for not fostering notions of patient autonomy and choice. Medical students are spending more time in community and primary care settings, where a patient-centred approach is more likely to be observed.

- There are a number of methods for the formative and summative assessment of ISDM. To assess performance ('does') incognito simulated patients may be a feasible method.

- Attitudinal assessment is more difficult but is an important area to consider, and the development of appropriate tools is necessary.

\section{Research questions}

The reviewed literature and evidence implies that doctors often do not adopt the ISDM model within their consultations. Some of the reasons suggested for the absence of informed shared decision making within consultations are lack of training in the required skills for adopting a patient-centred approach and ISDM within a medical curriculum predominantly based in secondary care, scarcity of role models who demonstrate the approach, and attitudes to patients that do not foster the process. However medical education curricula have changed since the time the reviewed doctors qualified, therefore it is important to explore whether there is such a lack of training within the current medical undergraduate curriculum. The main research question is thus: is the current medical undergraduate curriculum delivering the necessary training for the practice of the ISDM model within consultations? The quality of this delivery may be measured in terms of input and output, using a quality assurance framework, while the process relates to where the delivery might take place ${ }^{i 50}$.

The teaching input should include the components of ISDM. For junior medical students, whose learning concentrates on history-taking or information gathering, the important components are the psychosocial history and patient-centred approach. With regards to whether the curriculum is providing adequate input to junior medical students the question to be answered is whether students observe the patient-centred approach during training and understand its relevance. It is in this context that role models are important. The answer to this question must be sought from both the students receiving the input and tutors providing it. Following observation and moving on to skills training, are students taught and encouraged to elicit a psychosocial history? 
The domain of attitudes is more difficult to explore. How may the attitudes of students to ISDM, and in particular, to the related concept of concordance be measured? Interviewing all students is not feasible given the large numbers undertaking undergraduate studies, whereas a self-report method is possible. If such an instrument is developed to measure these, may the students' attitudes be changed by suitable educational input?

To measure output, or the achievement of the curriculum in delivering an end product in this case a doctor practising within an ISDM framework, the attitudes of newly qualified doctors (PRHOs) regarding their approach to ISDM need to be explored. Are PRHOs able and willing to practise the ISDM approach? Asking junior doctors about approach to consultations, while important, does not indicate whether they have indeed developed the necessary competencies in practice. Their behaviour must be assessed objectively. In contrast to medical students, PRHOs consult with and manage patients in the workplace, and thus their performance rather than competence may be measured. Could the use of incognito simulated patients be a feasible tool to aid in the assessment of ISDM skills for this purpose? A feasible tool would then help to measure output and to answer whether PRHOs practise ISDM.

With regards to process, the question is whether there is a difference in the delivery of ISDM training between primary and secondary settings, and if so what implications this has for medical education.

The research questions and their framework methods summarised in the table below. A brief indication the methods used to answer the questions is also listed. The methods are described in detail in the individual chapters, while methodological limitations are discussed in chapter 10 . 


\begin{tabular}{|c|c|c|c|}
\hline Research question & Context & Method & $\mathrm{Ch}$ \\
\hline $\begin{array}{l}\text { Is the current medical undergraduate curriculum } \\
\text { delivering the necessary training for the practice of the } \\
\text { ISDM model within consultations? }\end{array}$ & & & \\
\hline $\begin{array}{l}\text { Do medical students observe the patient-centred } \\
\text { approach during training and understand its relevance? }\end{array}$ & $\begin{array}{l}\text { Input: } \\
\text { observation }\end{array}$ & $\begin{array}{l}\text { Focus group interviews } \\
\text { of medical students }\end{array}$ & \\
\hline \multirow[t]{2}{*}{$\begin{array}{l}\text { Are medical students exposed to role models who } \\
\text { demonstrate a patient-centred approach and ISDM? }\end{array}$} & \multirow[t]{2}{*}{$\begin{array}{l}\text { Input: role } \\
\text { models }\end{array}$} & $\begin{array}{l}\text { Focus group interviews of } \\
\text { medical students }\end{array}$ & \\
\hline & & $\begin{array}{l}\text { Qualitative interviews of } \\
\text { GP tutors }\end{array}$ & \\
\hline $\begin{array}{l}\text { Are students taught and encouraged to elicit a } \\
\text { psychosocial history? }\end{array}$ & $\begin{array}{l}\text { Input: skills } \\
\text { training }\end{array}$ & $\begin{array}{l}\text { Log diary by medical } \\
\text { students }\end{array}$ & \\
\hline $\begin{array}{l}\text { How may the attitudes of students to these concepts, } \\
\text { specifically concordance, be assessed? }\end{array}$ & & $\begin{array}{l}\text { Development of attitude } \\
\text { questionnaire }\end{array}$ & \\
\hline $\begin{array}{l}\text { Can the attitudes of students to these concepts be altered } \\
\text { by a specific learning experience? }\end{array}$ & $\begin{array}{l}\text { Input: } \\
\text { specific } \\
\text { learning } \\
\text { experience } \\
\text { Output: } \\
\text { attitudes }\end{array}$ & $\begin{array}{l}\text { Intervention study with } \\
\text { pre- and post- } \\
\text { administration of } \\
\text { questionnaire }\end{array}$ & \\
\hline $\begin{array}{l}\text { Are PRHOs able and willing to practise the ISDM } \\
\text { approach? }\end{array}$ & $\begin{array}{l}\text { Output: } \\
\text { attitudes }\end{array}$ & $\begin{array}{l}\text { Qualitative interviews of } \\
\text { PRHOS }\end{array}$ & \\
\hline
\end{tabular}




\begin{tabular}{|l|l|l|c}
\hline $\begin{array}{l}\text { Is the use of incognito simulated patients a satisfactory } \\
\text { tool to assess whether ISDM skills are developing? }\end{array}$ & $\begin{array}{l}\text { Output: } \\
\text { measurement } \\
\text { of } \\
\text { performance }\end{array}$ & $\begin{array}{l}\text { Feasibility study of } \\
\text { incognito simulated } \\
\text { patients }\end{array}$ & 8 \\
\hline Do PRHOs practise the ISDM approach? & $\begin{array}{l}\text { Output: } \\
\text { performance }\end{array}$ & $\begin{array}{l}\text { Assessment by incognito } \\
\text { simulated patients }\end{array}$ & 9 \\
\hline $\begin{array}{l}\text { Do students and junior doctors have different learning } \\
\text { experiences relating to shared decision making in primary } \\
\text { and secondary care settings? }\end{array}$ & $\begin{array}{l}\text { Process } \\
\text { results of the previous } \\
\text { chapters that explore the } \\
\text { differences between the } \\
\text { two settings }\end{array}$ & $\begin{array}{c}2,3,7 \\
9\end{array}$ & \\
\hline
\end{tabular}

As this dissertation is based on published articles some repetition of information across the various chapters is inevitable. 


\section{References}

' Porter R. The rise of physical examination. In: Bynum WF, Porter R (Eds). Medicine and the five senses. Cambridge: Cambridge University Press; 1993. p 179-197.

${ }^{2}$ Lane J. The doctor scolds me: the diaries and correspondence of patients in eighteenth century England. In: Porter R (ed) Patients and practitioners. Cambridge: Cambridge University Press; 1985. p 207-247.

${ }^{3}$ Fissell ME. Patients, power and the poor in eighteenth-century Bristol. Cambridge: Cambridge University Press; 1991.

4 Porter D, Porter R. Patient's progress: doctors and doctoring in eighteenth century England. Stanford: Stanford University Press; 1989.

${ }^{5}$ Rutherford J. Clinical lectures. MS 4217. London: Wellcome Institute; 1752.

${ }^{6}$ Percival T. A handbook of medical ethics. London; 1803.

${ }^{7}$ Bernard C. An introduction to the study of experimental medicine. New York: Dover Publications; 1957. (First published in 1865.)

${ }^{8}$ Porter R. The greatest benefit to mankind. A medical history of humanity from antiquity to the present. London: Harper Collins; 1997.

${ }^{9}$ Loudon I. The concept of the family doctor. Bulletin of the History of Medicine 1984; 58: 347-362.

${ }^{10}$ Stevens J. Brief encounter. Factors and fallacies in learning and teaching the science of consultation for the future general practitioner. J Roy Coll Gen Pract 1974; 24: 5-22.

"Hutchison R, Rainey H. Clinical Methods. London: Cassell \& Co, 1897.

${ }^{12}$ Hutchison R, Hunter D. Clinical Methods. $9^{\text {th }}$ Edition. London: Cassell \& Co, 1929.

13 Judson Bury. Clinical Medicine. London: Charles Griffith, 1894.

${ }^{14}$ Fisher S, Todd AD. Introduction: Communication and social context - toward broader definitions. In: Todd AD \& Fisher S (eds.). The social organization of doctor-patient communication. New Jersey: Ablex Publishing Corporation; 1993. pl-16.

${ }^{15}$ Mishler EG. Viewpoint: critical perspectives on the biomedical model. In: Mishler EG, Amarasingham LR, Hauser ST, Liem R, Osherson SD \& Waxler N (eds). Social contexts of health, illness and patient care. Cambridge: Cambridge University Press; 1981.

${ }^{16}$ Waitzkin H. The politics of medical encounters. New Haven: Yale University Press; 1991. 
${ }^{17}$ Byrne PS, Long BEL. Doctors talking to patients. London: HMSO; 1967.

18 Haynes RB, McKibbon KA, Kanani R. Systematic review of randomised trials of interventions to assist patients to follow prescriptions for medications. Lancet $1996 ; 348$ : 383-386.

${ }^{19}$ Sackett DL, Snow JC. The magnitude of compliance and non-compliance. In: Haynes RB, Taylor WD, Sackett DL. (eds). Compliance in health care. London: Johns Hopkins University Press; 1979. pl1-22.

${ }^{20}$ Britten N, Stevenson FA, Barry CA, Barber N, Bradley CP. Misunderstandings in prescribing decisions in general practice: qualitative study. British Medical Journal 2000; 320: $484-488$.

${ }^{21}$ Royal Pharmaceutical Society of Great Britain. From compliance to concordance. Achieving shared goals in medicine taking. London: RPSGB; 1997.

${ }^{22}$ Parsons T. The social system. London: Routledge and Paul; 1951.

${ }^{23}$ Balint M. The doctor; his patient and the illness. London: Tavistock Publications, 1957.

${ }^{24}$ Kurtz S, Silverman J, Benson J, Draper J. Marrying content and process in clinical method teaching: enhancing the Calgary-Cambridge guides. Academic Medicine 2003; 78: 802-809.

${ }^{25}$ Rogers CR. Client-centred therapy: Its current practice, implications and theory. Boston: Houghton Mifflin; 1951.

${ }^{26}$ Stott NC, Davis RH. The exceptional potential in each primary care consultation. $J$ Roy Coll Gen Pract. 1979; 29: 201-205.

27 Pendleton D. Doctor-patient communication: a review. In: Pendleton D \& Hasler J (eds.). Doctor-patient communication. London: Academic Press; 1983.

28 Engel GL. A unified concept of health and disease. Perspectives in Biology and Medicine, 1960; 3: 459-485.

${ }^{29}$ Engel GL. The need for a new medical model: A challenge for biomedicine. Science 1977; 196: 129-136.

${ }^{30}$ Pendleton D, Scholfield T, Tate P, Havelock P. The consultation: an approach to learning and teaching. Oxford: Oxford University Press; 1984.

${ }^{31}$ Bensing J. Doctor-patient communication and the quality of care. Social Science and Medicine 1991; 11: 1301-1310. 
${ }^{32}$ Levenstein JH, McCracken EC, McWhinney IR et al. The patient-centred clinical method. 1. A model for the doctor-patient interaction in family medicine. Fam Practice. 1986; 3: 24-30.

${ }^{33}$ McKinley RK, Middleton JF. What do patients want from doctors? Content analysis of written patient agendas for the consultation. Brit J Gen Pract 1999; 49: 796-800.

34 Mead N, Bower P. Patient-centredness: a conceptual framework and review of the empirical literature. Soc Sci Med 2000; 51: 1087-1100.

${ }^{35}$ Stewart M, Brown JB, Donner A et al. The impact of patient-centred care on outcomes. J Fam Pract 2002; 49: 796-804

${ }^{36}$ Stewart M. Effective physician-patient communication and health outcomes: a review. Can Med Assoc J 1995; 152: 1423-1433.

${ }^{37}$ Evans BJ, Kiellerup FD, Stanley RO et al. A communication skills programme for increasing patients' satisfaction with general practice consultations. BrJ Med Psychol $1987 ; 60: 373-378$.

${ }^{38}$ Haezen-Klemens I, Lapinska E. Doctor-patient interaction, patients' health behaviour and effects of treatment. Social Science and Medicine 1984; 19: 9-18.

${ }^{39}$ Greenfield S, Kaplan S, Ware JE. Expanding patient involvement in care - effects on patient outcomes. An Intern Med 1985; 102: 520-528.

${ }^{40}$ Kaplan SH, Greenfield S, Ware JE. Assessing the effects of physician-patient interactions on the outcomes of chronic disease. Medical Care 1989; 275: 5110-5127.

${ }^{41}$ Little P, Everitt H, Williamson I et al. Preferences of patients for patient centred approach to consultation in primary care: observational study. BMJ 2001; 322: 468-474

42 Fletcher CM. Communication in medicine. Oxford: Nuffield Provincial Hospitals Trust; 1973.

43 Walton J, Duncan AS, Fletcher CM, Freeling P, Hawkins C, Kessel N, McCall I. Talking with patients, a teaching approach. London: Nuffield Provincial Hospitals Trust; 1980.

${ }^{44} \mathrm{Katz} \mathrm{J}$. The silent world of doctor and patient. London and Baltimore: John Hopkins University Press, 1984.

${ }^{45}$ Freidson E. Professional dominance. New York: Atherton, 1970. p143.

${ }^{46}$ Freidson E. Profession of medicine: a study of the sociology of applied knowledge. New York: Dodd Mead, 1970. pp369-370. 
${ }^{47}$ Haug M, Lavin B. Consumerism in medicine. London: Sage; 1983.

48 Hingorani M, Wong T, Vafidis G. Patients' and doctors' attitudes to amount of information given after unintended injury during treatment: cross sectional, questionnaire survey. BMJ 1999; 318: 640-641.

${ }^{49}$ Levinson W, Roter DL, Mullooly JP et al. Physician-patient communication. The relationship with malpractice claims among primary care physicians and surgeons. JAMA 1997; 277: 533-539.

${ }^{50}$ Roter D. Which facets of communication have strong effects on outcome - a metaanalysis. In: Stewart M, Roter D. (eds). Communicating with medical patients. London: Sage; 1989. p183-196.

${ }^{51}$ Tuckett D, Boulton M, Olson C, Williams A. Meetings with experts. An approach to sharing ideas in medical consultations. London: Tavistock Publications, 1985.

${ }^{52}$ Horder J, Moore GT. The consultation and health outcomes. Br J Gen Pract 1990; 40: 442-443.

${ }^{53}$ Szasz TS, Hollender MH. The basic model of the doctor-patient relationship. Arch Int Med 1956; 97: 585.

54 Roter DL, Hall JA. Doctors talking with patients/patients talking with doctors. Connecticut: Auburn House; 1992.

${ }^{55}$ Tomlinson T. The physician's influence on patient's choices. Theoretical Medicine 1986; 7: 105-121.

${ }^{56}$ Quill TE, Brody $\mathrm{H}$. Physician recommendations and patient autonomy: finding a balance between physician power and patient choice. Ann Int Med 1996; 125: 763-769.

${ }^{57}$ NHS Executive. Patient partnership: building a collaborative strategy' Leeds: NHS E; 1996.

${ }^{58}$ Edwards A, Evans R, Elwyn G. Manufactured but not imported: new direction for research in shared decision making support and skills. Patient Education and Counseling 2003; 50: 33-38.

${ }^{59}$ Kravitz RL, Melnikow J. Engaging patients in medical decision making. BMJ 2001; 323: 584-585.

${ }^{60}$ Edwards AGK, Barker J, Bloor M et al. A systematic review of risk communication improving effective clinical practice and research in primary care. Cardiff: University of Wales College of Medicine, Department of General Practice; 1998. 
${ }^{61}$ Edwards A, Elwyn G, Gwyn R. General practice registrar responses to the use of different communication tools in simulated consultations: a focus group study. $B M J$ 1999; 319: 749-752.

${ }^{62}$ Freeman GK, Horder JP, Howie JG et al. Evolving the general practice consultation in Britain: issues of length and context. BMJ 2002; 24: 880-882.

${ }^{63}$ Elwyn G, Edwards A, Kinnersley P. Shared decision-making in primary care: the neglected second half of the consultation. Brit J Gen Pract 1999; 49:477-482.

${ }^{64}$ Charles C, Gafni A, Whelan T. Shared decision-making in the medical encounter: what does it mean? (or it takes two to tango). Social Science and Medicine 1997; 44: 681-692.

${ }^{65}$ Towle A. Physician and patient communication skills: competencies for informed shared decision-making. [Informed Shared Decision Making Project] Vancouver: University of British Columbia; 1997.

${ }^{66}$ Towle A, Godolphin W, Richardson A. Competencies for informed shared decisionmaking (ISDM): Report on interviews with physicians, patients and patient educators and focus group meetings with patients. Vancouver: University of British Columbia; 1997.

67 Towle A, Godolphin W. Framework for teaching and learning informed shared decision-making. $B M J$ 1999; 319: 766-771.

${ }^{68}$ Greenhalgh T. Commentary: competencies for informed shared decision-making. $B M J$ 1999; 319: 770.

${ }^{69}$ Gambrill J. Commentary: proposals based on too many assumptions. BMJ 1999; 319: 770-771.

${ }^{70}$ Lelie A. Decision-making in nephrology: shared decision making? Patient Education and Counseling 2000; 42: $81-90$

${ }^{71}$ Elwyn G, Edwards A, Kinnersley P, Grol R. Shared decision making and the concept of equipoise: defining the competences of involving patients in health care choices. Brit $J$ Gen Pract 2000; 50: 892-899.

72 Stewart M. Towards a global definition of patient centred care. BMJ 2001; 322: 444445 .

${ }^{73}$ Guagagnoli E, Ward P. Patient participation in decision making. Social Science and Medicine 1998; 47: 329-339.

${ }^{74}$ Strull WM, Lo B, Charles G. Do patients want to participate in medical decisionmaking? Journal of the American Medical Association 1984; 252: 2990-2994. 
${ }^{75}$ Bowling A, Ebrahim S. Measuring patients' preferences for treatment and perceptions of risk. Quality Health Care 2001; 10 (suppl 1): 2-8.

${ }^{76}$ Elwyn G. Shared decision making. Patient involvement in clinical practice. PhD thesis. Nijmegen: 2001, p11

${ }^{77}$ Sackett DL, Snow JC. The magnitude of compliance and non-compliance. In: RB. Haynes, WD. Taylor \& DL Sackett (Eds). Compliance in health care London: Johns Hopkins University Press; 1979. p1 1-22.

${ }^{78}$ Bensing J, van Dulmen S, Tates K. Communication in context: new directions in communication research. Patient Education and Counseling 2003; 50: 27-32

${ }^{79}$ Urquhart J. Patient non-compliance with drug regimens: measurement, clinical correlates, economic impact. European Heart Journal 1996; 17 (Suppl A): 8-15.

${ }^{80}$ Korsch BM, Gozzi EK, Francis V. Gaps in doctor-patient communication. Pediatrics 1968; 42: 855-871

${ }^{81}$ Vermeire E, Hearnshaw H, Van Royen P, Denekens J. Patient adherence to treatment: three decades of research. A comprehensive review. Journal of Clinical Pharmacy and Therapeutics 2001; 26: 331-342.

${ }^{82}$ De Fine Olivarious N, Beck-Nielsen H, Andreasen AH, Hørder M, Pedersen PA. Randomised controlled trial of structured personal care of type 2 diabetes mellitus. British Medical Journal 2003; 323: 970-975.

${ }^{83}$ Greenfield S, Kaplan SH, Ware JE, Yano EM, Frank HJL. Patients' participation in medical care: effects on blood sugar control and quality of life in diabetes. $J$ Gen Intern Med 1988; 3: 446-457.

${ }^{84}$ Wright EB, Holcombe C, Salmon P. Doctors' communication of trust, care and respect in breast cancer: qualitative study. $B M J 2004 ; 328$ : 864-870.

${ }^{85}$ Britten N, Stevenson FA, Barry CA, Barber N, Bradley CP. Misunderstandings in prescribing decisions in general practice: qualitative study. British Medical Journal 2000; 320: $484-488$.

${ }^{86}$ Barry CA, Bradley CP, Britten N, Stevenson FA, Barber N. Patients' unvoiced agendas in general practice consultations: qualitative study. BMJ 2000; 320: 1246-1250.

87 Stevenson FA, Barry CA, Britten N, Barber N, Bradley C. Doctor-patient communication about drugs: the evidence for shared decision making. Social Science and Medicine 2000; 50: 829-840.

${ }^{88}$ Marinker M. Personal paper: writing prescriptions is easy. BMJ 1997; 314: 747-8. 
${ }^{89}$ Van Dam HA, van der Horst F, van den Borne B, Ryckman R, Crebolder H. Providerpatient interaction in diabetes care: effects on patient self-care and outcomes. A systematic review. Patient Education and Counseling 2003; 51: 17-28.

${ }^{90}$ Coulter A. Paternalism or partnership. BMJ 1999; 319: 719-720.

91 Pendleton D, Scholfield T, Tate P, Havelock P. The new consultation: developing doctor-patient communication. Oxford: Oxford University Press; 2003, p 41.

92 Elwyn G, Edwards A, Gwyn R et al. Towards a feasible model of shared decision making: focus group study with general practice registrars. BMJ 1999; 319: 753-756.

${ }^{93}$ Campion P, Foulkes J, Neighbour R et al. Patient centredness in the MRCGP video examination: analysis of large cohort. BMJ 2002; 325: 691-2.

94 Hannon FB. A national medical education needs' assessment of interns and the development of an intern education and training programme. Medical Education 2000; 34: $275-284$.

${ }^{95}$ Blendon RJ, Schoen C, Des Roches C, Osborn R, Zapert K. Common concerns amid diverse systems: Health care experiences in five countries. Health Affairs 2003; 22: $106-$ 121.

${ }^{96}$ General Medical Council. Tomorrow's doctors. London: GMC; 1993.

${ }^{97}$ General Medical Council. Tomorrow's doctors. London: GMC; 2002.

${ }^{98}$ Laine C, Davidoff F. Patient-centered medicine. A professional evolution. JAMA 1996; 267: 2221-2226.

${ }^{99}$ Lipkin M Jr, Quill TE, Napodano RJ. The medical interview: a core curriculum for residencies in internal medicine. Annals of Internal Medicine 1984; 100: 277-284.

${ }^{100}$ Association of American Medical Colleges. Learning objective for medical student education. Guidelines for medical schools. Washington DC: AAMC; 1998.

${ }^{101}$ Brown JB, Boles M, Mullooly JP, Levinson W. Effect of clinician communication skills training on patient satisfaction: a randomized controlled trial. Annals of Internal Medicine 1999; 131: 822-829.

${ }^{102}$ Newble D, Jaeger $K$. The effect of assessment and examinations on the learning of medical students. Medical Education 1983; 17: 165-171.

${ }^{103}$ Silverman J, Kurtz S, Draper J. Skills for communicating with patients. Abingdon: Radcliffe Medical Press; 1998. 
104 Kurtz SM, Silverman JD. The Calgary-Cambridge observation guides: an aid to defining the curriculum and organizing the teaching in communication training programmes. Medical Education 1996; 30: 83-89.

105 Kurtz S, Silverman J, Draper J. Teaching and learning communication skills in medicine. Abingdon: Radcliffe Medical Press; 1998.

${ }^{106}$ Mansfield F. Supervised role-play in the teaching of the process of the consultation. Medical Education 1991; 25: 485-490.

107 Barrows HS. An overview of the uses of standardized patients for teaching and evaluating clinical skills. Academic Medicine 1993; 68: 443-451.

${ }^{108}$ Whitehouse C, Morris P and Marks B. The role of actors in teaching communication. Medical Education 1984; 18: 262-268.

109 Hargie ODW, Morrow NC. Using videotape in communication skills training: a critical review of the process of self-viewing. Medical Teacher 1986; 8: 359-365.

110 Westberg J, Jason H. Teaching creatively with video: fostering reflection, communication and other clinical skills. New York: Springer; 1994.

${ }^{111}$ Brodky H. Stories of sickness. New Haven: Yale University Press; 1987.

112 Mazur DJ. Influence of the law on risk and informed consent. BMJ 2003; 327: 731734.

${ }^{113}$ World Federation for Medical Education. The Edinburgh Declaration. Medical Education 1988; 22: 481-2.

${ }^{114}$ Boaden N and Bligh J. Community-based medical education. London: Arnold, 1999. pp. 29-41.

115 Institute for the Future. Health and Health Care, 2010, the Forecast, the Future, the Challenge. San Francisco: Jossey-Bass, 2000. pp. 6-8.

${ }^{116}$ Green LA, Fryer GR Jr, Yawn BP, Lanier D and Dovey S. The ecology of medical care revisited. New England Journal of Medicine 2001; 344: 2012-2025.

${ }^{117}$ Secretaries of State for Health, Wales, Northern Ireland, and Scotland. Working for patients. London: HMSO, 1989.

${ }^{118}$ Hensher M, Edwards N, Stokes R. International trends in the provision and utilisation of hospital care. $B M J 1999 ; 319: 747-8$.

${ }^{119}$ Murray E. Teaching internal medicine in general practice: an evaluation. PhD thesis. Maastricht: 2001. 
${ }^{120}$ Murray E, Jolly B, Modell M. Can students learn clinical method in general practice? A randomised crossover trial based on objectives structured clinical examinations. $B M J$ 1997; 315: 920-923.

${ }^{21}$ Little P, Everitt H, Williamson 1 et al. Preferences for patient centred approach to consultation in primary care: an observational study. BMJ 2001; 322: 468-72.

122 Braddock $\mathrm{CH}$, Edwards $\mathrm{KA}$, Hasenberg $\mathrm{NM}$ et al. Informed decision making in outpatient practice. JAMA 1999; 282: 2313-2320.

${ }^{123}$ Thistlethwaite JE. Community-based teaching of patient-centred consultations to third year medical students: An evaluation of a new teaching initiative. MMEd thesis. Dundee: 1998.

${ }^{124}$ European Society of Family Medicine and General Practice. The European Definition of General Practice 2002: www.euract.org/html/page03a.shtml

${ }^{125}$ Frederiksen $\mathrm{N}$. The real test bias: Influences of testing on teaching and learning. $\mathrm{Am}$ Psychol 1984; 39: 193-202.

${ }^{126}$ Miller GE. The assessment of clinical skills/competence/performance. Academic Medicine (Supplement) 1990; 65: S63-67.

${ }^{127}$ Rethans J-J, Norcini JJ, Baron-Maldonado et al. The relationship between competence and performance: implications for assessing practice performance. Medical Education 2002; 36: 901-909.

${ }^{128}$ Rethans J-J, Sturmans F, Drop R, Van der Vleuten C, Hobus P. Does competence of general practitioners predict their performance? Comparison between examination setting and actual practice. $B M J 1991 ; 303: 1377-1380$.

${ }^{129}$ Van der Vleuten C. The assessment of professional competence: developments, research and practical implications. Advances in Health Sciences Education 1996; 1:4167.

${ }^{130}$ Harden RA, Gleeson FA. ASME medical educational booklet No 8: assessment of medical competence using an objective structured clinical examination (OSCE). $J$ Med Education 1979; 13: 41-54.

${ }^{131}$ Ram P, Grol R, Rethans J-J, Schouten B, van der Vleuten C, Kester A. Assessment of general practitioners by video observation of communicative and medical performance in daily practice: issues of validity, reliability and feasibility. Medical Education 1999; 33: 447-454.

${ }^{132}$ Shumway JM, Harden RM. AMEE Guide no. 25: The assessment of learning outcomes for the competent and reflective physician. Medical Teacher 2003; 25: 569584. 
${ }^{133}$ Rethans J-J, Sturmans F, Drop R and van der Vleuten C. Assessment of the performance of general practitioners by the use of standardized (simulated) patients. British Journal of General Practice 1991; 41: 97-99.

134 Van der Vleuten C and Swanson D. Assessment of clinical skills with standardized patients: state of the art. Teaching and Learning in Medicine 1990; 2: 58-76.

${ }^{135}$ Baker R. The development of a questionnaire to assess patients' satisfaction with consultations in general practice. British Journal of General Practice 1990; 40: 487 490.

136 Snadden D, Thomas ML. The use of portfolio learning in medical education. Medical Teacher 1998; 20: 192-199.

${ }^{137}$ Department of Trade and Industry. 360 degree feedback. Best practice guidelines. http://www.dti.gov.uk/mbp

138 Stiles WB, Putnam SM. Verbal exchanges in medical interviews: concepts and measurements. Social Science and Medicine 1992; 35: 347-355.

139 Kraan H, Crijnen A. The Maastricht history-taking and advice checklist: studies of instrumental utility. Amsterdam: Lundbeck; 1987.

140 Van Thiel, Kraan HF, van der Vleuten CPM. Reliability and feasibility of measuring interviewing skills: the revised Maastricht history-taking and advice checklist. Medical Education 1991; 25: 224-229.

141 Cox J, Mulholland H. An instrument for assessment of videotapes of general practitioners' performance. BMJ 1993; 306: 1043-46.

142 Brown J, Stewart EC, McCracken EC at al. The patient-centred clinical method, 2 Definition and application. Fam Practice. 1986; 3: 75-79.

${ }^{143}$ Elwyn G, Edwards A, Wensing M, Hood K, Atwell C, Grol R. Shared decision making: developing the OPTION scale for measuring patient involvement. Quality \& Safety in Health Care 2003; 12: 93-99.

${ }^{144}$ Elwyn G, Edwards A, Mowle S et al. Measuring the involvement of patients in shared decision making: a systematic review of instruments. Patient Education and Counseling 2001; 43: 5-22.

${ }^{145}$ Lebow JL. Consumer assessments of the quality of medical care. Medical Care 1974; 12: 328.

${ }^{146}$ Brown G, Manogue M, Rohlin M. Assessing attitudes in dental education: Is it worthwhile? British Dental Journal 2002; 193: 703-707. 
${ }^{147}$ Kaplan RM. Behaviour as the central outcome of health care. American Psychologist 1990; 45: 1211-1220.

148 Phelan S, Obenshain SS, Galey WR. Evaluation of the non-cognitive professional traits of medical students. Academic Medicine 1993; 68: 799-803.

149 Wolf TM, Balson PM, Faucett JM et al. A retrospective study of attitude change during medical education. Medical Education 1989; 23: 19-23.

${ }^{150}$ Donabedian, A. Evaluating the quality of medical care. Milbank Memorial Fund Quarterly 1966; 44(part2): 166-206. 


\section{Chapter 2}

\section{Patient-centred consultations: a comparison of student experience and understanding in two clinical environments}

Thistlethwaite JE, Jordan J.

Published as: Thistlethwaite JE, Jordan J. Patient-centred consultations: a comparison of student experience and understanding in two clinical environments. Medical Education 1999; 33: 678-685. 


\begin{abstract}
Objectives.

To explore students' perspectives on doctor-patient communication.

Design.

We interviewed students in focus groups before and after their placements. In semi structured interviews they were asked about their experiences of learning through clinical contact, with particular emphasis on patient-centred consultations, on the wards and during their community attachment. Students whose clinical skills training remained hospital based were also interviewed to compare the range of experiences.

Setting. Leeds University.

\section{Subjects.}

Third year medical students.

\section{Results.}

During hospital training students are rarely introduced, either through teaching or observation, to the idea of patient-centred consultations. In contrast, both the principles underpinning and/or the practice of such consultations were routinely encountered during the general practice placement. Students considered the community attachment to have helped them appreciate the value of exploring patients' concerns both in terms of enhancing the patients' overall healthcare experience and promoting effective clinical management. While they considered the nature and purpose of hospital care to be qualitatively different from that conducted in the community, the relevance of adopting a patient-centred approach on the wards was confirmed.
\end{abstract}

\title{
Conclusions.
}

Recommendations for clinical training are made. The relevance and best use of community and hospital-based attachments need to be evaluated further. 


\section{INTRODUCTION}

One of the fundamental skills any doctor must master is the ability to take a medical history. Traditionally, a medical approach to history-taking, based on the belief that every illness is caused be a disease, which has an external definable cause, has predominated ${ }^{\prime}$. Taking a history in this formal and structured way tends to make the consultation disease or doctor-centred ${ }^{2}$.

It has been demonstrated that consultations in which the doctor's agenda dominates negatively impact on a range of outcomes, including compliance with treatment ${ }^{3}$, patient satisfaction with the care provided ${ }^{4}$ and patient understanding of illness and its effects ${ }^{5}$. Conversely, an approach to care in which a doctor-patient partnership is emphasised has been shown to increase the probability of a positive health outcome for the patient ${ }^{6.7}$ and to reduce the risk of complaint against the doctor by the patient ${ }^{8}$.

Tomorrow's Doctors ${ }^{9}$ states that by the end of undergraduate education medical students will have acquired the ability to 'formulate with them [patients] plans for investigation and management'. Here, the two contrasting styles of consultation identified ${ }^{10}$ are relevant: doctor-centred and patient-centred.

The more holistic, patient-centred approach recognises that a problem may be defined in terms of its physical, psychological and/or social components. Involving the patient in management decisions presupposes a patient-centred approach to the clinical encounter. Not only does the doctor need to be aware of the nature and cause of the problem, but also s/he should investigate the patient's ideas, concerns and expectations as part of the management process ${ }^{11}$.

One way of encouraging students to become proficient in both aspects of consulting, that is taking a history to formulate a diagnosis and adopting a patient-centred approach to identify the patient's concerns to help in management, is to expose them to the idea of patient-centredness when they first enter clinical training. Moreover, it is increasingly being recognised that the importance of the patient's perspective should be emphasised within the wider programme of communication skills training ${ }^{12}$.

The general practitioner (GP) is seen as being "whole person" orientated while the specialist is focused more specifically on the (physical) disease and less on the patient's viewpoint and autonomy ${ }^{13}$. Dixon ${ }^{14}$ has suggested that this difference may be due to the environments in which the doctors practise rather than a difference in cognitive style. Giving students the opportunity to practise and develop their history taking in a community setting during their first clinical year may therefore help them foster a positive attitude towards patient-centred consultations and give them a blueprint for patient contacts in the future.

This paper focuses on students in their first clinical year at Leeds University, some of whom were attached to a general practice and some of whom were not. The aims of the 
study were to examine the students' perspectives on doctor-patient communication and their ability to develop a patient-centred approach, while comparing their experiences in the two different learning environments of hospital wards and general practice surgeries. We hoped to look at issues specific to the training on offer in Leeds and, in the process, make some more general comments about the opportunities for clinical training afforded within a primary care setting.

\section{METHOD}

A total of 198 third year medical students were registered during the study, of whom 71 took part in the community attachment study. The structure of the third year is shown in Table 1. Students are allocated randomly to firms by the medical school office while ensuring an even mix of sexes.

Table 1

The third year of the Leeds undergraduate medical curriculum

\begin{tabular}{llllc}
\hline 2 weeks & $6 \& 5$ weeks & 8 weeks & $5 \& 5$ weeks & 6 weeks \\
\hline $\begin{array}{l}\text { Introduction to } \\
\text { clinical skills }\end{array}$ & $\begin{array}{l}\text { Medical \& surgical } \\
\text { firms (one each) }\end{array}$ & $\begin{array}{l}\text { Laboratory } \\
\text { science }\end{array}$ & $\begin{array}{l}\text { Medical \& surgical } \\
\text { firms (one each) }\end{array}$ & $\begin{array}{c}\text { Special study } \\
\text { modules }\end{array}$ \\
\hline
\end{tabular}

The study involved students from four medical firms, two of which were professorial, being allocated to GP tutors. In order that the impact of the community attachment on student skills and understanding could be evaluated, students from two firms receiving hospital-based teaching only acted as controls.

The students spent one day a week during four weeks on their community placenient. Four students were attached to one GP tutor. The first morning was devoted to an introductory session for all students where the concept of the patient-centred consultation was introduced and the aims and objectives of the attachment outlined. During the attachment the students took histories from patients with chronic problems and patients with new problems. They visited housebound patients. The tutors observed the students and provided constructive feedback on performance.

The focus group method of discussion was chosen for several reasons. First, we needed to establish reasonably quickly the range of experiences and perspectives on the communication skills training and the relevance of patient-centred consultations to effective care ${ }^{15}$. Secondly, given that the students already knew each other and, moreover, were used to being taught and deliberating as a group, we thought the group interview an appropriate forum for relatively informal discussion of, at times, quite sensitive topics. Finally, given that the nature of the subject matter was comparatively unfamiliar, we considered that an environment which encouraged discussion and debate 
amongst interacting participants was the ideal way in which to ensure that as many relevant issues as possible were covered ${ }^{16}$.

In order that the discussion remained responsive to student understanding and experience a flexible interview schedule was devised, based on a number of open-ended questions. In this way we ensured that students could raise and explore issues which they considered relevant ${ }^{17}$, while at the same time allowing the interviewer to cover the broader subject matter of doctor-patient communication, including communication skills training and the importance of employing these skills in patient care. Ultimately, the aim was to allow thematic priorities to emerge as a result of discussion with and between students rather than being arbitrarily conceived by the researchers prior to data collection. Both facilitators ( $\mathrm{JT}$ and $\mathrm{J} J$ ) sought to promote a spontaneous discussion, intervening as little as possible once initial questions had been raised, and doing so only when it was considered necessary to prompt or probe in greater detail.

Group discussions were tape recorded and transcribed. Important issues raised by students were incorporated into subsequent discussions so that interviewing and analysis were simultaneous throughout the research process. Transcripts were analysed using an inductive approach whereby analysis of the content of the entire body of data (as opposed to analysis of isolated responses to individual questions) allowed for its organisation into a number of dominant thematic categories. These were constructed on the basis of the identification of recurrent patterns in the understandings expressed and experiences related by the students. In this way inductive analysis permits important themes to emerge out of the data unprompted by any researcher based analytical scheme $e^{18}$.

\section{RESULTS}

The focus group interviews were undertaken with firms III and IV, a total of 33 students participating. These firms were chosen as the students, towards the end of their third year, had gained a broad range of experience, having spent considerable time on the wards. The interviews involved talking with students in groups of three to six before and after their attachments (subjects). A total of 20 control students were also interviewed in the first and last weeks of their firm. In all, twenty-one groups were interviewed by either $\mathrm{JT}$ or JJ, the two authors. We achieved an almost $100 \%$ attendance record, with only two students failing to attend both the pre and post attachment interviews. All data was collected within an eight-week period. On analysis three major themes (Table 2) characterised student understanding of the learning process they had experienced in third year. Differences in the experiences and understandings between the subjects and the controls are highlighted as part of the broader discussion. 
1. The context of first clinical contact

Relating solely to the ward-based environment

(a) The ward as a working environment

(b) Dealing with real patients

(c) Precariousness of student position

2. Factors influencing the development of communication skills Comparison of ward and community environment
(a) Contact with patients
(b) Observation of others
(c) Structured teaching
(d) Feedback

3. The importance of a patient-centred approach

Relevant in both environments but stressed more in community

(a) Promoting respect for patients

(b) Contributing to successful clinical management

(c) Difference in care between general practice and hospital

(1) The context of first clinical contact.

a) The ward as a working environment

There was universal agreement that ward-based learning was problematic in a number of respects. Two related issues were of particular concern. Firstly, the fact that the ward was a palace of work meant that, from the outset, students were conscious of imposing upon clinical staff whose primary task was the care of patients.

'...They (the house officers) are the ones that you have most contact with, it just depends whether they have either got the time or they are willing to teach you.'

Secondly, the fact that the ward was a place of care meant that from the outset, students were keenly aware of being incidental tot he primary activity of looking after patients. To a greater or lesser degree, all expressed unease over the lack of not just a clear role but more importantly, a useful role in the care provided.

'The thing that struck me is that you just feel like a spare part and you are always in the way.'

As a result of their pervasive sense of 'imposition', students were often reluctant to undertake any activity, no matter how directly associated with their legitimate learning tasks, which might intrude upon what they considered to be an already burdened system. 


\section{b) Dealing with 'real' patients}

Not only were students acutely aware of the ambiguous role they played in terms of a meaningful contribution to day-to-day patient care but they saw their ward-based training as potentially or actively undermining that care in important respects. Thus, the fact that training in history-taking required students to question patients, some of whom were in pain or discomfort, with no purpose directly related to their care, caused some concern.

'If the patient is in a lot of pain, you feel very awkward talking to them, like they should just be recuperating not having me pester them. '

At times students cut short or failed to undertake history-taking sessions with those patients whom they felt should not be disturbed even when they had been recommended by ward staff.

While such avoidance never led to a situation where students failed to complete the necessary patient contact, nevertheless, it did make such contact more problematic and meant that they were having to deal with negative emotions about their training.

Ambivalence concerning their dealings with patients was particularly acute in relation to answering patients' questions. When these questions concerned patient clinical management students lacked authority to comment; where they concerned patient prognosis students either lacked authority or, as was more often the case, adequate knowledge and/or confidence to comment. The fact that at times they were treated by patients as 'proper' doctors only served to heighten student confusions and unease as they lacked the means to play out this role either to their own or to patients' satisfaction.

'I t'y and explain operations and stuff like that but any...other questions about prognosis...I don 't answer.'

Students felt an underlying tension or conflict between how they felt they ought to treat patients and what was involved as part of their training. Their dilemma then centred on achieving a balance between meeting their own needs and respecting the needs of patients.

'Sometimes I just pounce of a patient and I just feel as though how much more is this going to benefit me... and how much is it going to inconvenience you.'

\section{c) Precariousness of student position}

The fact that training took place in such a working/caring environment created in students a sense of themselves as dependent on a range of factors for the clinical content and teaching they received, all related to the vagaries of ward activity and all outside their control. Thus if a patient was called for tests or had a visitor, the student felt obliged tow withdraw. Even when their instincts took them elsewhere, students felt obliged to approach those patients 'selected' by ward staff. At times they were aware that the most 'obliging' or the most 'interesting' cases were singled out; although grateful students 
were also aware that this served only to increase the artificiality of the clinical experience they were gaining.

Consequently, students saw their training as vulnerable to, and unprotected against, both chance circumstances and the (lack of) goodwill of others, whether these others be patients or staff. Thus, despite the fact their training was designated to be self-directed to some extent, they experienced a sense of lacking authority over the clinical experience they gained.

\section{(2) Factors influencing the development of communication skills. \\ a) Contact with patients}

In order for students to gain experience in history-taking and physical examination for the development of their diagnostic skills, patients with a variety of problems or illnesses and from different backgrounds are necessary. However, the process is hampered by the nature of the teaching hospital environment, where firms are highly specialised and where there is often a paucity of patients to be interviewed. If the nature of the ward is such that patient turnover is low then students 'run out' of patients or the patients 'run out' of patience with the students.

'We end up sharing a patient when there are ten of us on a ward with 25 beds and you could not really go one after another onto the next patient because they were not too happy about that.'

History-taking, interviewing and the diagnostic experience gained during the community attachment was approved universally by students as less contrived and therefore more likely to aid development of clinical skills. This remained the case even when the GP tutors had selected patients since, in terms of the actual consultation, students still had to rely on their own skills.

'It just helped seeing a lot of patients...sometimes you will go through the day not speaking to anybody in the hospital... [in general practice] it was eight to ten patients a day and a better turnover of patients as well.'

In particular, the intimacy of the GP environment tended to make students feel more at ease and therefore more likely to develop and pursue lines of questioning which they would not in the ward situation. Further, given that students had the opportunity to consult with patients with new problems meant that patients were likely to 'present' in ways similar to a 'normal' GP situation.

I think in the GP scenario the patients are more likely to want to tell you stuff, like in the hospital they have probably been seen by five other doctors before and ten other students... when they come tot he GP they have got a problem... and they want to find out now so they are forced to tell you the whole thing.' 


\section{b) Observation of others}

There was universal agreement that observation of doctors in their dealings with patients was a vital component of training. Students wanted the opportunity to 'learn by example' so that ward doctors inevitably assumed importance as role models, both positive and negative. Where students had observed what they considered to be exemplary behaviour towards a patient, some or all of the following features were mentioned: displaying respect (see below), enquiring about patient concerns and/or treating the patients as distinct from the presenting illness only.

Moreover, students were aware that continual exposure to what they perceived initially as 'unacceptable' behaviour (negative role modelling) becomes acceptable in time. This was based on a dual recognition that, as students, they were not subject to the same pressures as hospital doctors, particularly in respect of time, and that indifference towards patients was an inevitable consequence of the habitual nature of the work.

\section{I think they get so used to doing it all the time they forget other people find it offensive.}

I think maybe the first time you see it and question it and think that surely it is not right but if you keep seeing it again and again and everybody is doing it I suppose in the end you must think... that's obviously right.

\section{c) Structured teaching}

Students were critical of what they perceived to be a lack of structure characterising ward-based teaching with a majority describing such teaching as typically ad hoc or frequently absent. As a result of these experiences they were grateful for and approving of a structured teaching framework. In general terms students highlighted the absolute necessity of a structured teaching timetable given the fact that not only were they being introduced to new concepts and ideas but that this was happening in an unfamiliar environment.

'Self-directed learning is one thing but being completely left to your own devices is quite another.'

In the absence of a structured teaching framework, students perceived their training to lack direction and purpose. Further they felt unable to rectify this situation, either in the short term because of the fraught nature of ward activity, or in the longer term because of limited dedicated teacher-student contact.

\section{d) Feedback}

Within the wider problem of inadequate teaching structure, the lack of feedback on performance and progress was of particular concern. All students experienced this lack with the majority describing this as typical of ward-based teaching. While they could understand this, given the current system of teaching being fitted round clinical duties, students remained aggrieved that such a system continued to operate. They highlighted 
the need for a system in which doctors were released from clinical duties regularly in order to undertake feedback as well as the entire spectrum of their teaching duties.

The problem with history-laking on the ward is that...there is no-one to...oversee the process so you can make as many mistakes as you want.

When feedback was provided students were effusive in their praise.

'My house officer got to me once...it was really good I learned more in that afternoon than I did basically the rest of the time.'

For many students the problem lay in the way in which feedback was undertaken.

A lot of the time when there is a doctor present and you are taking a history there is also 10 other students round the bed...very nerve racking. You don't perform as usual but when you are doing it on your won you don't get any feedback...

The perceived need to feedback and assessment was particularly acute given the lack of supervision on the wards. Students practised their history-taking largely on their own and had no way of determining progress unless some form of dialogue or assessment was developed. In the absence of assessment students often devised their own means of providing one another with feedback. Recommendations on how the current situation might be improved differed: for some the idea of being observed talking to patients as part of a group was unacceptable, for others any observation was better than nothing.

In this context the GP attachment was praised by students as having included observation and feedback. Although students were nervous at the prospect of being observed, none subsequently recommended that this component of the placement be abolished. The detailed feedback was universally approved as having instilled confidence in the development of skills. Students appreciated the fact that information was provided on both positive and negative aspects of consulting skills.

You can fob it off on the ward... [in general practice] you have to take a history... and then you get feedback on it and that was so helpful.

(3) The importance of a patient-centred approach

a) Promoting respect for patients

The importance of not just respecting the patient, but being seen to be respectful, was acknowledged by students. Significantly this acknowledgement had come about, in part, as a result of witnessing ward doctors show disrespect in their interaction with patients. Although students could recognize that routine work might impact negatively upon a doctor's approach to patients, nevertheless they were clear that such behaviour left patients feeling uncomfortable and, consequently, the standard of care was compromised.

Students provided criteria of showing respect including establishing eye contact, not interrupting the patient, asking the patient's permission, ensuring that the patient's body 
is covered during physical examination and addressing the patient by name. Although not essential to clinical management students were aware that adopting these could only promote high quality care, as it encouraged patient ease and security as well as confidence in the clinical staff responsible for their care.

\section{Contributing to successful clinical management}

The concept of adopting a patient-centred approach in clinical care was unfamiliar to students. Not only had the idea not been introduced during formal teaching but also its observed practice on the wards was the exception rather than the rule.

\section{'On our surgery firm...they said that's so GP-ish'}

Depending on the firms they had completed some students had the opportunity to observe doctors practising a whole patient approach. Examples included: asking patients if they had any concerns; how they were managing at home; actively listening to patients. Students were very clear that such an approach was ethically appropriate in that the patient was being treated as distinct from the isolated illness.

You have to look at the complete person...I don't think you can really treat somebody as just a gall bladder.

What they were worried about was really important for them... and that is what you have got to addiess.

Students praised the community attachment as having brought home to them the value of a patient-centred approach. In part, this was due to the nature of the work itself in that general practice necessarily concerned itself with the patient in context (at least until a diagnosis was made). However, having been introduced to its use in general practice students could easily identify the benefits of a whole person approach in hospital care. Quite simply, this care could only be improved through an understanding of patient need beyond the immediately clinical for example home environment, day-to-day personal care requirements and patient worries, possibly affecting recovery.

There is no point sending someone home from hospital if they are not going to manage at home.

As well as recognizing the benefits of such an approach students could also identify possible barriers to its use in hospital care. All revolved around the limited time available on wards so that while immediate (clinical) care needs were met, there was little opportunity to explore other aspects of patient welfare.

Although students acknowledged the benefits of asking a patient to raise concerns they might have, many remained reluctant to undertake such questioning themselves because of a perceived lack of ability to deal with the potential consequences. Many were worried that once embarked on such a course they would not be able to deal with the issues raised by patients. 
What's the point of bringing those up to the surface when you are just going to say I'm sorry I'm only a student?

Again the community attachment was praised as having encouraged students to recognize the relevance of addressing patient concerns as well as the opportunity to 'practise' this in an environment in which they felt comfortable. Not only had their hospital-based training failed to introduce the relevance of a patient-centred approach but the circumstances in which students clerked patients within a limited time and/or in the presence of onlookers, did little to encourage its adoption.

Differences in care between general practice and hospital

Not only was the clinical care in general practice and hospital deemed to be qualitatively different but the two environments were seen as very different, thereby requiring differences in approach to care provided. In general practice the more intimate environment promoted an informal, personal approach whereas the lack of intimacy in hospital encouraged more formality.

The GP is a more personal kind of consultation whereas a hospital ward is more...institutional.

I don't think I would want to tell somebody in a hospital anything about myself that is personal.

However, all students acknowledge that given its capacity to contribute to effective clinical management, a patient-centred approach was appropriate in hospital-based care. In particular, as highlighted above, its practical role in revealing the social context in which people live was advocated.

\section{DISCUSSION}

From these discussions with students approaching the end of their first clinical year, it would appear that students are rarely exposed to the concept of patient-centred consultations while they remain on hospital wards. They are also less likely to observe doctors asking about patients' concerns during teaching sessions in hospital. When this does happen it is more common on medical than surgical firms. There is also a lack of encouragement to delve into a patient's social history that may have a bearing on the patient's problems and subsequent outcome.

During their early clinical tuition students are not advised to ask about patients' concerns and are therefore unlikely to practise doing this themselves. However students can appreciate the value of asking about concerns when they are introduced to the concept. They tend to excuse the behaviour of clinicians as being the result of lack of time and a heavy workload. 
If students are not encouraged to adopt a patient-centred style from the start of their clinical experience, it is difficult to know where they will acquire such skills later. Certainly many studies have shown junior doctors have a propensity to neglect the psychosocial aspects of patients' problems ${ }^{19}, 20$. Communication skills courses before the onset of clinical training are helpful to establish interview techniques ${ }^{21}$ but may not facilitate the process of students inquiring about patients' psychosocial concerns ${ }^{22}$. Moreover students often have difficulty integrating communication skills and historytaking skills if the two are taught separately ${ }^{23}$. Usherwood ${ }^{24}$ found that students' consulting skills improved during a general practice based interviewing course in fifth year and suggested that such a course would be helpful earlier in the curriculum.

The community-based attachment described here took place early in clinical training, giving students experience of patient-centred consultations and allowing them the opportunity to practise asking patients about their concerns and social circumstances in a non-threatening environment. While both the subjects and controls grasped the nature of patient-centred consultations, the subjects were more likely to have seen examples of this type of consultation in a general practice setting, were better able to discuss the value of such a technique and were more likely to feel confident in their ability to put this into practice on the wards.

We have found a similar pattern of difficulties expressed by students about their early experience on the wards to Royston ${ }^{25}$. Students welcome a structure to their day particularly when first encountering patients on the wards. They value feedback on their performance, a commodity which could be provided as well in hospital as in the community. All clinical teachers should have training in giving and receiving feedback. Such training was offered to the GP tutors who were not already experienced trainers.

The role of ward-based teaching for helping students develop clinical skills needs to be reassessed and the advantages and disadvantages of the ward environment compared to general practice evaluated further. Community attachments do offer students the ability to talk to patients with a greater variety of problems and at different stages of an illiness. The relevance of the patient's social circumstances may be highlighted by home visits and by exploration of their concerns. However as with any new initiative, care must be taken to ensure that the quality and quantity of teaching does not fall off over time especially if general practitioners experience increasing demands on their time.

Four days of community-based teaching at this stage may not lead to any difference in students' performance later in their training. Students show a decline in their social history taking skills over time, possibly due to the culture of medicine to which they are exposed ${ }^{26}$. A further study is planned to investigate how much awareness of a patientcentred approach is retained in later clinical years. The concept needs to be reinforced throughout training. Students should be encouraged to ask patients about their concerns in any clinical encounter and in a ward setting need to be able to discuss these with their tutors or firm doctors. As role models are important, students should be able to observe hospital-based clinicians exploring patients' concerns and their psychosocial problems. The trend towards more community-based education should continue. In the long term 
introducing students to patient-centred practice and integrating their communication skills training with history-taking techniques should lead to improved concordance and higher patient satisfaction.

\section{References}

1. Fisher S, Todd AD. Introduction: Communication and social context - toward broader definitions. In: Todd AD, Fisher S (eds). The social organization of doctorpatient communication. New Jersey: Ablex Publishing Corporation; 1993.

2. Stevens J. Brief encounter. Factors and fallacies in learning and teaching the science of consultation for the future general practitioner. Journal of the Royal College of General Practitioners 1974; 24: 5-22.

3. Royal Pharmaceutical Society of Great Britain. From compliance to concordance. Achieving shared goals in medicine taking. London: New Jersey; 1997.

4. Levinson W. Physician-patient communication. A key to malpractice prevention. Journal of the American Medical Association 1994; 272: 1619-20.

5. Delbanco TL. Enriching the doctor-patient relationship by inviting the patient's perspective. Annals of Internal Medicine 1992; 116: 414-8.

6. Brown G, Atkins M. Explaining: In: Hargie ODW (ed). The handbook of communication skills. (Second edition). London: Routledge; 1997.

7. Horder J, Moore GT. The consultation and health outcomes. British Journal of General Practice 1990; 40: 442-443.

8. Annandale EC. The malpractice crisis and the doctor-patient relationship. Sociology of Health and Illness 1989; 11:1-22.

9. General Medical Council. Tomorrow's doctors. London: GMC; 1993.

10. Byrne PS, Long BEL. Doctors talking to patients. London: HMSO; 1976.

11. Pendleton D, Scholfield T, Tate P, Havelock P. The consultation: an approach to learning and teaching. Oxford: Oxford University Press; 1984.

12. Wolfe AMD, Ingelfinger JA, Schmitz S. Emphasizing attitudes toward the doctorpatient relationship in medical education. Academic Medicine 1994; 69: 895-896. 
13. Fraser RC. Setting the scene. In: Fraser RC (ed). Clinical method: a general practitioner approach. Sevenoaks: Butterworths; 1987.

14. Dixon AS. 'There's a lot of it about': clinical strategies in family practice. Journal of the Royal College of General Practitioners 1986; 36: 468-471.

15. Fitzpatrick R, Boulton M. Qualitative methods for assessing health care. Quality in Health Care 1994; 3: 107-113.

16. Kitzinger J. The methodology of focus groups: the importance of interaction between research participants. Sociology of Health and Illness 1994; 16: 103-121.

17. Kitzinger J. Introducing focus groups. British Medical Journal 1995; 311: 299-302.

18. Miles MB, Huberman AM. A sourcebook of new methods. Beverly Hill, CA: Sage; 1984.

19. Cantwell BM, Ramirez AJ. Doctor-patient communication: a study of junior house officers. Medical Education 1997; 31: 17-21.

20. Williams C, Milton J, Strickland P et al. Impact of medical school teaching on preregistration house officers' confidence in assessing and managing common psychological morbidity: a three-centre study. British Medical Journal 1997; 315: 917-918.

21. Kendrick T, Freeling P. A communication skills course for preclinical students: evaluation of general practice based teaching using group methods. Medical Education 1993; 27: 211-217.

22. Evans BJ, Coman GJ, Gross B. Consulting skills training and medical students' interviewing efficiency. Medical Education 1996; 30: 121-128.

23. Clack GB. Medical graduates evaluate the effectiveness of their education. Medical Education 1994; 28: 418-431.

24. Usherwood T. Subjective and behavioural evaluation of the teaching of patient interviewing skills. Medical Education 1993; 27: 41-47.

25. Royston V. How do medical students learn to communicate with patients? A study of fourth-year medical students' attitudes to doctor-patient communication. Medical Teacher 1997; 19: 257-262.

26. Pfeiffer $\mathrm{C}$, Madray $\mathrm{H}$, Ardolino A, Williams J. The rise and fall of students' skills in obtaining a medical history. Medical Education 1998; 32: 283-288. 


\section{Chapter 3}

The views of general practitioner tutors on developing medical students' communication and management skills.

Thistlethwaite JE, Storr E.

Published as: The views of general practitioner tutors on developing medical students' communication and management skills. Education for Primary Care 2004; 15: 370-377. 


\begin{abstract}
Summary
Community based education and communication skills training are key aspects of modern undergraduate medical curricula. In primary care settings medical students are able to learn and practise communication skills, however the management of patients using a shared decision making model is often neglected. The aim of this paper is to consider the views of GP tutors on how medical students may learn about patient management and shared decision making, taking into account the GPs' experiences of teaching and whether they act as role models by using a shared decision making model themselves The GPs' views will inform the planning of future primary care attachments. This is a study using qualitative analysis of semi-structured interviews with the eleven GP tutors who teach medical students in years two, three and four of a fiveyear undergraduate curriculum. We identified three main themes with subsidiaries. GPs enjoy teaching and have useful ideas about how to involve students in patient management. On the whole they try and encourage patients to share decisions about management and have developed strategies to decide how much information to share with patients. The GPs feel that over the years with changes in undergraduate curricula, the students' communication skills have improved. For students to become better skilled at shared decision making with patients, they need to have longer attachments in primary care with the ability to follow-up patients. We concluded that while GPs are being asked to take on increasing amounts of undergraduate teaching, they are keen to help students learn consultation skills and are good role models for shared decision making strategies. Longer attachments in primary care have implications for workload and curriculum planning but appear to be one method to help students manage patients.
\end{abstract}




\section{Introduction}

Community settings, including general practices, have become increasingly important for the delivery of medical undergraduate education in the last twenty years. The impetus for change arose first in the developing world ${ }^{1}$, with Europe and the USA also adopting a move towards a higher proportion of community-based education ${ }^{2}$. The reasons for this are well documented and include: changing patterns of healthcare delivery with reduced numbers of hospital in-patients ${ }^{3}$ and recognition that patients in teaching hospitals are not representative of the general population ${ }^{4}$ and an emphasis on community management of chronic disease ${ }^{5}$.

In parallel with this more community-orientated approach to undergraduate education have been other developments in curriculum design. Since the acknowledgment of communication skills as a core competence for doctors ${ }^{6}$, medical students now spend more time learning and practising communication and consultation skills. Such skills are learnt well in primary care settings. General practitioners (GPs) have a wealth of experience in learning and teaching consultation skills ${ }^{7}$. However there is concern that while both doctors and students are becoming more expert in adopting a patient-centred approach to patient encounters, a more doctor-centred approach is applied to management and treatment of patients ${ }^{8}$. Skills needed for the second half of consultations such as explanation of risk, discussion of treatment options and negotiation of management ${ }^{9}$ are often neglected in training ${ }^{10}$. Yet informed shared decision making has been shown to improve patient satisfaction ${ }^{11}$ and lead to concordance. In the United States of America it has been suggested as the future of health care ${ }^{12}$. The General Medical Council (GMC), which approves the undergraduate curricula of British medical schools, emphasises that doctors should be able to give information to patients in a way they can understand and fully involve patients in decisions about their care ${ }^{13}$.

By the time medical students qualify and become junior doctors they have rarely had the opportunity to formulate management plans and discuss these with patients, though they may have been taught some of the skills and practised them with simulated patients ${ }^{14}$. As patient management and informed shared decision making skills are fundamental to the work of a GP and as medical students are now spending more time with GPs, the question arises as to how we might best combine these two factors to improve students' skills in this area. This paper considers the views of GP tutors, who teach students from different years of the undergraduate programme at Leeds, about these issues. It builds on previous work looking at shared decision making from the perspective of pre-registration house officers in the Yorkshire region of the United Kingdom ${ }^{14}$. 15. The aim is to identify ways to help medical students learn about patient management and practise informed shared decision-making, taking into consideration the GPs' experiences of teaching and their position as role models. 


\section{The educational setting}

The five-year undergraduate course at the Leeds School of Medicine was redesigned in 1999 , following the GMC's recommendations ${ }^{16}$. Students spend more time in primary care (Table 1). Common objectives are communication skills, including information gathering and explaining (years 2 and 3), consultation skills using the 'shared understanding model' and formulating an appropriate management plan (years 4 and 5).

Table 1: primary care attachments in the undergraduate programme

\begin{tabular}{|c|c|c|c|}
\hline Year & Sessions ( 0.5 days & Objectives & Note \\
\hline $2 \& 3$ & 5 & Clinical skills & All students \\
\hline 3 & 48 & $\begin{array}{l}\text { History \& examination } \\
\text { Junior firm } \\
\text { History \& examination } \\
\text { Investigations } \\
\text { Diagnosis }\end{array}$ & 16 only at presen \\
\hline 4 & 32 & $\begin{array}{l}\text { Primary care } \\
\text { Consultation skills }\end{array}$ & All students \\
\hline 5 & 32 & Senior firm & 80 \\
\hline
\end{tabular}

\section{Method}

While there are a large number of practices that take students in year 4 , fewer take students in other years. Because of the areas we wished to explore we interviewed those GPs who have students in their practices from years 2, 3 and 4 . We identified eleven such GPs, two of whom also have students from year 5 . The GPs have been in practice between 1.5 and 20 years (average 12 years) and have been teaching students for between 1 year and 10 years (average 6.5 years).

The interviews were semi-structured based on a series of questions (Table 2), lasted $30-$ 60 minutes and took place in the surgeries. Ten were carried out by one of the authors (ES) and one by the other (JT). Each interview was audiotaped and transcribed and checked by the authors. The transcriptions were analysed qualitatively and manually by one of the authors (JT) and emerging themes checked and discussed by both, in line with a modified grounded theory approach ${ }^{17.18}$

\section{Table 2: Interview questions}

Motivation to teach

Positive and negative experiences of teaching

Learning to teach

Students' communication and consultation skills

Change in skills over years

Learning to manage patients

Model(s) of management used

Giving information to patients

Facilitating students to learn management skills

Students and shared decision-making 


\section{RESULTS}

Three main themes and their subsidiaries were identified (Table 3). Quotes have been chosen to illustrate the themes, GPs being identified by letter $(\mathrm{A}-\mathrm{K})$.

\section{Table 3: Themes from the interviews}

1. The experience of teaching

- Motivation

- Predominantly a positive experience

- Tendency to learn to teach 'on the job'

- Keen to improve skills

2. Students' communication and consultation skills

- Have improved over the years

- Lack of knowledge a problem

3. Learning and teaching about management and shared decision making

- GPs learn this by experience themselves

- GPs describe themselves as using the shared decision model

- A key skill is deciding how much information to give to patients

- Students know the model

- Strategies for helping students

\section{The experience of teaching}

For eight of the GPs the prime motivation for teaching is enjoyment, only two doctors identified financial incentives and one definitely said teaching was not undertaken for the money. Also mentioned as motivating factors were teaching adding variety to the working day and providing a challenge, as well as making a difference.

'Particularly when you see the second and third years...you can see almost at the end of your two weeks or ten days they're with you, the difference that you make in terms of the communication skills.' (F)

All the GPs said that teaching medical students is a positive experience and all hoped to continue. Teaching helps them keep up their own knowledge and skills, three mentioning specifically that they had become more reflective.

'It keeps me up to date with things, makes it...because it's, there's an incentive then to...students ask questions and if I don't know the answers I have to go and look it up and so... I think that's a positive thing.' (I) 
I'm much more aware of my consultation skills, much, much more aware. I don't say I always do it correctly still, but at least I know when I'm cutting corners... ... and when I'm missing things.' (D)

Mounting time pressures may affect how both students and patients are dealt with.

'The biggest thing is that I find it hard having students in with me when I'm consulting, because I feel that I don't meet fully the needs of the patient or the students. I feel sort of torn between both... when they're with me and it does take a lot longer having students consulting with you, you can't through patients at the same rate.' (I)

Five of the tutors had primarily learnt their teaching skills through the experience of teaching themselves. In the past GPs taught fourth year students without having to attend courses run by the School of Medicine. The current contract stipulates that GP tutors must attend 'training the trainers' type courses in the School. Two GPs mentioned their own experience of being taught as a guideline, while the more recent courses provided at the university were helpful: clinical skills teaching, teaching in groups and one-to-one teaching. However there were issues with attendance at courses in terms of timing, distance to the university and difficulty having time off during the week. As regards improving their teaching skills further, they saw peer review as a useful tool, though it would be intimidating.

'Peer review is very helpful and I also get more ideas for how people teach various things. I know how I teach them but because it's been relatively isolated...it would be interesting to know.' (D)

Having a fellow tutor sit on consultations was also seen as potentially helpful but none of the tutors suggested video recording of teaching sessions for later discussion with their peers.

'It would be nice for someone to sit with me and, and comment on my communication skills...on my consultations because I'm used to doing that with students and maybe somebody should be doing that with me.' (E)

\section{Students' communication and consultation skills}

Those GPs who have been teaching longer acknowledged that the students' skills in these areas have improved, in parallel with the introduction of communication skills teaching in the early years of the undergraduate programme.

'Overall excellent...certainly compared to anything I was used to in my day...or even in my hospital days...clearly there's far more attention paid to consultation as an art and consultations skills...they're far more aware and, and understanding.' (B)

'They are generally speaking more empathic...more able to see the patient as a person rather than as a set of problems that they will solve.' (J) 
One of the main difficulties highlighted by the GPs is the students' ability to integrate their communication skills, taught as a separate course, with their medical history taking, primarily taught by clinicians on wards and in lectures. The communication skills course emphasises the use of open questions and discussing a patient's ideas and concerns, the history taking often relies on closed questions and tends to be more doctor-centred.

'They find it hard to get the balance. They're never really sure whether they should be concentrating on one to the exclusion of the other: ' $(\mathrm{H})$

Several doctors also mentioned that students seem to lack basic knowledge.

'Where they fall down I think, the fourth years, is that their general medical knowledge base is not as good... but unfortunately you can't teach everything. '(E)

\section{Learning and teaching shared decision making}

The GPs recognised this as a problem area that needs to be addressed. Looking back on their own experience, all but one remembered that they did not begin to learn about management skills until after qualification, with two stating it was during their hospital senior house officer posts, six in general practice and two not really until after several years of general practice.

'If you said management I'd say, I'd say about five years ago. It was when I was in practice working as a doctor...but it certainly wasn't before then. '(J)

As far as being role models for students the GPs felt that on the whole they adopted a shared decision making model during consultations including patients in the management plan to some extent (7 GPs) or they described themselves as patient-centred ( $3 \mathrm{GPs}$ ). A typical response to this line of questioning was:

'I would always include patients... for lots of reasons. 1. I like that and it feels good. 2. It's a way to avoid litigation - that's not my motivating factor, it's motivated by the fact I like it but it does avoid litigation. 3...it works.' (B)

The doctors had developed various strategies for deciding how much to involve the patients in the decision making process. The main factor is how well the doctor knows the patient, an obvious difficulty for medical students trying to practise this approach. GPs make value judgements about how much information to give to their patients, taking into account the patient's intelligence and background, whether the patient asks questions and appears to want more information, the nature of the problem and the patient's expectations. Three doctors gauge the extent to which patients wish to be involved by asking them if they want to know more. For one GP the process is helped by 'gut feeling' (I), but it does sound as if such judgement depends on varying factors at different times. 
'Well to start with it'll depend on the patient because there are still those that don't want the information they just want to be told this is what's going to happen... and I suppose that's part and parcel of the, the build up of the way that the patient doctor relationship is happening and if the patient is in a position to want information then I'll give them as much as I am able and they require.' (C)

'A lot of that comes from one's own knowledge of the patient and their background and a guess at the level of information they would want to have...I think one should always start off from asking, finding your baseline, asking what the patient knows already.' (E)

As regards medical students learning about management styles and shared decision making, the tutors do not feel this is important until fourth year. By then they have become more interested in diagnosis, investigations and management. The earlier years should be a sound preparation for this next stage. The general practice attachment is a good time to learn about this process.

'Well I'm sure they get loads of other opportunity, I hope they do to, to get into the final detail of clinical diagnosis... and... well I think what they appreciate here is that they get more sort of practical discussion of the management of patients. ' $(\mathrm{K})$

The GP suggested various ways of helping students including: discussing case studies, sitting in with doctors, hands-on contact with as many patients as possible and following up patients. Consultations with simulated patients were recognised as a useful adjunct but the important factors are real-life experience and lots of patient exposure.

'Oh I think again you know they need to, need to do one-to-one consultations with, with patients and then for us to sort of either observe them or test their, test afterwards how they've got on with it.' $(\mathrm{K})$

This type of experience should take place both in hospital and primary care. A main drawback to most attachments however is the short time that students stay in one place, usually between two and four weeks. This reduces the impact of the longer-term effects of management decisions for both doctor and patient.

'I suppose in terms of general practice it would be... hopefully what, what we try do to which is to use random cases that come through the door and discussion, random case analysis I suppose...to formulate your impression, your diagnosis, your management, your follow-up... hopefully that's something that we do in discussion...they're not really here long enough to follow those things through.' (B)

'They would have to be following a patient through the course of an illness to see the consequences of their decisions.' (C) 
There is a difference between helping students formulate management plans and helping them discuss and negotiate them with patients. The former can be done with students sitting in on consultations as long as the tutor involves the student.

'I still talk to students... who say that when they are with their GP they were stuck in the corner and they've nodded off to sleep because they didn't get any questions. They weren't asked anything, they weren't stimulated. That still happens and I think regard needs to be paid to feedback from students because they often do mention it in their feedback and maybe the GPs in a positive way need to be encouraged...to be asking about management things.' (E)

The latter means letting the students do full consultations, which the GPs are encouraged to do. However this method only succeeds if the patient's problem and its management are familiar to the student.

'I do ask them to explain things to patients and obviously it depends on their level of knowledge because if you don't have the knowledge then you know you can't really...you know you might be very good at explaining things but if you don't actually know about the subject yourself then but I did try to let them and let them have a go, explaining things to patients.' $(\mathrm{G})$

The early teaching the students receive has introduced them to the consultation models, but without practice they cannot develop the strategies that the doctors have in deciding on how much information to impart:

'I think they know now that the emphasis is on patient-centred...decision-making and they, and how you do that is you give people you know three volumes...to read and then they, and then they'll know everything they need to know! And you, you...so the idea is they either do nothing or everything. ' $(J)$

\section{Discussion}

General practitioners are being asked to take on increasing amounts of undergraduate medical education. The GPs interviewed for this study are characteristic of our tutors. With qualitative work of this nature there is a concern that interviewees say things they think the interviewer wishes to hear. However we felt that the GPs were frank and honest in their answers, having nothing to gain by not being so. It is of course difficult to prove this honesty without interviewing a much larger number of GPs and comparing their responses. These doctors are motivated to teach and while money may be a factor it is not of prime consideration. However to retain our tutors we must ensure that teaching continues to be enjoyable and that the teaching load is such that neither patients nor students are perceived to be receiving an inferior service. GPs wish to improve their teaching skills and if asked to take a greater responsibility for helping students manage patients, we need to ensure that appropriate and accessible courses are available.

Just as these experienced GPs do, junior doctors develop their own strategies for discussing treatment with patients and deciding how much information to give them. This 
is particularly the case if they work as junior doctors in general practice ${ }^{15}$. Learning by experience in the workplace is fundamental to adult learning ${ }^{19}$ however experience varies in the immediate post qualification years and is not always reinforced by feedback. Such learning should also preferably build on skills that all students begin to practise as undergraduates and be facilitated by doctors practising a similar approach who can act as positive role models. Competences for shared decision-making ${ }^{20}$ and strategies for information giving ${ }^{21}$ have been defined and may be taught. The GPs believe that their own knowledge and skills are improved by teaching medical students. Thus, by asking them to include management and shared decision making skills in their education repertoire, it is probable that the doctors own skills will be enhanced, leading to greater patient partnership in the future. Peer review should be an important part of the GP tutors' continuing development.

The GPs are keen to help students in this way. Their suggestions that students need longer on attachments in order to follow-up patients and see the consequences of management decisions, and should be able to carry out more consultations on their own with feedback has implications for workload and curriculum planning. Longer attachments would also help students gain greater knowledge of certain patients to help with information giving strategies. There also needs to be a balance between practice with simulated patients and real patients in primary care settings.

The perceived improvements noted in the students' communication skills have been brought about by a change in the undergraduate programme. In the early years it is important to help students integrate history taking and communication ${ }^{22}$, while not neglecting their knowledge base, though the amount and type of science facts that students are taught needs to be reassessed to allow time for appropriate training ${ }^{23}$. In the later years further discussion needs to focus on the next stage: the second half of the consultation, how it may be taught and practised.

\section{References}

1 World Federation for Medical Education. The Edinburgh Declaration. Medical Education 1988; 22: 481-2.

${ }^{2}$ Boaden N and Bligh J. Community-based medical education. London: Arnold; 1999. p 29-41.

3 Institute for the Future. Health and Health Care, 2010, the Forecast, the Future, the Challenge. San Francisco: Jossey-Bass; 1999. p 6-8.

${ }^{4}$ Green LA, Fryer GR Jr, Yawn BP, Lanier D and Dovey S. The ecology of medical care revisited. New England Journal of Medicine 2001; 344: 2012-2025. 
${ }^{5}$ Secretaries of State for Health, Wales, Northern Ireland, and Scotland. Working for patients. London: HMSO; 1989.

${ }^{6}$ World Health Organisation. Doctor-patient interactions and communication. Geneva: WHO; 1993.

7 Whitehouse CR. The teaching of communication skills in UK Medical Schools. Medical Education 1991; 25: 311-318.

${ }^{8}$ Elwyn G, Edwards A and Kinnersley P. Shared decision-making in primary care: the neglected second half of the consultation. British Journal of General Practice 1999; 49: $477-482$.

9 Towle A. Physician and patient communication skills: competencies for informed shared decision-making. [Informed Shared Decision Making Project]. Vancouver: University of British Columbia; 1997.

10 Sanson-Fisher RW, Redman S, Walsh R, Mitchell K, Reid AL and Perkins JJ. Training medical practitioners in information transfer skills: the new challenge. Medical Education 1991; 25: 322-333.

1 Arborelius E and Bremberg S. What can doctors do to achieve a successful consultation? Video-taped consultations analysed by the 'consultation map'. Family Practice 1992; 9: 61-66.

12 Rockefeller R. Informed shared decision making: is this the future of health care? Health Forum Journal 1999; 42: 54-56.

${ }^{13}$ General Medical Council. Duties of a doctor. London: GMC; 1995.

14 Thistlethwaite JE. Making and sharing decisions about management with patients: the views and experiences of pre-registration house officers in general practice and hospital. Medical Education 2002; 36: 49-55.

${ }^{15}$ Thistlethwaite JE and van der Vleuten C. Informed shared decision making: views and competencies of pre-registration house officers in hospital and general practice. Education for Primary Care 2004; 15: 83-92.

${ }^{16}$ General Medical Council. Tomorrow's doctors. London: GMC, 1993.

17 Strauss A and Corbin J. Basics of qualitative research. Second Edition. London: Sage, 1998.

18 Titscher S, Meyer, M, Wodak R and Vetter E. Methods of text and discourse analysis. London: Sage; 2000. p 74-89. 
${ }^{19}$ Burton $\mathrm{J}$ and Jackson $\mathrm{N}$. Theory and practice of work based learning and why work based learning in the new NHS. In: Burton J, Jackson N (Ed). Work based learning in primary care. Abingdon: Radcliffe Medical Press; 2003. p 5-12.

${ }^{20}$ Elwyn $G$ and Charles $C$. Shared decision-making: the principles and the competences. In: Edwards A, Edwards G (Ed). Evidence-based patient choice. Oxford: Oxford University Press; 2001. p 118-143.

${ }^{21}$ Silverman J, Kurtz $S$ and Draper J. Explanation and planning. In: Skills for communicating with patients. Abingdon: Radcliffe Medical Press; 1998. p 118-143.

${ }^{22}$ Thistlethwaite JE. Integrating communication skills and history-taking. Medical Teacher 1999; 21 : 83-84.

${ }^{23}$ Hamid R and Cook DA. Some thoughts on medical education in the twenty-first century. Medical Teacher 2003; 25: 229-238. 


\section{Chapter 4}

\section{An assessment of medical students' experiences of learning}

about the psychosocial enquiry during their introductory

\section{clinical course.}

Brennan C, Thistlethwaite JE, Williams CJ.

Published as: An assessment of medical students' experiences of learning about the psychosocial enquiry during their introductory clinical course.

Medical Teacher 2001; 23: 65-70 


\section{SUMMARY}

\section{Introduction}

Medical students' communication skills and their ability to take a meaningful psychosocial history have been shown to decline during their clinical training. We postulated that psychosocial histories are given a low priority in busy clinical attachments. The aim of the study was to identify factors that affect how medical students gain skills in psychosocial assessment.

\section{Method}

A random sample of 37 medical students filled in a questionnaire before and after their introductory course and they were asked to keep a logbook of their experiences of teaching about psychosocial history taking.

\section{Results}

There were 504 teaching experiences recorded of which less than half were positive. Negative experiences often related to poor communication by clinicians. At the end of the course less than half the students felt confident in taking a psychosocial history.

\section{Discussion}

To improve doctors' skills in this important area of patient assessment, we suggest that teaching in psychosocial history taking should be made explicit, as an integrated part of the overall assessment of a patient. 


\section{Introduction}

Significant emotional distress and psychiatric illness exists amongst patients in a general hospital setting, which often goes undetected'. This is important since psychopathology has been shown to affect physical morbidity and outcome ${ }^{2,3}$ leading to added costs for the individual and the health service. One opportunity to detect psychiatric problems occurs during general hospital admission.

Although newly qualified pre-registration house officers routinely ask patients about a range of physical symptoms, they rarely ask about symptoms of anxiety and depression or even consider psychiatric disorders. As a result, significant psychiatric morbidity, which would be important to consider in the differential diagnosis and management of the patient ${ }^{4}$, may be overlooked. We are interested in the reasons why doctors fail to enquire about psychological and social problems particularly in the early postqualification years.

One study looking at communication and interviewing skills of students over four years of medical school training found that skills initially increased but declined in the later clinical years 5 . This was particularly noticeable in the skill of taking the psychosocial history. The psychosocial history involves the clinician considering the social circumstances and mental health of the patient, which may inform the process of diagnosis, including psychological as well as physical conditions. The biopsychosocial model of health and illness may be contrasted with the more traditional biomedical model in that it acknowledges the role of cultural, ecological and behavioural factors in defining disease, illness, diagnosis and treatment ${ }^{6}$. Understanding patients' concerns and anxieties as well as their personal circumstances helps to involve patients in decisions about their management. Students have been shown to find it difficult to integrate communication skills with taking a clinical history ${ }^{7}$. Whereas a standard clinical history may be obtained with the use of closed questions and check lists, a full range of communication skills are needed to obtain a full psychosocial history and to put the clinical history into the context of the patient's life. We postulate that patients' psychosocial histories are given a low priority in busy clinical attachments and therefore important psychosocial aspects of assessment may be overlooked.

At the University of Leeds School of Medicine students start their clinical training in their third year with a thirteen week introductory course which consists of an orientation week, followed by two hospital firms of six weeks each (one medical and one surgical). Formal teaching is organised for one day a week at the two main Leeds teaching hospitals. During the rest of the week they are attached to clinical firms based at five local hospitals. Half the students also have teaching in a general practice setting for four days during this time. In previous work clinical students interviewed in groups after their hospital placements stated that they were less likely to see examples of doctors asking about patient's concerns in hospital compared to community settings ${ }^{8}$. We were interested in trying to quantify what teaching the students receive about psychosocial issues in their first experiences of clinical teaching and practice. The aims of the study 
included identifying overt and covert factors, which may reinforce or deter students from gaining skills in psychosocial assessment. We defined psychosocial for the purpose of this study as psychological symptoms or social problems contributing to ill health.

\section{Method}

We selected a random sample of 50 out of 195 third year medical students (51\% male and $49 \%$ female) at Leeds University at the start of their first clinical attachment.

We contacted the selected students by letter prior to starting their third year inviting them to participate in the study. A meeting was arranged at which the purpose of the study was explained. Students were assigned an identification number known only to them and the researchers to ensure confidentiality and anonymity of any information they disclosed in the study. They were asked to complete a questionnaire recording basic demographic details and their opinions about the importance of the psychosocial history in various medical specialities (Figure 1). We defined the concept of the psychosocial history and reminded them of previous teaching relating to this in their second year communication skills course. We gave them examples of how a psychosocial history was obtained and reminded them of the importance of asking about patients' ideas and concerns.

\section{Figure 1: First questionnaire}

Please rate how important you feel it is for the following people to ask patients about psychosocial problems using a scale of $1-5$, where $1=$ very unimportant,

$2=$ unimportant, $3=$ ambivalent, $4=$ important, $5=$ very important

\section{Nursing staff}

Junior doctors

General practitioners

Consultant physicians

Consultant surgeons

Consultant in medicine for the elderly

Medical students

Please read the following statements and tick the box that best expresses your view: I feel confident in taking a history in the following areas:

\begin{tabular}{|l|l|l|l|l|l|}
\hline & $\begin{array}{l}\text { Strongly } \\
\text { disagree }\end{array}$ & Disagree & $\begin{array}{l}\text { Neither agree } \\
\text { nor disagree }\end{array}$ & Agree & $\begin{array}{l}\text { Strongly } \\
\text { agrec }\end{array}$ \\
\hline Cardiovascular symptoms & & & & & \\
\hline Respiratory symptoms & & & & & \\
\hline Gastrointestinal problems & & & & & \\
\hline Psychosocial problems & & & & & \\
\hline
\end{tabular}


We gave the students a logbook, the content of which was explained in detail. We asked them to record on a daily basis in the logbook their experiences of teaching about psychosocial history taking. We were interested in whether they were encouraged or discouraged to take a psychosocial history from patients in any teaching setting during the thirteen weeks introductory course. Examples of possible encouraging and discouraging comments were given. The teaching could include both direct and indirect references made about the need for a psychosocial history. Indirect references could include a student's observation of a clinician's practice with patients. We also asked the students to note if they felt there were no direct references made and whether they did not learn anything about psychosocial assessment by observation: this was to be recorded as 'neutral'.

We arranged to meet the students on a weekly basis after their formal teaching day to collect any completed sheets from the logbook and to see if there were any difficulties in filling it in. We wrote to any students, who were not contacted in this way, after six weeks to remind them of the study and encourage them to continue to complete the logbook regularly.

Students were invited to a second meeting at the end of the thirteen weeks to hand in their logbooks and to complete a second questionnaire (Figure 2). This aimed to look at whether there was any change in their views about the importance of different health professionals taking a psychosocial history by the end of the course. We asked them to rate how confident they felt in taking this part of the history. We also asked them to comment about their general experiences of being taught psychosocial history taking skills on each of their firm attachments.

Figure 2: Second questionnaire (as first questionnaire with the following additional question)

During my attachment on a medical firm the following were emphasised:

The practice of asking patients about psychosocial problems

$\begin{array}{ccccc}\text { Strongly disagree } & \text { Disagree } & \text { Ambivalent } & \text { Agree } & \text { Strongly agree } \\ 1 & 2 & 3 & 4 & 5\end{array}$

The relevance of asking patients about psychosocial problems

\begin{tabular}{lrrrrr} 
Strongly disagree & Disagree & \multicolumn{2}{c}{ Ambivalent } & Agree & \multicolumn{2}{c}{ Strongly agree } \\
1 & 2 & & 3 & 4 & \multicolumn{2}{c}{5}
\end{tabular}

During my attachment on a surgical firm the following were emphasised:

The practice of asking patients about psychosocial problems

$\begin{array}{ccccc}\text { Strongly disagree } & \text { Disagree } & \text { Ambivalent } & \text { Agree } & \text { Strongly agree } \\ 1 & 2 & 3 & 4 & 5\end{array}$

The relevance of asking patients about psychosocial problems

$\begin{array}{ccccc}\text { Strongly disagree } & \text { Disagree } & \text { Ambivalent } & \text { Agree } & \text { Strongly agree } \\ 1 & 2 & 3 & 4 & 5\end{array}$


In order to assess the validity of using student logbooks in this way, two clinicians were asked to refer directly to psychosocial history taking in two specified teaching sessions in order to identify if the students recognised this and recorded it in their logbooks.

\section{$\underline{\text { Results }}$}

One of the fifty students dropped out before the year began and one left during the study. Thirty-seven students responded to our invitation and attended the first meeting. It proved difficult to meet with the students weekly because attendance at the lectures was rather erratic.

\section{Logbooks}

Only sixteen logbooks were returned, a response rate of $43 \%$. Six students gave reasons why they had not filled in any logs:

- Two students wrote that there was never any teaching about psychosocial issues on their firms

- One wrote that there had been teaching every day

- Two wrote that they didn't have time to complete them

- One wrote that there was not any relevant teaching on the surgical firms but that there was teaching about psychosocial issues every day on the medical firm.

All submitted logbooks had been completed as requested by ticking the box indicating if the teaching session had been positive, negative or neutral with regard to the psychosocial history. These were often qualified with written comments about the teaching. The hospital-based teaching sessions given by the two primed clinicians were not recorded

There were 504 teaching experiences recorded, 215 were positive, 57 negative and 232 were neutral. Positive experiences were noted in a variety of teaching settings. These included organised teaching in tutorials, teaching ward rounds and small group teaching on the ward. Students also recorded positive experiences when observing clinicians interacting with patients and their attitudes when listening to students' presentations of this part of the history. These positive experiences were from all grades of medical staff on both medical and surgical firms and during general practice attachments. Examples of positive comments written in the logbooks are:

- Consultant listened to patient's queries and concerns about their illness and seemed keen to put their mind at rest.

- Registrar emphasised importance of asking about health of spouse/family members.

- GP showed concern whether young patient with alopecia was coping well with her condition.

The negative experiences were all qualified by a written comment. Most of these were comments about observing the clinicians interacting with patients and often related to poor communication with patients generally, not just inattention to the psychosocial history. There were many comments about clinicians not listening to patients' worries or 
being insensitive to them, for example by not asking them how they felt about being involved in teaching sessions with students and talking about them as an interesting illness rather than as a person. One consultant surgeon told a student, who was presenting a patient's history, that he was spending too much time on the patient's worries, which was 'time wasting'. Again the recorded experiences were from all grades of staff on medical and surgical firms and in general practice. Examples of negative comments written in the logbooks are:

- Consultant appeared not to be interested how the patient (an elderly lady) lived at home or that she appeared quite worried.

- SHO very dismissive of one or 2 patients' concerns during ward round (rudely so)

- GP does not show any interest at all when diabetic patient said that she had problems getting a permanent job/being discriminated against because of her illness.

Students recorded their experiences as 'neutral' most frequently. This was rarely qualified by a written comment. It was often unclear to which situations the students were referring when they recorded 'neutral'. There were references made to some of the formal teaching sessions including the weekly organised teaching at the two hospital sites and some small group teaching by consultants was recorded as 'neutral'. This teaching was noted to be on specific subjects or on developing a particular clinical skill, for example 'examining the cardiovascular system'. No students felt that reference to psychosocial issues was relevant in these situations. With regards to the two teaching sessions assessing validity, only one student who attended these sessions returned a logbook and the sessions were rated as 'neutral'.

Three of the students who completed the logbooks had spent four days at a general practice during the study time. In contrast, they identified thirteen positive comments, one neutral and only one negative.

\section{Questionnaire}

Thirty-seven questionnaires were completed at the start of the study and twenty-one at the end (response rate 57\%). Students found that the practice and relevance of asking patients about psychosocial problems were emphasised more often on medical rather than surgical firms. At the end of their two firms, one hundred percent of the respondents (21) felt confident in taking a history of cardiovascular and respiratory symptoms, but only $42 \%$ felt confident in taking a history of psychosocial problems.

Because of the small number of questionnaires returned, the students' ratings of the importanı $\approx$ of various health professionals asking about psychosocial problems were combined into two categories: not important/ambivalent and important. Their ratings from both questionnaires are shown in Table 1. These figures were analysed by Fisher's exact test, ' hich showed that there were no significant difference in opinion before and after the in: sductory course (Table 2). The confidence intervals are wide because of the small sam size and they all cross zero, indicating no significant differences. However, the figures iw that a greater number of these medical students do feel that it is more 
important for nurses, junior doctors and general practitioners to take a psychosocial history than for consultant physicians and surgeons.

Table 1: Responses to 'Please rate how important it is for the following people to ask patients about psychosocial problems.

\begin{tabular}{l|rr|r}
$\begin{array}{l}\text { Before clinical } \\
\text { placements }\end{array}$ & $\begin{array}{c}\text { Not } \\
\text { important }\end{array}$ & Important & Total \\
\hline Nursing staff & 1 & 36 & 37 \\
Junior doctors & 3 & 34 & 37 \\
GPs & 1 & 36 & 37 \\
Physicians & 2 & 35 & 37 \\
Surgeons & 5 & 32 & 37 \\
Medicine for & 1 & 36 & 37 \\
elderly & & & \\
Medical students & 3 & 34 & 37
\end{tabular}

After clinical

placements

\begin{tabular}{l|rr|r} 
& $\begin{array}{c}\text { Not } \\
\text { important }\end{array}$ & Important & Total \\
\hline Nursing staff & 0 & 21 & 21 \\
Junior doctors & 1 & 20 & 21 \\
GPs & 0 & 21 & 21 \\
Physicians & 4 & 17 & 21 \\
Surgeons & 6 & 15 & 21 \\
Medicine for & 0 & 21 & 21 \\
elderly & & 19 & 21 \\
Medical students & 2 & 19 &
\end{tabular}

Table 2 Comparison of rating before and after attachment using Fisher's exact test, with $95 \%$ confidence intervals.

$\begin{array}{lll}\text { Nursing staff } & \mathrm{P}=0.638 & (-0.08 \text { to } 0.03) \\ \text { Junior doctors } & \mathrm{P}=0.385 & (-0.16 \text { to } 0.09) \\ \text { GPs } & \mathrm{P}=0.638 & (-0.08 \text { to } 0.03) \\ \text { Physicians } & \mathrm{P}=0.237 & (-0.05 \text { to } 0.32) \\ \text { Surgeons } & \mathrm{P}=0.291 & (-0.07 \text { to } 0.37) \\ \text { Medicine for the elderly } & \mathrm{P}=0.698 & (-0.08 \text { to } 0.03) \\ \text { Medical students } & \mathrm{P}=0.357 & (-0.14 \text { to } 0.17)\end{array}$


Comments from the questionnaires:

- I found it almost impossible to fill in the log charts for the psychosocial project because during both my firms psychosocial issues were not really addressed. I became very despondent with the whole thing as I never had anything to write on the $\log$ sheets... I gave up after a couple of weeks on each firm.

- During my medical placement the relevance of psychosocial problems was mentioned in the introductory lecture on the $1^{\text {st }}$ day. After this, the only other times were when a patient broke down in tears during a consultation and again on conversation with a particularly conscientious house officer. During the surgical firm I found much attention paid to the worries of women at breast clinics. However there was no mention of this sort of thing in formal teachings or elsewhere on the firm.

- My medical firm was excellent at ensuring that I got used to taking a full psychosocial history, as many patients were elderly and in obvious need of support on discharge. I realised how many patients were obviously distressed by being in hospital and think that even a student talking to them about it helped...my surgical firm, however, whilst not discouraging psychosocial history taking, did not actively encourage it...overall, I am glad I did my medical firm first as it enabled me to carry on my practice of taking a psychosocial history whilst taking histories on my surgical firm.

\section{Discussion}

In 1984, Maguire called for changes in the training of doctors as he felt that traditional lists used in history-taking focused on physical symptoms and that medical students were given little explicit advice on how to determine patients' feelings'. In 1979, Stott and Davis emphasised the need within a consultation to combine clinical acumen with an insight into human behaviour ${ }^{10}$. They suggested that doctors need to develop skills in order to make a comprehensive assessment of the patient's problems: 'the integrated physical and psychosocial formulation is relevant to every speciality'. Yet twenty years later studies on junior doctors have shown that they do not feel they have the skills to deal with patients' psychosocial problems ${ }^{11}$. While specific courses on communication skills may help, this training needs to be not only taught but also reinforced on the wards during students' clinical experience.

This study was an attempt to see if students are receiving teaching about the importance of asking about psychosocial issues as well as physical problems in clinical situations. The log book method was chosen as a means of students recording their experiences and the completed logs appear to be helpful in this respect. However, due to the small numbers completed and subsequent poor response rate, it is difficult to form any broad conclusions about the students' clinical experiences. Some students were highly motivated to complete the logs, but our difficulty in meeting them regularly due to their dispersal to different hospitals and the lack of attendance at set teachings made it hard to motivate them all. However, in spite of this poor response rate for log book completion, we believe that this study together with previous work with third year medical students 8 , suggests that there is a definite lack of teaching about psychosocial issues and role 
modelling of psychosocial history taking. The results in Figure 3 also show a low emphasis on the teaching or example of psychosocial assessment and on the relevance of asking such questions throughout the twelve-week block, particularly on surgical firms.

There is an issue about whether students recognise psychosocial teaching as such. As the validity study related to only one student, who did not identify psychosocial issues in the teaching, it is hard to draw any conclusion from this. However, the community attachment was rated highly for psychosocial teaching content, a specific objective of the attachment. It is how students define their own experiences that is important and whether they pick up references to discussing patients' worries which will provide them with a template for future practice. This points to the need to ensure that tutors emphasise psychosocial issues in their teachings and provide students with a structure with which to make such an assessment. These students did feel it was important for certain health professionals to ask patients about psychosocial issues and this included junior doctors. It is disappointing but understandable that students were less confident in their ability to carry out a psychosocial assessment than to assess physical symptoms. This reinforces the need for clear and structured teaching on psychosocial assessment, throughout the medical curriculum.

In spite of the study's limitations, we were interested to note that there were a large number of occasions on which students were taught to explore or observed clinicians inquiring about patients' concerns. There were fewer occasions on which the students were discouraged from or observed clinicians ignoring patients' concerns. However in most teaching sessions these issues were not even noticed. The students' experiences depended on which firms they were allocated to although on the whole there were more positive experiences on medical firms and in general practice, than on surgical firms.

The students who participated in the study have had additional exposure to the idea of the importance of the psychosocial history. We suggest that teaching in psychosocial assessment should be made very explicit and should be integrated into the standard history-taking teaching throughout the clinical years. Moreover these skills need to be further emphasised by being examined in clinical examinations but not as stand-alone skills in for example a 'communication skills' OSCE station but rather as an integrated part of the overall assessment of a patient.

Students adopt clinicians as role models ${ }^{12,13}$ and junior doctors have been shown to rate highly as role models those physicians who teach the psychosocial aspects of medicine ${ }^{14}$. Worryingly, we find that the students were less likely to see it as important for consultant surgeons or physicians to assess psychosocial issues compared to other hospital staff after their introductory course, although this was a non-significant result. Therefore we need to encourage clinicians of all grades to recognise and acknowledge patients' anxieties and personal circumstances. By doing so we believe there will be benefits not only for students but also for patients and those that the students go on to influence as they become role models for the trainees of tomorrow. 


\section{References}

'Mayou R, Hawton K. Psychiatric disorder in the general hospital. British Journal of Psychiatry 1986; 149: 172-190.

${ }^{2}$ House AO, Farthing M, Peveler R. Psychological care of medical patients. British Medical Journal 1995; 310: 1422-1423.

${ }^{3}$ Friedman $\mathrm{M}$ et al. Alteration of Type A behaviour and its effects on cardiac recurrences in post-myocardial infarction patients: summary results of the Recurrent Coronary Prevention Project. American Heart Journal 1986; 112: 653-665.

${ }^{4}$ Williams CJ, Milton J, Strickland P et al. Impact of medical school teaching on preregistration house officers' confidence in assessing and managing common psychological morbidity: three centre study. British Medical Journal 1997; 315: 917-918.

'Pfeiffer C. Madray H, Ardolino A, Williams J et al. The rise and fall of students' skill in obtaining a medical history, Medical Education 1998; 32: 283-288.

${ }^{6}$ Engel G. The need for a new medical model: a challenge for biomedicine. Science 1977; 196: $129-135$.

7 Clack GB. Medical graduates evaluate the effectiveness of their education. Medical Education 1994; 28: 418-431.

${ }^{8}$ Thistlethwaite JE, Jordan J. Patient-centred consultations: a comparison of student experience and understanding in two clinical environments. Medical Education 1999; 33: 678-685.

${ }^{9}$ Maguire P. Communication skills. In: A. Steptoe, A. Matthews (eds). Healthcare and human behaviour. London: Academic Press; 1984.

${ }^{10}$ Stott NC, Davis RH. The exceptional potential in each primary care consultation. Journal of the Royal College of General Practitioners 1979; 29: 210-205.

"Cantwell BM, Ramirez AJ. Doctor-patient communication: a study of junior house officers. Medical Education 1997; 31: 17-21.

${ }^{12}$ Lublin JR. Role modelling: a case study in general practice. Medical Education 1992; 26: $116-122$.

${ }^{13}$ Wright S, Wong A, Newill C. The impact of role models on medical students, Journal of General Internal Medicine 1997; 12: 53-56.

14. Wright SM et al. Attributes of excellent attending-physician role models. New England Journal of Medicine 1998; 339: 1990-1994. 


\section{Chapter 5}

Are health professionals ready for the new philosophy of concordance in medicine taking?

Raynor DKT, Thistlethwaite JE, Hart K, Knapp PR.

Published as: Are health professionals ready for the new philosophy of concordance in medicine taking? International Journal of Pharmacy Practice 2001; 9: 81-89. 


\section{Abstract}

\section{Objectives}

To develop and administer a practical, valid and reliable tool to measure attitudes to concordance in medicine taking - a new concept where decisions depend on an equal partnership between patient and prescriber.

\section{Method}

A postal questionnaire was devised comprising of statements from the original concordance document, along with statements reflecting the orthodox model of medicine taking. Respondents rated each statement on a 4-point Likert agreement scale. The questionnaire also included 3 scenarios of consultations involving medicine prescribing and taking, with associated statements for rating as true or false.

\section{Setting}

A random sample of 207 medical, nursing and pharmacy graduates in the North of England at the time of qualification. We received 81 completed questionnaires $(39 \%)$

\section{Key Findings}

Item analysis reduced the 22 -item scale to a 12 -item scale with good reliability (Alpha $=$ .79) and construct validity was demonstrated through correlation with responses to the scenarios. Although the typical respondent had a positive attitude towards concordance (mean $=2.3$ ), $25 \%$ of respondents had negative attitudes. Pharmacists showed the least favourable attitudes $(\mathrm{p}<0.05)$.

\section{Conclusions}

The 12-item Leeds Attitude Towards Concordance (LATCon) scale is a reliable and valid tool for assessing health care providers' attitudes to the new concept of concordance in medicine taking. Newly qualified doctors, nurses and pharmacists tended to hold favourable attitudes, although a significant minority - especially pharmacists - hold negative attitudes. These results have implications for undergraduate and continuing professional education. 


\section{Introduction}

Concordance in medicine taking is a concept that is integral to the partnership model of health care. It puts prescriber and patient on an equal footing, with decisions about medicine-taking being a negotiation between partners'. It seeks to promote an open exchange of information and a spirit of co-operation between both parties in a consultation $^{2}$. These skills and attitudes are important components of the "information for shared decision making" model of the consultation. This requires competencies which include making or negotiating decisions about management in partnership, and resolving conflict $^{3}$. Such patient-centred care, with patients becoming part of the decision-making process, has become national policy in the $\mathrm{UK}^{4}$ and has been further emphasised with the publication of the National Plan for the $\mathrm{NHS}^{5}$.

The prescribing of medicines is the most common intervention in health care, yet it is estimated that around $50 \%$ of patients do not take their medicines as intended ${ }^{6}$. Misunderstandings about prescriptions between doctor and patient often relate to failure of communication about the doctor's decisions, leading to non-adherence to treatment ${ }^{7}$. However, in the past, the sub-optimal use of medicines has been conceptualised as poor compliance on the part of the patient. Concordance, in contrast, implies a respect for the patient's own beliefs and wishes rather than a "doctor knows best attitude". The term does not replace compliance; it is based on the need for concordance between two parties, whereas compliance relates only to the action of the patient.

There is little evidence regarding the acceptance by health professionals of concordance and the general aim of this study was to assess these attitudes. To facilitate this, we developed an attitudinal scale which we used to identify and quantify potential discrepancies between newly qualified health professionals' attitudes and the concept being put forward as the new philosophical ideal. If significant discrepancies exist, this would imply the need for improved education and training in the undergraduate curriculum for future students, as well as the training needs for continuing professional development in already qualified professionals.

\section{Method}

\section{Attitudinal Scale}

The main instrument developed to measure attitudes towards concordance was named the Leeds Attitude Towards Concordance (LATCon) scale. In order to generate the original pool of statements for this scale, we relied heavily on the monograph produced by the concordance working party: 'From Compliance to Concordance: Achieving Shared Goals in Medicine Taking' ${ }^{1}$ (ensuring an accurate reflection of the concept). The list also included statements that would reflect the traditional or 'orthodox' approach.

The result was a 22-item pool. For scoring purposes, statements which reflected the orthodox approach were reverse coded, such that high scores on the scale indicate greater endorsement of the concept of concordance. Items were endorsed using the following four point Likert scale: 'strongly disagree' (0); 'disagree' (1); 'agree' (2); and 'strongly 
agree' (3). We subsequently undertook item-remainder correlational analyses to reduce the scale to more manageable proportions, using the data generated by responses to the 22 -item scale in this study.

\section{Case Scenarios}

For the purposes of validating the scale, we developed a separate and independent measurement tool. This consisted of three scenarios based on typical patient-prescriber interactions concerning medication use. Each case was described in a short paragraph and respondents were then presented with a list of 8-10 opinion statements, and asked to indicate which statements are true. We designed the scenario responses to reflect a mix of options, with some consistent with concordance and some consistent with the orthodox approach. One case is shown in Figure 1.

\section{Figure 1}

Albert is a fit 78-year-old man. He was found to have hypertension following a hip replacement three years ago. He was started on treatment. He comes to the surgery because he feels deaf. The doctor notices that he has not had a prescription for his raised blood pressure for six months. Albert says he feels well; he is older now than his father was when he died. He see doesn't see the point in taking expensive pills

In your opinion, which of the following statements is True or Probably True? Just circle the letter at the left side of statements you feel are True or Probably True.
A. Treatment should not be free if patients have strokes due to refusing to take tablets.
B. Albert should take his medication.
C. The doctor should respect Albert's decision not to take his tablets.
D. The doctor should spend time with Albert to explain why it is best he takes his tablets.
E. The doctor should explore the reasons why Albert has not taken his tablets.
F. The doctor should try and persuade Albert to take his tablets.
G. The doctor \& Albert should reach an understanding as to whether he should take his tablets or not.
H. Albert is demonstrating non-compliance.
I. Patients should always take their medicine as prescribed
[A, B, F, H, I are orthodox and C, D, E and G are concordant]

To establish the face validity of our research 'keys' for the two types of response options (i.e., either 'concordance' or 'orthodox'), we had two independent experts in the area of concordance independently judge and agree on the classification of the statements. In a few instances, a response option was subsequently judged to be ambiguous (not clearly concordant or orthodox), and these options were excluded from the data analyses. Because we were interested in using the case scenarios to assess respondents' generalised response tendency, our data analyses collapsed across the three cases. Given there were two types of responses nested within each scenario, we summated across the cases to 
create a single subscale score reflecting 'concordance' responses. Similarly, for the purposes of scoring, we developed a second subscale reflecting 'orthodox' responses.

\section{Participants}

A self-completion questionnaire, comprising the attitudinal statements and the 3 scenarios, was sent to 207 health-care professionals at the time of qualification in the summer of 1999. These comprised a random sample of 50 medical students and 100 nursing students from the University of Leeds and all hospital based pre-registration pharmacists qualifying in the North West, Yorkshire and Northern Regions (57).

\section{Results}

We received 81 completed questionnaires (39\%). Of the nurses, $37(37 \%)$ responded, there were $23(46 \%)$ responses from the doctors and $21(37 \%)$ from the pharmacists

\section{Reliability of the LATCon Scale}

None of the distributions of scores for each of the 22 individual items was skewed. In order to reduce the size of the scale, we conducted a series of item-remainder correlational analyses, in which each item in turn was correlated with the remaining 21 items. In such analyses, a negative correlation coefficient indicates the item measures an attitude in the opposing direction to the remainder; a weak, positive correlation indicates that the item contributes little to the attitude being measured by the remaining items. We dropped those items with an item-remainder correlation of less than .30. This resulted in a scale of 12 positively worded items (see Figure 2), with an internal consistency (Cronbach's Alpha) of .79. The mean score for the 12 item scale was $2.3(n=81)$, indicating the average respondent tended to 'agree' with the concept of concordance. However analysis also showed that $25 \%$ of respondents scored 2 or less.

\section{Validity of LATCon Scale}

In order to establish construct validity, we conducted correlational analyses (Spearman's Rho) between the 12-item scale and the case-scenario response subscales. The correlation between the 12-item scale and the scenario subscale representing concordant responses was .361 (two tailed, $\mathrm{p}<.01$ ). Although the inverse correlation with the traditional responses scenario subscale was in the expected direction, it was not statistically significant -.153 (two, tailed, $\mathrm{p}=.15$ ). 


\section{Figure 2}

\section{2 item Attitudes to Concordance Scale}

1. The consultation between the prescriber \& patient should be viewed as a negotiation between equals

2. Prescribers should respect the validity of their patients' personal beliefs \& coping strategies

3. The best use of medicines is that which is compatible with what the patient wants and is capable of achieving

4. Just as prescribing is an experiment carried out by the prescriber, so too is medication taking an experiment carried out by the patient

5. Prescribers should give patients the opportunity to communicate their thoughts about their illness and negotiate how it is treated

6. Enhanced health outcomes would follow from mutual and co-operative interaction between prescribers and patients

7. A high priority in the consultation between prescriber and patient is to establish a "therapeutic alliance."

8. Prescribers should be sensitive to patient desires, needs and capabilities

9. Prescribers should try to assist patients to make as informed a choice as is possible about benefits and risks of alternative treatments

10. During the prescriber-patient consultation, it is the patient's process of deciding that is most important

11. I believe that prescribers should be more sensitive to how patients react to the information they give

12. I believe that prescribers should try to learn about the beliefs their patients hold about their medicines

\section{Differences amongst respondent sub-samples}

For exploratory purposes, we compared the mean LATCon score for nurses, medical doctors and pharmacists (Table 1). Results of a one-way analysis of variance showed a statistically significant variation between the three subgroups of respondents $(F=3.16$, $\mathrm{p}<.05$, $\mathrm{df}=2,78$ ). Post-hoc tests (using Least Significant Difference test) showed that pharmacists had significantly lower scores than both the other groups, indicating they had the least positive attitude to concordance. Exploration of the raw data did not show any particular items or aspects of concordance on which pharmacists differed from the other groups. However, $51 \%$ nurses and $52 \%$ medical doctors scored 0 or 1 to at least one of the 12 items, whereas the equivalent figure for pharmacists was $86 \%$. 
Table 1: Mean (Standard Deviation) LATCon scores for the three professional groups.

\author{
Professional group \\ Nurses $(n=37)$ \\ Pharmacists (21) \\ Doctors (23)
}

\author{
Mean score (SD) \\ $2.34(0.37)$ \\ $2.15(0.25)$ \\ $2.37(0.28)$
}

\section{Discussion}

The concordance concept of medicine-taking requires a major shift in thinking. The attitudes of patients and health professionals will be crucial to its success. This work suggests that a scale to measure such attitudes to concordance can be devised which has internal reliability, when reduced it to a manageable 12 -item scale. The construct validity is shown by the positive correlation of the scale to the concordance sub-scale of the case scenarios. This provides preliminary evidence to suggest health professionals who score high on the scale (i.e. with a positive attitude toward concordance) are prone to think and act differently in the context of the consultation, relative to their lower scoring colleagues. As expected, the direction of the relationship linking scores to the 'orthodox' subscale of the scenarios was negative (and again supports the discriminant validity of the scale) but failed to reach statistical significance. This may be attributable to the under-representation of 'orthodox' response options in both the scale and the scenarios. The 12 statements have general face validity according to 4 experts consulted, although the evolving nature of the concordance concept highlighted some differences of opinion.

The results of the application of the scale to our sample of newly qualified health professionals suggest a sizeable discrepancy between their attitudes and the concordance concept being put forward. Specifically, $25 \%$ of our sample had a mean attitude score of less than two, indicating they either 'disagreed' or 'strongly disagreed' with the concept. If this finding were replicated with other samples of health care providers, it would suggest that a significant number still adhere to the orthodox paternalistic approach.

It has been suggested that the reason why shared decision making in general is not happening in practice is that GPs may not agree with the concept, feeling that their training and experience means that they are in a good position to tell patients what to $\mathrm{do}^{8}$. The preliminary conclusion from this work is that attitudes to concordance are not universally in favour amongst health professionals, even on qualification when they lack such experience. We believe that such significant lack of acceptance of the concordance concept should be a high priority concern to those providing education and training at undergraduate level and as part of continuing professional development. The original concordance document proposed that concordance should be an integral aspect of medical, nursing and pharmacy education '. This could form part of the training programmes in communication skills and techniques to promote shared-decision making recommended by Coulter et al. ${ }^{9}, \mathrm{GMC}^{10}$ and now in the NHS Plan ${ }^{5}$. Further support 
comes from work on registrars in general practice who report not being trained in the interpersonal skills necessary for the involvement of patients in clinical decisions ${ }^{11}$ as training in the patient-centred method often neglects the second half of the consultation where management decisions take place ${ }^{12}$.

The attitudes of health professionals other than doctors is important, due to the increasing reality of the multi-disciplinary health care team and the prospect of the widening of prescribing rights to nurses, pharmacists and others 5 . Results of our sub-group comparisons indicate education and training needs may slightly differ by professional area. For example, the attitudes of pharmacists were found to be statistically significantly less positive than nurses or doctors. However, the practical significance appears relatively small and the benefits of multi-professional learning might outweigh the benefits a uniprofessional approach.

Significant issues remain about the nature of concordance and how it relates to the NHS currently. While successful patient partnerships may lead to more efficient use of resources and prescribing, time constraints may make them difficult to implement ${ }^{13}$. As the concept of concordance evolves, this will need to be mirrored in the scale. Conclusions from this preliminary work are tentative in that the response rate to the questionnaire was less than $50 \%$. We do not know how likely it is that the nonresponders were more 'against' than 'for' concordance. More work is needed to find out if scores correspond with behaviour.

Patients are more likely to reject the sharing concept if doctors are not able to change their consulting styles ${ }^{14}$. However, for the two-way process that is concordance to become a reality, changes in ways of working and attitudes are needed as much in patients as in health professionals. We plan to administer the reduced 12-item questionnaire to larger groups of professionals and then to see if it can be used with patients.

Implementing concordance depends on professionals' understanding and support for the concept. The LATCon 12 item scale appears to discriminate between people. Professionals seem broadly positive towards concordance, but there is a significant minority who is not. If we want to take forward concordance, then changes in education and training are needed. We also need to know if attitudes change as professionals start to practice.

\section{References}

1. Royal Pharmaceutical Society of Great Britain. From compliance to concordance. Achieving shared goals in medicine taking. London: RPSGB; 1997.

2. Mullen PD. Compliance becomes concordance. British Medical Journal 1997; 314: 691. 
3. Towle A. Physician and patient communication skills: competencies for informed shared decision-making. [Informed Shared Decision Making Project] Vancouver: University of British Columbia, Vancouver; 1997.

4. NHS Executive. Patient partnership: building a collaborative strategy. Leeds: NHSE; 1996.

5. The NHS Plan. A plan for investment. A plan for reform. London: Stationary Office, London; 2000.

6. Haynes RB, McKibbon KA, Kanani R. Systematic review of randomised trials of interventions to assist patients to follow prescriptions for medications. Lancet 1996; 348: 383-386.

7. Britten N, Stevenson FA, Barry CA, Barber N, Bradley CP. Misunderstandings in prescribing decisions in general practice: qualitative study. British Medical Journal $2000 ; 320$ : 484-488.

8. Stevenson FA, Barry CA, Britten N, Barber N, Bradley CP. Doctor-patient communication about drugs: the evidence for shared decision making. Soc Sci \& Med 2000; 50: 829-840.

9. Coulter A, Entwhistle V, Gilbert D. Sharing decisions with patients: is the information good enough? British Medical Journal 1999; 318: 318-322.

10. General Medical Council. Good medical practice. London: GMC; 1998.

11. Elwyn G, Edwards A, Gwyn R, Grol R. Towards a feasible model for shared decision making: focus group study with general practice registrars. British Medical Journal 1999; 319: 753-756.

12. Elwyn G, Edwards A, Kinnersley P. Shared decision-making: the neglected half of the consultation. Br J Gen Pract 1999; 49: 477-482.

13. Middleton JF, McKinley RK. What kind of partnership in the consultation? $\mathrm{Br} J$ Gen Pract 2000; 50: 268-269.

14. Savage R, Armstrong D. Effect of a general practitioner's consulting style on patients' satisfaction. British Medical Journal 1990; 301: 968-970. 


\section{Chapter 6}

Medical students' attitudes towards concordance in medicine taking: exploring the impact of an educational intervention.

Thistlethwaite JE, Raynor DKT, Knapp PR.

Published as: Medical students' attitudes towards concordance in medicine taking: exploring the impact of an educational intervention. Education for Health 2003; 16: 307 317. 


\begin{abstract}
Background and objectives

Concordance has been suggested as a new way of describing the agreement about medicine taking during the consultation process. The aim is a decision on management agreed on by both doctor and patient. As such it has strong links with shared decisionmaking and patient partmership. In order to encourage doctors to adopt a concordant model, we need to foster a positive attitude towards the concept. We decided to investigate the attitudes of first and second year medical students towards concordance as a base for further educational interventions.
\end{abstract}

\title{
Setting
}

The School of Medicine, Leeds University.

\section{Methods}

We administered the Leeds Attitude toward Concordance scale (LATCon) to first and second year medical students at the beginning of the academic year, and to the same second year students after they had completed a written exercise relating to concordance.

\section{Results}

The response rate was over $80 \%$ for each group. There was no difference in the attitudes towards concordance of the first years and the second years prior to the intervention. After they had completed the exercise, the second years' attitudes towards concordance improved by a small but significant amount.

\section{Conclusions}

A paper-based exercise with questions focussing on concordance and based around cases appears to improve medical students' attitudes towards the concept. This exercise needs to be followed up with skills training and observation of role models in order that the attitudes of the students translate into practice once they are qualified. 


\section{Introduction}

About 50 per cent of patients with chronic diseases do not take their medication as prescribed in fully therapeutic doses and so medication compliance is an important issue for medical students to discuss. Students are usually introduced to the concept of compliance during pharmacology modules. In this context, compliance has been defined as the extent to which a patient's actual history of drug taking corresponds to the prescribed regimen ${ }^{2}$. The idea that a patient may be compliant or non-compliant due to various factors may also be discussed during primary care attachments. However, in communication skills courses, students practise the skills of explaining to patients and are asked to adopt a patient-centred approach ${ }^{3}$ to patient care. This patient-centred approach does not fit well with the concept of the 'compliant' patient, who follows 'doctor's orders' and does not take an active role in planning and managing his or her own care.

Patient partnership is also a strategy that aims to equalise relationships between health professionals ${ }^{5}$. Integral to this partnership is the concept that decision making about management, which may involve the prescribing of drugs, should be shared between the two people in the consultation ${ }^{6}$. Even if the doctor has a paternalistic style and controls the decision making process during the consultation, patients rarely relinquish their decision making role entirely ${ }^{7}$, and may decide later not to follow the doctor's instructions, perhaps including not taking their medicine as prescribed. The word 'concordance' has been suggested as a new way of describing the consultation process as a negotiation between equals, that results in a decision on management agreed on by both health professionals, eg doctor and patient ${ }^{8}$. This management decision may be an agreement not to prescribe medication, if the patient does not wish to take it. On the other hand, sharing information with patients about the advantages and disadvantages of drug treatment should ensure that once a decision to prescribe has been made, the patient will take that medication. Thus ultimately, not only is a consultation more open, but there will be less wastage of unwanted and untaken medicines.

Despite the shift to thinking about concordance rather than compliance, there is little evidence to suggest that health professionals, including doctors, have positive attitudes to concordance that translates into practice. Our previous study showed that while newly qualified doctors, nurses and pharmacists tend to have favourable attitudes, a significant minority do not, suggesting that a number still adhere to the orthodox paternalistic approach to prescribing?.

It is logical when teaching medical students about the patient-centred approach to history taking, which includes asking patients about their ideas, concerns and expectations about treatment, that they should also learn about the importance of patients' health beliefs about medicine taking. The fact that many people do not take their medication properly, if at all, comes as a shock to many medical students in our experience. The attitudes of students to concordance are important, as they are the prescribers of the future. We should be encouraging them to adopt the patient-centred and concordant model in their patient interactions. 
The aim of this study was to investigate students' attitudes towards the concept of concordance, including the idea of the consultation as a negotiation between equals and the importance of the patient's decision. We wished to see whether their attitudes change in response to learning and writing about the patient-centred method in their first year and following a more specific course about the concept during second year in order to plan further educational interventions to promote the concordance model.

\section{Method}

The Leeds Attitude to Concordance scale (LATCon) was developed and validated in $2001^{9}$. It consists of a 12 -item scale (Box 1). The respondent scores each item on a four point Likert scale: strongly disagree (0), disagree (1), agree (2), strongly agree (3). The total maximum score is therefore 36. A mean item score of between 2 and 3 indicates that the respondent tends to 'agree' with the concept of concordance, while an average score below 2 suggests that he/she does not. We administered the LATCon to all first year medical students in the first month of their studies, to all second year medical students in the first month of their second year and again to the same second year cohort at the end of the second year during the academic year 2001-2002.

At Leeds University School of Medicine medical students learn about the patient-centred approach in their first year and this model is referred to extensively in their personal and professional development (PPD) course, which includes communication skills. Concordance is not mentioned specifically in the first year of PPD but students are asked to explore patients' experience of health care and their involvement in decision making during the early patient contact in the first term.

As part of their assessment of PPD the second year students complete a Personal Development Exercise at the end of their second term. This exercise counts for one-fifth of the marks for PPD. PPD as a core unit was introduced within the new Leeds undergraduate curriculum in 1999. The second year Personal Development Exercise was introduced in 2000. The students who completed the LATCon were the second cohort of second years to complete this exercise.

The exercise consists of a series of case vignettes and questions relating to these, as well as asking for reflection on the course. The students are encouraged to take a patientcentred approach to the questions. Two of the questions (Numbers 1 and 3) are related to concordance and medicines management issues (Box 2). Hypertension was chosen as one topic as it has served as a model for compliance research and is a common condition $^{10}$. To help them with the exercise, the students are referred to two articles about concordance ${ }^{11,12}$.

Facilitators handed out the questionnaires at the beginning of the year in one of the PPD tutorial sessions, accounting for the high response rate of over $90 \%$ (see results section). The questionnaire at the end of the second year was handed out to students when they came to collect their marked Personal Development Exercise, nine weeks after submitting 
it for assessment. Those students who did not attend to collect their work were emailed a questionnaire and invited to reply by email. The questionnaires were returned anonymously; those questionnaires, which were returned by email, were printed off and not identified by sender. The students were asked to fill in the questionnaires according to how they felt and, as they returned the forms anonymously, they were reassured that individual replies could not be traced to check if students were demonstrating desirable attitudes.

\section{Box 1: 12 item LATCon Scale}

\begin{tabular}{|c|c|c|c|c|}
\hline & $\begin{array}{l}\text { Strongly } \\
\text { Disagree }\end{array}$ & $\begin{array}{l}\text { Disagree } \\
\end{array}$ & Agree & $\begin{array}{l}\text { Strongly } \\
\text { Agree }\end{array}$ \\
\hline \multicolumn{5}{|l|}{$\begin{array}{l}\text { 1. The consultation between the doctor \& patient should be viewed as a } \\
\text { negotiation between equals }\end{array}$} \\
\hline \multicolumn{5}{|l|}{ 2. Doctors should respect their patients' personal beliefs \& how they cope } \\
\hline \multicolumn{5}{|l|}{$\begin{array}{l}\text { 3. The best use of medicine is when it is what the patient wants and is able } \\
\text { to achieve }\end{array}$} \\
\hline \multicolumn{5}{|l|}{$\begin{array}{l}\text { 4. Just as prescribing is an experiment carried out by the doctor, so too is } \\
\text { medication taking an experiment carried out by the patient }\end{array}$} \\
\hline \multicolumn{5}{|l|}{$\begin{array}{l}\text { 5. Doctors should give patients the opportunity to talk about their thoughts } \\
\text { about their iliness and negotiate how it is treated }\end{array}$} \\
\hline \multicolumn{5}{|l|}{$\begin{array}{l}\text { 6. Better health would follow from co-operation between doctors and } \\
\text { patients }\end{array}$} \\
\hline \multicolumn{5}{|l|}{$\begin{array}{l}\text { 7. A high priority in the consultation between doctor and patients is to } \\
\text { establish agreement about the need for medicine }\end{array}$} \\
\hline \multicolumn{5}{|l|}{ 8. Doctors should be sensitive to patient desires, needs and abilities } \\
\hline \multicolumn{5}{|l|}{$\begin{array}{l}\text { 9. Doctors should try to help patients to make as informed a choice as } \\
\text { possible about benefits and risks of alternative treatments }\end{array}$} \\
\hline \multicolumn{5}{|l|}{$\begin{array}{l}\text { 10. During the doctor-patient consultation, it is the patient's decision that is } \\
\text { most important }\end{array}$} \\
\hline \multicolumn{5}{|l|}{$\begin{array}{l}\text { 11. Doctors should be more sensitive to how patients react to the } \\
\text { information they give }\end{array}$} \\
\hline \multicolumn{5}{|l|}{$\begin{array}{l}\text { 12. Doctors should try to learn about the beliefs their patients hold about } \\
\text { their medicines }\end{array}$} \\
\hline & $\begin{array}{l}\text { Strongly } \\
\text { Disagree }\end{array}$ & Disagree & Agree & $\begin{array}{c}\text { Strongly } \\
\text { Agree }\end{array}$ \\
\hline
\end{tabular}

(c) University of Leeds 2000 


\section{Box 2: Personal development exercise: questions relating to concordance}

1. Mr Smith, a 68-year old man, has been attending his GP's surgery and has been found to have high blood pressure on three occasions (average >150/106). He smokes 15 cigarettes a day and his cholesterol level is 6.8. The guidelines suggest his hypertension should be treated.

1.1 How would you explain this to him and why would you do it in this way?

1.2 Mr Smith agrees to treatment with a beta-blocker (standard first-line treatment) and to try and stop smoking. He is prescribed one month's treatment and asked to return then for review. You next see him six months later. He has not taken his treatment, his blood pressure is still high and he is still smoking.

Give 3 reasons, with evidence from the literature, why Mr Smith might not have 'complied' with his treatment.

3. A patient is prescribed a drug to help control his Type 2 diabetes and he is advised to lose weight. He does not take the tablets regularly and only manages to lose $2 \mathrm{lb}$ in 2 months. The doctor informs him he is not complying with his medication. The patient feels he has not been given adequate information about his condition.

3.1 There is a trend nowadays to speak of the concept of 'concordance' rather than compliance when discussing drug prescribing and taking. Try and find 3

papers/articles/chapters that discuss concordance ( $\&$ compliance) and use them to discuss what the concept means.

3.2 In what way could the doctor use this information about concordance in the consultation with this patient?

\section{Statistical methods}

Comparisons between both total scale scores and individual scale items from different time points were made using parametric analyses (i.e. the $t$ test). Since the $t$ test can be susceptible to non-normality of distributions, the findings were confirmed by nonparametric analyses (using the Mann-Whitney test).

\section{Results}

The response rates were high: first years $92.5 \%$ (236/255); second years (start) $80 \%$ (151/189); second years (end) $84.5 \%(160 / 189)$.

\section{Year I students}

Of the 236 returned questionnaires, $19(8.0 \%)$ had missing items; therefore the analysis was based on 217 completed questionnaires. The mean score was 26.6 (standard deviation 3.1), median score 27 (range 19 - 34). The item mean was 2.2 . The distribution of mean scores was normal. Of the 19 missing total scores, mostly single items were left uncompleted. The item most often left was item 4 ( 10 participants), followed by item 3 ( 4 participants). Cronbach's Alpha (test of internal reliability) was 0.630 . Individual item means ranged from 1.5 to 2.8 (Table 1 ). 
Table 1: Comparison of items means across the three sets of results.

\begin{tabular}{cccr} 
ITEM & \multicolumn{3}{c}{ MEAN (Standard deviation) } \\
& Year 1 & Year 2 (siart) & Year 2 (end) \\
& & & \\
1 & $2.0(0.7)$ & $2.1(0.7)$ & $2.4(0.6)$ \\
2 & $2.8(0.4)$ & $2.6(0.5)$ & $2.7(0.5)$ \\
3. & $1.8(0.7)$ & $1.9(0.7)$ & $2.1(0.6)$ \\
4 & $1.5(0.7)$ & $1.6(0.7)$ & $1.9(0.7)$ \\
5 & $2.6(0.6)$ & $2.6(0.5)$ & $2.6(0.5)$ \\
6 & $2.6(0.5)$ & $2.5(0.5)$ & $2.6(0.5)$ \\
7 & $1.9(0.6)$ & $1.8(0.7)$ & $1.9(0.6)$ \\
8 & $2.7(0.5)$ & $2.6(0.5)$ & $2.6(0.5)$ \\
9 & $2.6(0.5)$ & $2.4(0.5)$ & $2.5(0.5)$ \\
10 & $1.8(0.7)$ & $1.7(0.6)$ & $1.9(0.7)$ \\
11 & $2.2(0.5)$ & $2.3(0.5)$ & $2.3(0.5)$ \\
11 & $2.1(0.5)$ & $2.2(0.5)$ & $2.4(0.6)$ \\
TOTAL & $26.6(3.1)$ & $26.2(3.6)$ & $\mathbf{2 8 . 1}(4.1)$
\end{tabular}

Year 2 students (start data)

Of the 151 returned questionnaires, $12(7.9 \%)$ had missing items; therefore the analysis was based on 139 completed questionnaires. The mean score was 26.2 (standard deviation 3.6), median score 26 (range 19-35). The item mean was 2.2. The distribution of mean scores was normal. Of the 12 missing total scores, all had left a single item uncompleted. The item most often left was item 4 ( 5 participants), followed by items 3 and 8 ( 2 participants each). Cronbach's Alpha was 0.746 . Individual item means ranged from 1.6 to 2.6 (Table 1).

Comparison of year 1 and year 2 students at the start of their respective years

The total scale scores $t$-test showed no statistical difference between the two years $(t=$ $1.08, \mathrm{df}=354, \mathrm{p}=.28$ ).

Year 2 students (end data)

Of the 160 returned questionnaires, 14 scales (8.7\%) had items left uncompleted; therefore the analysis was based on 146 completed questionnaires. The mean score was 28.1 (standard deviation 4.1), median score 28 (range 20 - 36). The item mean was 2.3 . The distribution of mean scores was normal, with a slight positive skew. There were 14 missing total scale scores, all had 1 or 2 items left uncompleted. The item most often left was item 10 (10 participants), followed by item 4 ( 3 participants). Cronbach's Alpha was 0.825 . Individual item means ranged from 1.9 to 2.7 (Table 1 ). 
The comparison of year 2 start and end data

The start year mean was 26.2 ( $95 \%$ confidence intervals 25.6 to 26.8 ); the end year mean was 28.1 ( $95 \%$ confidence intervals 27.5 to 28.8 ). There was an equal distribution of variances and each distribution was approximately normal, so a comparison was made using the independent samples $t$-test: $t=4.179, \mathrm{df}=283$. Therefore, the mean LATCon score of the students increased by almost 2 points, on average, an effect size of $7.2 \%$. This difference was statistically significant at the $p<.001$ level.

\section{Item by item comparisons.}

In order to see whether the increased total scale scores were the result of increases on most or few items, the mean scores of each item were compared by $t$ test (Table 2). The variances were unequal for four items (items 4,6,7,12) and the findings were confirmed by non-parametric analyses (the Mann-Whitney test). The mean score of none of the items decreased between year start and year-end. The means scores of five of the items increased statistically significantly (at the $5 \%$ level): items $1,4,7,10$ and 12 . Item 3 was close to statistical significance $(p=.09)$.

\section{Table 2: Item by item comparisons, year 2 start and end}

\begin{tabular}{llllll} 
Item & \multicolumn{2}{l}{ Means (start, end) } & t value, & significance & (df) \\
1 & 2.1 & 2.4 & 4.34 & *** & 308 \\
2 & 2.6 & 2.7 & 1.17 & ns & 309 \\
3 & 1.9 & 2.0 & 1.71 & ns & 305 \\
4 & 1.5 & 1.9 & 5.02 & $* * *$ & 301 \\
5 & 2.6 & 2.6 & 0.06 & ns & 309 \\
6 & 2.6 & 2.6 & 1.23 & ns & 308 \\
7 & 1.8 & 2.0 & 2.96 & $* *$ & 308 \\
8 & 2.6 & 2.6 & 0.61 & ns & 307 \\
9 & 2.4 & 2.5 & 1.58 & ns & 308 \\
10 & 1.7 & 1.9 & 2.42 & $*$ & 298 \\
11 & 2.2 & 2.3 & 1.33 & ns & 308 \\
12 & 2.2 & 2.3 & 2.10 & $*$ & 308 \\
& \multicolumn{7}{l}{} \\
ns & not significant $(\mathrm{p}>.05)$ & & \\
$*$ & $\mathrm{p}<.05$ & & \\
$* *$ & $\mathrm{p}<.01$ & & & \\
$* * *$ & $\mathrm{p}<.001$
\end{tabular}

In order to check if the increase in scores across the year was due to a general increase across the items, rather than being due to a dramatic increase in a few items, we looked at the proportion of students who scored a 2 or 3 (ie agree or strongly agree) on each item, and then compared these proportions for start and end year data (Table 3). The results appear to show a meaningful shift on items 1,3,4 and 7, a similar, but not identical, pattern to that seen on the t-test (which used the arithmetic mean). Taking all these 
results together, it is apparent that the LATCon attitude scores increased significantly over the course of year 2 .

Table 3: Percentage of students scoring agree or strongly agree on each item (year 2)

$\begin{array}{ccc}\text { Item } & \text { Year start } & \text { Year end } \\ 1 & 84 & 95 \\ 2 & 99 & 99 \\ 3 & 72 & 82 \\ 4 & 54 & 78 \\ 5 & 99 & 99 \\ 6 & 97 & 98 \\ 7 & 67 & 81 \\ 8 & 98 & 98 \\ 9 & 97 & 97 \\ 10 & 67 & 69 \\ 11 & 93 & 95 \\ 12 & 95 & 94\end{array}$

Comparison of items means across the three sets of results.

The lowest scoring items at the start of both first and second year (items 3, 7, 10) were those which appear more controversial, putting the patient at the centre of the decision making process, and item 4 which talks in terms of experimentation. These items also scored low in the end of second year results though the scores become higher. Those items which are less controversial and which are covered in communication skills courses $(2,5,6,8,9)$ scored high in all three sets of results (Table 1 ).

\section{Discussion}

An understanding of patients' behaviour, as regards medicine taking and the influences on it such as health beliefs and doctor behaviour, is fundamental to the doctor-patient relationship. Doctors need to shift the emphasis away from encouraging patients to take their prescribed medicine towards trying to understand how they can contribute to the decisions that patients make about taking their medication ${ }^{13}$. Getting medical students to start thinking about the patient's role in decision making and the concept of concordance has implications as regards the future quality of patient care, given that such medical students are tomorrow's doctors with responsibility for the treatment of patients. A simple exercise relating to prescribing and management appears to have changed the attitudes of the students to these issues by a statistically significant, although relatively small amount.

Medical students at the start of their undergraduate education appear to have reasonably positive attitudes to the patient-centred approach, scoring highly on items that mention respect for patients and sensitivity. Their attitudes to other concordance features such as the patient's decision being important are less favourable. According to our work 
comparing two cohorts of students, these attitudes do not appear to change after one year's study, which included patient contact and communication skills training. However after an exercise that involves reading specifically about concordance and answering questions relating to cases in which patients have 'complied' poorly with doctors' advice, students' attitudes to concordance improve.

In comparing the attitudes of the first years to those of the second years, we assume that the two populations of students are broadly similar. They came through the same selection process for medical school and have similar demographics (gender and age). In comparing the second year students at the start and end of the year it is possible that the scores increased as a function of the same students completing the questionnaire twice. We have not measured the questionnaire's test-retest reliability and so this explanation is a possibility. However the length of time between the two questionnaires (eight months) will have minimised this effect.

It would be interesting to track the students' attitudes towards concordance through until qualification and beyond to see if their exposure to role models and patients in more clinical settings affects them. Of course this questionnaire only measures attitudes and not behaviour. The questionnaire has good internal reliability ${ }^{9}$ but its construct validity can only be assessed by seeing how its attitude scores predict behaviour in practice. To check if students and doctors actually practise concordance would require very different methods. A study of first year residents in South Carolina suggests that newly qualified doctors are willing to give control to patients in theory but change behaviour to become more paternalistic when describing what they would do in concrete cases in practice ${ }^{14}$. Theoretical training needs to be followed up with work-based practice and observation of concordance in action.

As medical educators we need to promote a shared decision making model and the concept of concordance to our students in order to improve patient outcomes and motivate patients to become partners in their own health care.

\section{References}

' Sackett DL, Snow JC. The magnitude of compliance and non-compliance. In: RB. Haynes, WD. Taylor \& DL Sackett (Eds). Compliance in health care London: Johns Hopkins University Press; 1979. p11-22.

${ }^{2}$ Urquhart J. Patient non-compliance with drug regimens: measurement, clinical correlates, economic impact. European Heart Journal 1996; 17 (Suppl A): 8-15. 
${ }^{3}$ Levenstein JH, McCracken EC, McWhinney IR, Stewart MA, Brown JB. The patientcentred clinical method. 1. A model for the doctor-patient interaction in family medicine. Family Practice 1986; 3: 24-30.

${ }^{4}$ McWilliam CL, Brown JB. Choices and chances - whose responsibility? In: $M$ Stewart, JB Brown, WW Weston, IR McWhinney, CL McWilliam \& TR Freeman. Patient-centered medicine. Transforming the clinical method. London: Sage; 1995. p 87-88.

${ }^{5}$ Coulter, A. Paternalism or partnership. British Medical Journal 1999; 319: 719-720.

${ }^{6}$ Elwyn G, Charles C. Shared decision-making: the principles and the competences. In: A Edwards \& G Edwards (Eds). Evidence-based patient choice. Oxford: Oxford University Press; 2001. p118-143.

${ }^{7}$ Deber RB, Kraetschmer N, Irvine J. What role do patients wish to play in treatment decision-making? Annals of Internal Medicine 1996; 156: 1414-1420.

${ }^{8}$ Royal Pharmaceutical Society of Great Britain. From compliance to concordance. Achieving shared goals in medicine taking. London: RPSGB; 1997.

${ }^{9}$ Raynor DK, Thistlethwaite JE, Hart K, Knapp P. Are health professionals ready for the new philosophy of concordance in medicine taking? International Journal of Pharmacy Practice 2001; 9: 810-84.

${ }^{10}$ Dunbar-Jacob J, Dwyer EJ. Compliance with antihypertensive regimen: a review of the research in the 1980s. Annals of Behavioral Medicine1991; 12: 31-39.

"Mullen PD. Compliance becomes concordance. British Medical Journal 1997; 314: 69.

${ }^{12}$ Marinker M. Personal paper: Writing prescriptions is easy. British Medical Journal 1997; 314: 747-748.

${ }^{13}$ Vermeire E, Hearnshaw H, Van Royen P, Denekens J. Patient adherence to treatment: three decades of research. A comprehensive review. Journal of Clinical Pharmacy and Therapeutics 2001 ; 26: 331-342.

${ }^{14}$ McKeown RE, Reiniger BM, Martin M, Hoppman RA. Shared decision-making: views of first year residents and clinic patients. Academic Medicine 2002; 77: 438-445. 


\section{Chapter 7}

Making and sharing decisions about management with patients: the views and experiences of pre-registration house officers in general practice and hospital.

Thistlethwaite JE.

Published as: Making and sharing decisions about management with patients: the views and experiences of pre-registration house officers in general practice and hospital. Medical Education 2002; 36: 49-55. 


\begin{abstract}
Objectives

To explore the views and experiences of pre-registration house officers (PRHOs) in general practice and hospital settings regarding the concept of patient partnership and their experience of involving patients in management decisions.

\section{Design}

The 12 PRHOs who had graduated from British universities and who were working within the Yorkshire Deanery were interviewed towards the end of their four-month general practice attachments. The interviews were semistructured and analysed qualitatively.

\section{Results}

Three major themes emerged. The PRHOs perceived differences in approach between consultations carried out in hospital and primary care settings, with general practitioners being more likely to share information and decisions with patients. As medical students the PRHOs had had little opportunity to practise sharing information and management decisions with patients and variable experience of this after graduation. On the whole they were favourable to the concept of patient partnership.

\section{Conclusions}

Medical students and PRHOs lack training and opportunity to decide on management and discuss this with patients and yet, particularly in general practice settings, they have to practise these skills. The PRHOs had begun to develop strategies to decide how much information to give to patients and to what extent to involve patients in management decisions. This is an area that needs further consideration when planning both undergraduate and postgraduate medical education.
\end{abstract}




\section{Introduction}

Health professionals are beginning to accept that patients' views about treatment should be taken into account, while the paternalistic model in which doctors make decisions about management on behalf of their patients is increasingly regarded as old-fashioned ${ }^{1}$. Consultations in which the doctor's agenda dominates have been shown to decrease patients' satisfaction, while increasing the likelihood of complaints ${ }^{2}$, and hinder patients' understanding of their illness ${ }^{3}$. Thus patient partnership is now in the ascendancy. Coulter has suggested that partners work together to achieve common goals and that their relationship is based on mutual respect for each other's skills. As successful partnerships are non-hierarchical, partners share decision making and responsibility. The model is of particular benefit for clinicians intervening to reduce the risk of disease in their patients, where individualised calculations of risks and benefits are used and where choices about treatment are being made 5 .

Towle has defined a series of steps that should occur in consultations that would enable doctors and patients to share in the decision-making process, using the term informed shared decision making' (ISDM) to describe this model ${ }^{6}$. These steps include: establishing a context in which patients' views about treatment options are valued and necessary, and eliciting patients' preferences so that appropriate treatment options are discussed. The shared decision-making process is thus an integral part of a patientcentred consultation ${ }^{7}$, in contrast to doctor-centred consultations that end with the doctor making a diagnosis and formulating a management plan. Doctor-centred consultations hinder compliance with treatment ${ }^{8}$; the term compliance in itself suggesting the power base of the transaction.

One of the defining characteristics of effective patient-centred consultations is the doctor eliciting the patient's ideas, concerns and expectations 9 . In less effective consultations the doctor fails to recognise or ignores the patient's agenda ${ }^{10}$. Doctors who take a paternalistic approach make decisions in what they think is in their patient's best interests without exploring the patient's values and concerns ${ }^{11}$.

Sharing decisions is not simply sharing information, and then leaving the decision making as solely the prerogative of the patient (the informed model) ${ }^{12}$. While courses in communication skills are now commonplace in undergraduate and postgraduate medical curricula, these mainly concentrate on the first part of the consultation (achieving rapport, matching agendas, problem-solving) rather than management and negotiation ${ }^{13}$. Thus, patient partnership, while a term open to different interpretations, combines within the concept notions of a patient-centred approach and ISDM.

This paper explores, by interviewing pre-registration house officers (PRHOs) working in hospital and general practice, when, where and how junior doctors, first become involved in management decisions about patients and whether they are in a position to involve patients in these decisions. While there have been PRHO placements in general practice for a number of years in London ${ }^{14}$ the widening of this scheme to the rest of the United Kingdom has only occurred since 1999. The PRHOs in Yorkshire who undergo a four- 
month attachment in general practice combine this in rotation with four months each of medicine and surgery on more traditional hospital firms. These junior doctors therefore draw on experience of working in different environments. The attitudes of these doctors to the informed shared decision making model were explored, as these are an important aspect of whether the model is carried out in practice. As ISDM stems from a patientcentred approach to the consultation, the PRHOs were asked about various aspects of this approach including eliciting the patient's biopsychosocial problems as appropriate, and their ideas and concerns.

\section{Participants and methods}

Twelve PRHOs were interviewed over the course of 1999-2000 in the Yorkshire Deanery. These doctors were all the British graduates undertaking pre-registration posts in Yorkshire, thus the sample size was dictated by the available pool of PRHOs undergoing this rotation. The PRHOs were interviewed towards the end of their fourmonth general practice attachment; for four this was their first attachment (coded in the results as PRHOs 1-4), for three the middle attachment (5-7) and for five the final attachment (8-12).

The interviews were semi-structured and flexible, being based on a number of openended questions that varied depending on the subject's previous hospital experience, if any. In this way interviewees were able to raise and explore issues that they considered relevant. Ultimately the aim was to allow themes to emerge as a result of the interviews ${ }^{15}$. Important issues and themes emerging from interviews were incorporated into subsequent interviews so that interviewing and analysis were simultaneous throughout the research process in line with qualitative research methodology ${ }^{16}$. As the number of interviewees was limited to the number of PRHOs who were on a rotation involving a GP attachment the categories and themes arising from the interviews are not necessarily saturated ${ }^{17}$, but further interviews with the next cohort of PRHOs is planned.

The interviews were audiotaped, transcribed and then coded using a system of open coding. The transcripts were read many times and analysed using an inductive approach whereby analysis of the content of all the interviews allowed for its organization into a number of dominant themes. These were constructed on the basis of the identification of recurrent patterns in the statements made by the PRHOs about their feelings and experiences. The PRHOs are identified number and their quotes have been chosen as being most appropriate to illustrate the theme under discussion.

\section{Results}

On analysis three major themes were identified which characterised the PRHOs' experiences and attitudes to patient partnership (Box 1). 
Box 1: Themes arising from the interviews

1. Perceived differences between consultations in general practice and hospital.

(a) The patient-centred approach more important in primary care than hospital.

(b) Hospital clinicians tend to adopt a doctor-centred approach.

(c) Sharing information more likely in general practice than in hospital.

2. Factors influencing sharing information/decisions with patients.

(a) Patients in hospital are relatively powerless.

(b) Lack of opportunity as students to practise sharing information and management decisions with patients.

(c) Variable experience as PRHOs

(d) Being observed during PRHO posts

(e) PRHO experience and knowledge

(f) Patients vary in their desire and ability to share decisions.

(g) Methods of judging how much information to give to patients.

(h) Time is an important consideration.

3. Attitudes to patient partnership

\section{Perceived differences between consultations in general practice and hospital.}

\section{Patient centred approach}

Seven of the PRHOs acknowledged that it was important to ask about patients' ideas and concerns. They felt that this was likely to be more important, more feasible and happened more often in general practice, though concerns would be explored in hospital if the patient was obviously distressed.

I don't think you do (ask about concerns in hospital) I'm looking back now, hopefully when I go back into hospital I will, I'll ask about patients' concerns but I never did before. (PRHO 6)

Knowing a patient's ideas and concerns was thought necessary to provide continuity of care and two had been advised to do this by their GP tutors. Some PRHOs remembered that this had been mentioned in the undergraduate programme but they had no practical experience of doing it until they worked in general practice.

We've been taught about it...but we haven't actually come down and used it like now. I think it's more because I'm getting my own clinics, my own surgeries and seeing patients I can try out different techniques. (PRHO 2)

\section{Sharing information}

Shared-decision making was thought to be more likely in general practice because of the open consulting style. From the experience of the majority it was thought less likely to happen in hospital, with any explanations to patients being brief or poor: 
Often as a house officer you see the patient after the consultant's gone and you go round and talk to them, they haven't really understood what they've said to them. (PRHO 10)

Though this may be due partly to the passivity of the patients:

I think part of the consultation in general practice is a lot about patient education so it's explaining things to them, it's much more a two way process than in hospital really, well I feel patients (in hospital) don't really ask...they don't tend to ask questions as much. (PRHO 7).

One PRHO did think that consultants were beginning to involve patients in their management, demonstrating the difference in experience and role models available to PRHOs in different posts. While most of the PRHOs had been aware of this process of sharing information as students it had been stressed in the practices during their PRHO posts:

You've probably been made aware of it as an undergraduate but I think it's definitely enforced here, whether all GPs are like that I don't know (PRHO I)

There was greater opportunity for junior doctors to discuss management with patients in primary care compared to hospital. General practice consultations highlighted the information-sharing process more efficiently so that the doctors realised what two-way negotiation was really about:

A recent tutorial I had with one of my $(G P)$ supervisors here helped me to see that the consultation isn't all about the doctor telling the patient what to do but more of a two way thing, the negotiation to achieve an end and that was quite a new thing for me. (PRHO 8)

Factors influencing sharing information/decisions with patients.

Patients in hospital are relatively powerless

The general feeling was that in hospital patients are resigned and powerless whereas patients are more open in general practice and expect to share their worries:

...the patients come to you here (general practice) with their own ideas, whereas in hospital it seems to be they are sort of resigned to being in hospital. (PRHO 2)

\section{Lack of opportunity as students}

A lack of opportunity as medical students to become involved in the management of patients meant that the doctors had not had a chance to talk to patients about management decisions before qualifying. The usual scenario was that the senior student would 'clerk' a patient and then present the case to a doctor. The doctor and student would then discuss possible investigations and treatment but not in the presence of the patient: 
I don't think there's been anything specific that necessarily prepares you to discuss options with patients but you should do (PRHO 4)

\section{Variable experience as PRHOs}

Some of the PRHOs had to start managing their own patients early on in their first house jobs

Day one in the hospital I think I kind of had to...I was on my own a lot in the first job so I could, there would not be any other doctors seeing the patients for that day so you sort of had to do bits to them. (PRHO 5)

For others the need to manage patients came in their general practice post:

I think it's been in general practice actually. I don't think I did it as a student...and doing surgery for four months I didn't really. I wasn't expected to and I didn't try to in any case. (PRHO 6)

There appeared to be more likelihood of the PRHOs managing patients during medical house jobs rather than surgical. In general practice the PRHO had to manage patients, there was no choice; the patients expected it:

I think because in general practice they are just there, it's just you and the patient, you really have no choice but to discuss what you are going to do with them because that's what they expect anyway. (PRHO 4)

\section{Being observed}

Only one of the PRHOs had been observed interacting with patients and been given feedback in hospital and that was on ward rounds. It was more likely that feedback was given on the written history:

I did have management discussions on what I'd written down and whether they were a good or a bad thing...so that was discussed but not how l'd discussed it with the patient. (PRHO 10)

Four of the PRHOs in general practice had consulted with the GP tutor sitting in and five had been videotaped and given subsequent feedback on their consultation techniques, including discussing management. Overall the PRHOs would like more feedback, though felt that this was unlikely to be practical in the hospital setting:

I can't imagine the consultants would be very keen to take the time to sit and watch us but I think it would be useful...even if it's only once or twice.

(PRHO 10) 


\section{PRHO experience and knowledge}

The PRHOs varied in the amount and ways in which they involved patients in management decisions. Depending on the circumstances the same doctor might prefer to choose the option or explain options to the patient and let the patient choose:

Quite a lot I do say I think we should do this what do you think? Or I mean would you like me to do this or would you like to take something else? I do try and do that (PRHO 6)

Two doctors commented that letting the patient help decide the management was useful because of the doctor's lack of knowledge. However, there was a division in feeling about how increased confidence in practice and a greater medical knowledge would affect the management process. Some felt that a current lack of knowledge meant that the doctor was only aware of one treatment option and therefore could give the patient no obvious choices:

The reason why I don't do it (negotiate) at the moment is because I'm probably less competent about the different avenues to take and maybe there's one specific one that I know is a definite option and we can take it (PRHO 8)

However five of the doctors also felt that confidence in practice together with more medical knowledge would mean that they would be better able to guide patients:

I don't tell patients what they need, I think that comes with a lot more confidence (PRHO 2)

though this could still be expressed as an option:

(with experience) I think I'll have more of an opinion of what's the best approach to take. I mean I don't think that will stop me from sort of discussing the options but I think I'm more likely to have an opinion on certainly what might be the best thing to do. I don't mean I'll force it on them (PRHO 4)

However it was felt likely that a more experienced doctor would give less information about options because of knowledge of what works, as the PRHOs said that ultimately the doctor has to make the final decision on treatment:

I can only say from observation that I think I'd probably give them less because I'd probably have personal experience of what works and what doesn't which probably wouldn't be very evidence based. (PRHO 5)

Considering the process of negotiation, it was felt that a doctor could influence the patient's decision by how issues were explained: 
I think they are quite influenced by how you describe the choices, it's the way you phrase questions that makes patients come back to your idea. (PRHO 2)

\section{Patients vary in their desire and ability to share decisions}

How much information and explanation was given to patients depended on how ill the patient was and/or on how much he/she could understand. Sharing information and decision making also depends on judging what the patient wants and whether they want options or they want the doctor to decide. Some patients already know what they want:

I mean there's some people that come and they know exactly what they want and I think it would be just a waste of time to negotiate with people like that. (PRHO 9)

Others are capable of making decisions or want to:

You tend to ask them...these are the options would you like to and then 'you're the doctor and you tell me' and you get a feel for how involved they do want to be in their treatment (PRHO 10)

\section{Methods of judging how much information to give}

Making judgements about whether patients would want to or be able to be involved in management decisions was a process the doctors found difficult to describe:

I don't know that I consciously think about it. I suppose it depends what they've got wrong with them. I mean I usually try to...you sort of assess on a subconscious level how much you think they are going to understand and if you think they seem to be understanding more you might explain more (PRHO 3)

I think part of it is instinct and body language and whether they feel happy I mean I guess it is intuition, you feel that they're satisfied with what you've told them (PRHO 11)

This process may begin as soon as the patient works in through the door, an advantage of general practice where judgements may be made on the basis of how the patient is dressed, where the practice is located or the age of the patient. The PRHOs also spoke about the need for doctors to assess how much information patients could cope with and their understanding of the situation. This assessment could be done in different ways: it depended on the questions patients asked, what their background was and the nature of the problem:

To be honest you go on things like the social class factors and the age of the patient, if they've got a job or not...I suppose you shouldn't but you do pre-judge and where they live and things and whether you think they're intelligent or not. (PRHO 6) 
Other factors that contributed to how much the doctors involved the patients in decisionmaking were the doctors' perception of the patient's level of understanding and by asking the patient if they wanted to be involved:

You can still ask them what do you think you should do and if they say I don't know then I'll leave it in your hands really but they might say something specific like I don't really want to take tablets (PRHO 6)

\section{Time}

Sharing decisions was seen as time consuming. The PRHOs felt that when they were rushed it was difficult to be patient-centred. The feeling was expressed that doctors are under pressure both in hospital and in general practice:

Hospital doctors are very bad at explaining to patients what's happening to them, I think it's time (PRHO 5)

I think each doctor can vary depending on how rushed they are...if they're in a rush they only just want to get that patient out of the room quickly so they just treat the problem and nothing else (PRHO 7)

\section{Attitudes to patient partnership}

The PRHOs were generally favourable to the idea of the patient partnership as they see it as benefiting both doctor and patient:

I'm all for it as long as at the end of the day you are sure and happy that that patient can make the decision for himself or herself (PRHO 1)

However concern was expressed as to how well the model could be applied:

That's how it ought to be but whether it'll always work in practice is another matter. I can imagine the little old ladies...would find it difficult to have the doctor wanting to work in partnership with them on some levels. (PRHO 3)

\section{Discussion}

The PRHOs were generally favourable to the idea of patient partnership and sharing decision making with patients. Communication skills courses at an undergraduate level usually cover the sharing of information but this is not the same as sharing decisions ${ }^{18}$. Thus the PRHOs were unprepared for making management decisions and sharing these with patients. In spite of this many of them had to manage patients with some supervision in their first few weeks on the wards, for example prescribing painkillers or antibiotics, and in general practice. In the hospital setting senior doctors often appeared to make 
decisions about management with little discussion with the patients. Sometimes it was the junior doctor who had to explain to the patient what was going on. In general practice, the PRHOs had to decide on management and explain this to their patients, often entering into some form of negotiation. The PRHOs received some training or had discussion about this with their GP tutors but the process was prompted by the demands of the patients, many of whom expected information and involvement in treatment. Of course in hospital the patients are usually more acutely ill than in primary care and some are unable to share in the decision-making process.

In adopting the ISDM it is necessary to determine which patients want to be offered choices and which prefer a more passive role of medical decision-making'. The PRHOs had begun to develop ways of deciding how much information to give to patients and to what extent to involve them in management decisions. This development appeared to be self-learnt through experience, though the process was also influenced by the amount the PRHO knew and understood about the patient's condition. It was interesting that some of the doctors felt that with greater experience and knowledge they would be more likely to want to decide on management for their patients while others felt that the same experience would give them more options to discuss with patients to help the patients decide. The PRHOs highlighted factors such as age and intelligence that might limit negotiation similar to those in a study of general practice registrars with more consultation experience ${ }^{19}$.

This study highlights several areas of concern. Appropriate tasks for PRHOs have been identified as talking and explaining to patients, liaising with patients and informing patients as well as prescribing in non-complex cases ${ }^{20}$. Yet junior doctors are not adequately prepared to manage patients, share information with them and discuss options, yet they are put into a position where this is expected of them to some extent. Of course they are supervised as a senior doctor checks their management decisions, but the patient interaction and sharing of information is not observed. These PRHOs received little if no feedback about their performance in these areas, though it was more likely in the general practice setting. Yet feedback has been defined as an essential component of supervision while there is recognition that there are difficulties in finding time for such supervision $^{21}$

Role models who adopt a patient-centred approach to consultations were more likely to be observed by the PRHOs in primary care settings than in hospital settings. This is similar to the experience of medical students ${ }^{22}$. More information sharing and negotiation may take place in outpatient departments but PRHOs rarely attend these clinics to observe senior doctors. Thus, junior doctors who spend no further time in primary care after qualifying and who do not undertake PRHO posts in general practice may not be exposed to patient partnership models to any great extent on the wards. Moreover the PRHOs working in hospital were not encouraged to ask about their patients' concerns, though this was emphasised in general practice.

In order to promote patient partnership medical students must be exposed to the concept during their training and observe it in practice, preferably in both hospital and primary 
care settings. They need experience in deciding on management, sharing information with patients and negotiating treatment, certainly in non-complex cases. Such experience should be built into the curriculum and emphasised in all clinical settings and should not be focussed upon solely in communication skills courses. At an undergraduate level this may best be carried out with the help of simulated patients; at a postgraduate level junior doctors should be observed and given feedback when undertaking these tasks. Given the differences in exposure and experience of PRHOs in hospital and general practice, it would seem sensible to ensure that all junior doctors at some stage in their careers work in both primary care and outpatient settings.

\section{References}

${ }^{1}$ Richards T. Patients' priorities. British Medical Journal 1999; 318: 277-277.

${ }^{2}$ Levinson W. Physician-patient communication. A key to malpractice prevention. $J$ Am Med Assoc 1994; 272: 1619-1620.

${ }^{3}$ Delbanco TL. Enriching the doctor-patient relationship by inviting the patient's perspective. Ann Intern Med 1992; 116: 414-418.

${ }^{4}$ Coulter A. Paternalism or partnership. British Medical Journal 1999; 319: 719-720.

${ }^{5}$ Edwards AGK, Barker J, Bloor M et al. A systematic review of risk communication improving effective clinical practice and research in primary care. Cardiff:

Department of General Practice, University of Wales College of Medicine; 1999.

6 Towle A. Physician and patient communication skills: competencies for informed shared decision-making. [Informed Shared Decision Making Project] Vancouver: University of British Columbia, Vancouver; 1997.

${ }^{7}$ Charles C, Gafni A, Whelan T. Shared decision-making in the medical encounter: what does it mean? (or it takes two to tango). Social Science and Medicine 1997; 44: 681-692.

${ }^{8}$ Royal Pharmaceutical Society of Great Britain. From compliance to concordance. Achieving shared goals in medicine taking. London: RPSGB; 1997.

${ }^{9}$ Byrne PS \& Long BEL. Doctors talking to patients. London: HMSO; 1986.

${ }^{10}$ Levenstein JH, McCracken EC \& McWhinney IR et al. The patient-centred clinical method. 1. A model for the doctor-patient interaction in family medicine. Family Practice 1986; 3: 24-30.

"Charles C, Gafni A, Whelan T. How to improve communication between doctors and patients. British Medical Journal 2000; 320: 1220-1221. 
${ }^{12}$ Charles C, Whelan T, Gafni A. What do we mean by partnership in making decisions about treatment? British Medical Journal 1999; 319: 780-782.

${ }^{13}$ Elwyn G, Edwards A, Kinnersley P. Shared decision-making in primary care: the neglected second half of the consultation. British Journal of General Practice 1999; 49: 477-482.

${ }^{14}$ Harris CM. Pre-registration posts in general practice. Medical Education 1986; 20: $136-139$.

${ }^{15}$ Miles HB, Hubermann AM. A sourcebook of new methods. California: Sage; 1984.

${ }^{16}$ Strauss A, Corbin J. Basics of qualitative research. Second Edition. London: Sage; 1998.

17 Silverman D. Doing qualitative research. A practical handbook. . London: Sage; 2000.

${ }^{18}$ Ong LML, de Haes JCJM, Hoos AM, Lammes FB. Doctor-patient communication: a review of the literature. Social Science and Medicine 1995; 40: 903-918.

${ }^{19}$ Elwyn G, Edwards A, Gwyn R, Grol R. Towards a feasible model for shared decision making: focus group study with general practice registrars. British Medical Journal 1999; 319: 753-756.

${ }^{20}$ Stewart J, O'Halloran C, Harrigan P, Spencer JA, Barton R, Singleton SJ. Identifying appropriate tasks for the pre-registration year: modified Delphi technique. British Medical Journal 1999; 319: 224-229.

${ }^{21}$ Kilminster SM, Jolly BC. Effective supervision in clinical practice settings: a literature review. Medical Education 2000; 34: 827-840.

${ }^{22}$ Thistlethwaite JE, Jordan JJ. Patient-centred consultations: a comparison of student experience and understanding in two clinical environments. Medical Education 1999; 33: $678-685$. 


\section{Chapter 8}

The use of incognito simulated patients in general practice: a feasibility study.

Thistlethwaite JE.

Published as: The use of incognito simulated patients in general practice: a feasibility study. Education for Primary Care 2003; 14: 419-425. 


\section{SUMMARY}

The use of simulated patients in the training and assessment of medical students and doctors is now widespread. However in the UK simulated patients have not been used covertly in general practice though this practice has been introduced elsewhere. The aim of this study was to investigate the feasibility of introducing incognito simulated patients into general practices and to explore the experiences of the doctors and simulated patients involved. Covert simulated patients attended five general practice surgeries in West Yorkshire for consultations with eleven pre-registration house officers, followed by semistructured interviews of the doctors and reports from the patients. Six of the doctors deduced that the simulated patient was not a 'real' patient. There were various reasons for this. The doctors did not object to the experience, though some were worried about revealing a perceived lack of knowledge, and valued getting feedback on their consultations. This is a valuable method, amongst others, of looking at GP consultations but involves difficult logistics. A code of practice needs to be adhered to so that the doctors and simulated patients do not feel threatened by the experience. Special care needs to be taken with the patient scenario. 


\section{Introduction}

In the United Kingdom simulated (standardized) patients are used as a resource for both teaching and assessing medical students and doctors. Simulated patients (SPs) are lay people who learn how to portray patients in a consistent and standardized way ${ }^{1}$. In medical education they help students and doctors develop and practise communication, consultation and clinical skills, giving valuable feedback from the patient's perspective ${ }^{2}$. In assessment they are widely used in objective structured clinical examinations (OSCEs) and simulated surgeries, the latter as one of the components of summative assessment of GP registrars ${ }^{3}$ and the MRCGP examination ${ }^{4}$. In the Netherlands ${ }^{5}$, New Zealand ${ }^{6}$ and Canada', they have been used posing as 'real' patients for the validation or assessment of GPs' performance and also in secondary care settings ${ }^{8}$. The use of SPs in this way has been shown to be a valid and reliable method for assessing actual clinical performance in the workplace?

In the UK the use of SPs to study the performance of GPs is overt (the doctor knows that the patients are simulators) rather than covert (when the doctor is unaware of this fact ${ }^{10}$ ). If the doctors are unaware that the patient is a simulator, their clinical performance is likely to be more authentic and not simply a test of competence. ${ }^{4}$. However there are logistical problems to overcome when trying to introduce a simulated patient into a general practice surgery without the doctor knowing. This paper describes what happened when such an exercise was undertaken.

This paper is solely concerned with the logistics of using simulated patients in real surgeries and consultations and the opinions of the PRHOs and simulated patients about the experience. However to put this into context, the main aim of the study was to investigate the attitudes and practice of pre-registration house officers (PRHOs) in general practice as regards informed shared decision-making. The first two years of the three-year study involved interviewing the PRHOS within the Yorkshire Deanery, while in the third year simulated patients were used to corroborate the statements of the doctors with regards to their consultation process with the permission of the doctors. Part of this work has been presented elsewhere ${ }^{11}$ and part is ongoing.

\section{Method}

The PRHOs were undergoing a rotation of one year that included four months each in medicine, surgery and general practice in any order. In the third year of the study we correlated the PRHOs' replies regarding their consultation behaviour with evidence of their performance in a consultation with a simulated patient, following advice from medical educators in the Netherlands. We obtained permission to do this from the Postgraduate Dean and the GP tutors. Eleven PRHOs were advised that a simulated patient would attend the surgery at some time in the last two months of their placement, if this were acceptable. All agreed. Five surgeries (coded A - E) were visited. In Yorkshire there are eight practices that take PRHOs. These five practices were chosen for ease of access of the SPS and because the PRHOs were all British graduates. The schedule of visiting is shown in Table 1. Two SPs were used (X, Y). 


\section{Table 1}

Timing of interviews relating to position of general practice attachment in the year's PRHO rotation and surgery visited

\begin{tabular}{|l|c|c|c|}
\hline Timing & $1^{\text {st }} 4$ months & $2^{\text {nd }} 4$ months & $3^{\text {rd }} 4$ months \\
\hline Number of PRHOs & 4 & 4 & 3 \\
\hline Surgeries visited & $\mathrm{A}, \mathrm{B}, \mathrm{C}, \mathrm{D}$ & $\mathrm{A}, \mathrm{C}, \mathrm{D}, \mathrm{E}$ & $\mathrm{A}, \mathrm{B}, \mathrm{D}$ \\
\hline Simulated patient & $\mathrm{X}$ & $\mathrm{X}$ & $\mathrm{Y}$ \\
\hline
\end{tabular}

When deciding on a role for the SP several considerations had to be taken into account. There would be no computerised record for the patient and for this study it was considered too onerous to compile 'fake' records. Therefore the SP had to be either a new patient or a temporary resident. The latter was thought to be more suitable. The patient had to be given a name and temporary address in the practice area. The GP tutor supplied the address. The GP tutor and the practice manager were aware of the SP's identity in order to erase the records and the temporary resident claim for payment form after the consultation. As the purpose of the main study was to investigate the development of shared decision making by the PRHOs, the SP had to have a condition that facilitated this approach with several management options that would not merit instant investigation or referral. There were some differences in the brief for the two SPs used because of a ten-year difference in age. A brief summary of the role is shown in Box 1.

\section{Box 1: Simulated patient scenario}

Temporary resident. Staying with sister. Teacher, recently retired. Divorced. Doesn't see ex-wife. One child, a son, living in London. Been feeling tired for several months. No other physical symptoms. Sleep problems. Few hobbies apart from gardening. Come up to stay with widowed sister for a few weeks, because she has been worried about how he sounds on the phone. Been there about two weeks and she has made him come to the surgery because of his lack of interest. He thinks the main problem is that he has stopped working and hasn't adjusted.

The SPs were asked to write a written report on their visit including any problems they had encountered, as well as rating the consultation in terms of shared decision making. During the semi-structured interviews by the author for the main purpose of the study, the PRHOs were also asked about their experience with the SP and their feelings about the process. Important issues emerging from the interviews were incorporated into subsequent interviews so that interviewing and analysis were simultaneous throughout the research process in line with qualitative research methodology ${ }^{12}$. The PRHOs were offered feedback on their performance if they wished to have it. All of them were interested in receiving this feedback. 


\section{Results}

\section{Was the patient convincing?}

Six of the PRHOs deduced that the SP was not a real patient. These all consulted with SP ' $X$ '. Of these six, two recognised the SP from teaching sessions in the School of Medicine in Leeds and two specifically said that the patient being a temporary resident was a factor (Table 2).

Table 2: Recognition or not of simulated patient

\begin{tabular}{|c|c|l|}
\hline PRHO/SP & Deduced SP & Reason/reason not \\
\hline $1 / \mathrm{X}$ & No & \\
\hline $2 / \mathrm{X}$ & Yes & Temporary resident; previous experience of SPs \\
\hline $3 / \mathrm{X}$ & Yes & 'Clocked after one minute, temporary resident \\
\hline $4 / \mathrm{X}$ & Yes & Recognised SP \\
\hline $5 / \mathrm{X}$ & Yes & Recognised SP \\
\hline $6 / \mathrm{X}$ & No & Thought patient 'odd' but didn't put it together \\
\hline $7 / \mathrm{X}$ & Yes & No past records \\
\hline $8 / \mathrm{X}$ & Yes & 'Didn't behave like real patient' \\
\hline $9 / \mathrm{Y}$ & No/yes & No clue until last minute \\
\hline $10 / \mathrm{Y}$ & No & \\
\hline $11 / \mathrm{Y}$ & No & Hadn't a clue \\
\hline
\end{tabular}

I guessed actually to be honest... just twigged about the whole sort of situation and the fact it was a temporary resident. To be honest I twigged that he was an actor because I've worked with actor's before as a student and I kind of just got a feel for it. He was very good but I just felt I just knew. (PRHO 2)

I think it would be better if it was somebody who had just moved into the area... so he'd still be a new patient and you've not got any information (PRHO 6).

When the SP ' $Y$ ' was substituted only one of the 3 PRHOs realised he was not a real patient and that was very late on in the consultation.

I had no clue until the very last minute. I was...totally sucked in. (PRHO 9) 


\section{Was the scenario convincing?}

If the SP was not rumbled the scenario appeared convincing and the PRHOs treated it as a normal consultation. However one PRHO made a comment about the classical history that SP $\mathrm{X}$ gave:

He came in presenting with these classical symptoms of depression and l'd never experienced that at all. (PRHO 8)

SP Y was therefore asked to modify the symptoms and this appeared to help.

I hadn't got a clue he was making it up. (PRHO 11).

\section{Attitudes towards the SP consultation}

While the PRHOs were apprehensive about the consultations, two of them in particular being worried about showing up gaps in their knowledge, none of them was upset by the experience and indeed all welcomed the chance to get feedback from the SP on their performance. All of the PRHOs had had experience of consulting with SPs before and this helped reduce the trauma of the event.

It didn't really bother me to be honest...I mean I suppose I was worried depending on what case it was...so I was worried that I might come across as not knowing... (PRHO 3)

It wasn't any bother. I mean you know we had them as students. (PRHO 7)

As the aim of the encounter was not an assessment, the experience was less upsetting, indicating the need for proper briefing of the doctor as to the purpose of the exercise.

I wouldn't say I was anxious about it but I was certainly apprehensive about it although I knew I wasn't being assessed...It was towards the end of my four months and I kind of felt confident about seeing anyone really because of course you've always got help at the end of the corridor...(PRHO I)

However one felt that the timing of the SP encounter should be more closely defined and that once the consultation had taken place this should be notified to the doctor.

I didn't know... whether it was just going to happen and you do sort of go...now did anybody come or is anybody going to come tomorrow? (PRHO 5)

All the PRHOs but one felt they had conducted the consultation as they would normally, even if they had recognised that this was an SP.

I definitely wouldn't have done anything differently...I did my best really. I wanted him to leave the room feeling that it went ok and he had been helped by seeing a doctor. (PRHO 2). 
However, one who recognised the SP, did change behaviour:

I think you always try a bit harder when you know it's a simulated patient and I probably took a bit longer... and there's a couple of things that I maybe went into a bit more... (PRHO 5).

This consultation was extended from twenty minutes (the usual length at this level) to thirty minutes.

SP Y seems to have been more convincing and this led to possible problems. PRHO 10 tried to ring him at the number given to confirm that counselling would be available, but was told there was no-one of that name at the address (this was the practice manager's house). PRHO 11's emotions were upset:

After he'd gone I sort of sat and had a little think about him and felt sorry for him and then I found out he was a fake and...he'd been lying to me. (PRHO 11).

\section{Experience of simulated patients}

On the whole the organisation in the practice went well and the SP was expected and treated at the front desk as a 'normal' patient. On two occasions there had been a problem with communication and the patient's appointment had not been listed. This was sorted out by reference to the practice manager in each case but caused some delay. When this happened to SP Y he wrote 'I felt depressed at contributing in a poorly organised manner at this practice' which was very busy'. SP Y who has had less experience as an SP compared to $\mathrm{X}$, was also unhappy with 'duping' the doctors compared to his overt work with medical students and doctors.

In the first consultation the patient $(X)$ was asked to make an appointment for a blood test, luckily the doctor did not ask to take the sample during the consultation.

\section{Discussion}

There are a number of issues relating to the covert use of SPs in general practice and recommendations for any further work of this nature. Before introducing incognito patients into a clinical setting, GPs should be familiar with the use of known SPs. This is likely to be the case with doctors who are recently qualified, as the use of SPs is well established in medical schools and is becoming so on vocational training schemes. This familiarity may however be a drawback in that there may only be a small pool of SPs and care should be taken to ensure that the doctor has not had contact with the particular SP before. In this study there was no record of which students had been exposed to which SPs, leading to recognition by two doctors of the 'incognito' patient. Doctors should of course be informed beforehand that a SP will be visiting their practice and the reasons for this should be fully explained, whether formative or summative assessment. The doctors should give permission for the exercise. The dissemination of any results of the 
assessment of the consultation should be agreed prior to the visit and the method that the assessment is to take, particularly if the assessment is to be used for appraisal or revalidation purposes.

The use of SPs in this manner does raise ethical issues. While the method was discussed and agreed with the relevant authorities and with the PRHOs beforehand, as well as with educators experienced with this type of work in the Netherlands, following this study we feel that any widespread adoption of this practice should involve written informed consent as it does in the Netherlands. Unlike the Dutch experience ${ }^{13}$ we do feel that using SPS in this way should also be discussed with the local ethics committee particularly as practice staff are also involved. This was not done prior to this work, as no patients were involved in the study. However, in retrospect, due to the reactions of one PRHO and one SP we believe that there are wider concerns relating to involving health care workers in this way. While medical students are familiar with SP work, and however valid the experience is, the simulated nature of the consultation is understood. Covert use of simulated patients is unfamiliar, to both doctors and SPs and may take time to become as well accepted in this country as elsewhere. In Leeds we are at present looking into the possibility of having an ethical committee specifically to comment on work relating to educational research involving medical students and junior doctors.

In this feasibility study no official assessment was involved so the PRHOs, though they had some misgivings, were on the whole happy to be involved and welcomed the feedback they received. The fact that one PRHO felt she had been lied to does again emphasise the need for proper briefing of the exercise and the difference in nature of this encounter compared to overt simulation.

The method has advantages and disadvantages compared to others used for assessing doctors' consultation behaviour. As this was a feasibility study these are not focussed on in this paper. However as changing a doctor's behaviour is most effective when feedback is received on real consultations ${ }^{14}$, video and covert SP methods are perhaps preferable to overt SP consultations as educational tools, with the latter being preferable because of the possibility of feedback from patients. However, given that six of the PRHOs detected the simulation in this study, attention to detail and scenario is important. Such detection has not been a problem in the Dutch experience ${ }^{13}$, though this may become so as the use of SPs in training becomes more widespread.

This type of procedure may be used as formative assessment, particularly of GP registrars. Indeed some doctors may be glad of the chance to receive feedback on their performance from a trained SP, as such SPs are reliable in their assessment ${ }^{15}$. When used in the assessment of doctors it must be remembered that consultation behaviour cannot be assessed reliably with one consultation alone?

Special care needs to be paid to the scenario and status of the SP. Ideally SPS should be involved in developing the scenario, particularly if there is the potential that a physical examination is likely given the patient's history. However consultations of this type are best used to assess a doctor's communication skills rather than examination. The 
scenario should ideally be based on the case of a real patient as happens with simulated surgeries for summative assessment of GP registrars ${ }^{3}$. The scenario used here was criticised by one PRHO as being too classical. This was partly because the purpose of the consultation was to look at shared decision making rather than diagnosis so the patient's problem had to be unambiguous. This does however highlight the importance of getting the case right for the purpose of the exercise being undertaken. As soon as possible after the consultation the doctor should be informed of the identity of the SP to reduce ensuing problems relating to further management or anxiety. In 'normal' surgeries PRHOs are usually debriefed at the end of each surgery, if not consultation. With junior doctors it would be preferable to debrief immediately after the consultation. This would also allow the SP to give feedback. For more experienced practitioners this may not be so vital unless the scenario was such as to lead to a referral.

\section{Conclusion}

This method is useful in assessing what actually happens between a GP and a patient in the workplace but the ethical issues, limitations and logistical problems need to be thought through carefully before undertaking such an exercise.

\section{References}

1 Barrows HS. An overview of the uses of standardized patients for teaching and evaluating clinical skills. Academic Medicine 1193; 68: 443-451.

${ }^{2}$ Whitehouse C, Morris P, Marks B. The role of actors in teaching communication. Medical Education 1984; 18: 262-268.

${ }^{3}$ Allen J, Evans A, Foulkes J, French A. Simulated surgery in the summative assessment of general practice training: results of a trial in the Trent and Yorkshire regions. British Journal of General Practice 1998 48: 1219-1223.

${ }^{4}$ Burrows PJ, Bingham L. The simulated surgery - an alternative to videotape submission for the consulting skills component of the MRCGP examination: the first year's experience. British Journal of General Practice 1999; 49: 269-272.

${ }^{5}$ Rethans J-J, Sturmans F, Drop R, van der Vleuten C. Assessment of the performance of general practitioners by the use of standardized (simulated) patients. British Journal of General Practice 1991; 41: 97-99. 
${ }^{6} \mathrm{O}$ 'Hagan JJ, Davies LJ, Pears RK. The use of simulated patients in the assessment of actual clinical performance in general practice. New Zealand Medical 1986; Journal 99: 948-951.

${ }^{7}$ Renaud M, Beauchemin J, Lalonde $\mathrm{C}$ et al. Practice settings and prescribing profiles: the simulation of tensions headaches to general practitioners working in different practice settings in the Montreal area. American Journal of Public Health 1980; 70: 1068-1073.

${ }^{8}$ Gorter SL, Rethans J-J. Scherpier AJJA et al. How to introduce incognito standardized patients into outpatient clinics of specialists in rheumatology. Medical Teacher 2001; 23: 138-144.

${ }^{9}$ Van der Vleuten C, Swanson D. Assessment of clinical skills with standardized patients: state of the art. Teaching and Learning in Medicine 1990; 2: 58-76.

${ }^{10}$ Kinnersley P, Pill R. Potential of using simulated patients to study the performance of general practitioners. British Journal of General Practice 1993; 43: 297-99.

"Thistlethwaite JE. Making and sharing decisions about management with patients: the views and experiences of pre-registration house officers in general practice and hospital. Medical Education 2002; 36: 49-55.

12 Strauss A and Corbin J. Basics of qualitative research. Second Edition. London: Sage; 1998.

${ }^{13}$ Rethans J-J, Drop R, Sturmans F, van der Vleuten C. A method for introducing standardized (simulated) patients into general practice consultations. British Journal of General Practice 1991; 41: 94-96.

${ }^{14}$ Davis DA, Thomson MA, Oxman AD et al. Changing physician performance. A systematic review of the effect of continuing medical education strategies. Journal of the American Medical Association 1997; 274: 700-705.

${ }^{15} \mathrm{Vu}$ N, Marcy M, Colliver J et al. Standardised patients' accuracy in recording clinical performance checklist items. Medical Education 1992; 26: 99-104. 


\section{Chapter 9}

Informed shared decision making: views and competencies of pre-registration house officers in hospital and general practice.

Thistlethwaite JE, van der Vleuten C.

Published as: Informed shared decision making: views and competencies of preregistration house officers in hospital and general practice. Education for Primary Care 2004; 15: 83-92. 


\section{SUMMARY}

The objectives of this qualitative study were to explore whether newly qualified doctors feel adequately trained to discuss management with patients, their attitudes to the concept of sharing decisions about treatment with patients and their strategies for coping with managing patients. Thirty-six pre-registration house officers in general practice were interviewed over the course of three years. The doctors also carried out a consultation with a simulated patient in their practice to match their attitudes to their behaviour.

Six themes arose from the interview data. Medical students infrequently formulate management plans and only one had discussed such a plan with a real patient before qualifying. Yet all the PRHOs had to manage patients once in post. They felt ill prepared to do this, however they had developed strategies to manage patients and believe that shared decision making is appropriate. The PRHOs feel that discussing options with patients is more likely in general practice than hospital and they have more opportunity to practise sharing decisions in primary care. There was evidence that the PRHOs do involve patients in the decision making process. However medical students and PRHOs need further training and practice in sharing decisions with patients and feedback on their skills. 


\section{INTRODUCTION}

The patient-centred approach to doctor-patient interactions ${ }^{1}$ is a fundamental part of the learning process for medical undergraduates and GP registrars. However the second part of such interactions covering patient management issues and patient involvement in decisions has often been neglected ${ }^{2}$. The rise in such concepts as concordance ${ }^{3}$ and patient partnership ${ }^{4}$ in the last few years suggests that doctors can no longer expect to adopt a paternalistic approach to patient care. The informed shared decision making (ISDM) framework has been formulated as a method of involving patients in their own management ${ }^{5}$. In such a shared approach both patients and doctors disclose treatment preferences for a particular problem based on available evidence and personal preferences; negotiation then follows to build a consensus about the best treatment to choose ${ }^{6}$.

Doctors have to develop certain skills and attitudes in order to involve patients in decisions about management. These include identifying the patient's choice, presenting the correct evidence, negotiating a decision and resolving any conflicts ${ }^{7}$. In order for doctors to be able to work with patients in such a climate of increasing patient autonomy, medical educators need to ensure that medical students are aware of, are able to observe and to practise shared decision making in readiness for qualification. Preliminary work interviewing the first cohort of pre-registration house officers (PRHOs) in general practice in the Yorkshire Region in 1999-2000 suggested that medical students had little opportunity to practise discussing management with patients though within a few weeks of qualification they had to manage patients on the wards or in primary care ${ }^{8}$. It is important to explore how junior doctors cope with the transition from passive interactions with patients as students to active management and discussion with patients in order to suggest educational interventions at both undergraduate and postgraduate level to improve shared decision making.

The second set of interviews $(2000-2002)$ was aimed at exploring in more depth the PRHOs' strategies for managing patients and the perceived benefits of the general practice attachment. We wished to know whether newly qualified doctors feel adequately trained to discuss management with patients and their attitudes to the concept of sharing decisions about treatment with patients, and whether this has changed in the last three years with changes in curricula content. In particular shadowing of PRHOs had been introduced in the fifth year for the last cohort of doctors interviewed. As the first cohort of PRHOS interviewed suggested that they practise shared decision making ${ }^{8}$, this was corroborated with data from a simulated patient (SP) consultation in the practices in order to ascertain whether the PRHOs do consult in accordance with their stated views on shared decision making, or whether their attitudes are influenced by the interview process. An understanding of these issues has implications for medical education and ultimately for improved patient care. 


\section{PARTICIPANTS AND METHODS \\ Study sample}

In the United Kingdom, following qualification, junior doctors must complete a preregistration year. In this study we interviewed PRHOs undergoing a rotation of one year that included four months each in medicine, surgery and general practice in any order, to compare the experiences and attitudes of newly qualified doctors in the two settings of hospital and primary care. Permission was obtained from the Postgraduate Dean and GP tutors to interview the PRHOs during their 4-month general practice attachment. The PRHOs were informed by letter that we would like to interview them towards the end of the attachment if this was acceptable.

All thirty-five British-trained PRHOs on the rotation, plus one Netherlands graduate, were interviewed over the course of 1999-2002 in the Yorkshire Deanery. The timing of the interviews is indicated in Table 1.

Table 1: Timing of interviews relating to position of general practice attachment in the year's PRHO rotation

$\begin{array}{lccc}\text { Year } & \mathbf{1} \text { st } \mathbf{4} \text { months } & \mathbf{2}^{\text {nd }} \mathbf{4} \text { months } & \mathbf{3}^{\text {rd }} \mathbf{4} \text { months } \\ 1999-2000 & 4 & 3 & 6 \\ 2000-2001 & 3 & 5 & 4 \\ 2001-2002 & 4 & 4 & 3\end{array}$

\section{Interview structure}

The initial interview schedule in the first year (1999-2000) was based on a number of relevant topics relevant to our research question. The questions were altered as the research progressed during the next two years and various themes emerged (Box 1). The interviews were semi-structured and flexible so that issues arising could be explored in greater depth. The aim was to allow themes to emerge as a result of the interviews? Important issues and themes emerging from interviews were incorporated into subsequent interviews so that interviewing and analysis were simultaneous throughout the research process in line with qualitative research methodology ${ }^{10}$. By the end of the third year of interviews no further themes were emerging suggesting that saturation had been reached".

\section{Analysis}

The interviews were taped, transcribed and then coded using a system of open coding. The transcripts were read several times and analysed using an inductive approach whereby analysis of the content of all the interviews allowed for its organization into a number of dominant themes based on the identification of recurrent patterns in the statements made by the PRHOs about their feelings and experiences. The PRHOs are identified by number. The most appropriate quotes have been chosen to illustrate the theme under discussion. 


\section{Box 1: Interview schedule}

- What were your first impressions of working in general practice?

- Did you feel able to cope with working as a PRHO, in hospital, in general practice?

- When was the first time you formulated a management plan for a patient?

- When was the first time you discussed a management plan with a patient?

- Did you feel prepared to manage patients?

- Did you feel prepared to discuss management plans with patients?

- How did you learn to manage patients? Discuss plans with patients?

- How do you decide on a management plan if there is more than one option?

- Do you discuss options with patients?

- When and where did you learn to do this?

- Have you observed doctors discussing management plans with patients?

- Have you been observed discussing management plans with patients?

- Would you always discuss a plan with a patient?

- What might stop you involving the patient in a management plan?

- What do you think about the idea of sharing decisions with patients?

- What do you feel have been the advantages and disadvantages of this general practice attachment?

\section{Simulated patient consultation}

In the third year we correlated the PRHOs' replies regarding their consultation behaviour with evidence of their performance in a consultation with an SP. Permission was again obtained to do this. The PRHOs were not told of the identity of the SP who was registered by the GP tutor as a temporary resident in order that the PRHOs would carry out a normal consultation. The PRHOs were advised that this procedure was not to assess their performance but as part of ongoing research into the PRHO general practice attachment. The SP gave a history of mild depression. Issues relating to the use of covert SPs in this way are discussed elsewhere ${ }^{12}$. The SPs were asked to comment on the PRHOs' consultation skills using a marking schedule developed in Leeds for the assessment of the consultation skills of medical students, and with which they were familiar. This schedule gives an indication of whether the patient is involved in decisions about management. 


\section{RESULTS}

\section{Themes}

Six themes emerged from the data (Box 2).

\section{Box 2: Themes arising from the interviews}

- Lack of opportunity to formulate management plans as a medical student

- Rarity of discussing management plans with patient prior to qualification but necessity of doing this as PRHO; feeling unprepared to do this

- Attitudes to shared decision making generally favourable

- Observation and/or adoption of a shared decision making model more likely in general practice than in hospital

- PRHOs make value judgements about patients with regard to how much information should be shared

- Benefits of PRHO in GP attachment apparent

\section{Lack of opportunity to formulate management plans as student}

Students were asked rarely to formulate management plans though if they were this tended to happen in their final $\left(5^{\text {th }}\right)$ year (Table $\left.2 \mathrm{~A}\right)$.

\section{Table 2: Timing of formulation of management plans and discussion with patients}

\section{A: When did you first formulate a management plan?}

Never as a student

As a student: but rarely/not often

As a student: not sure when

End of $3^{\text {rd }}$ year

$4^{\text {th }}$ year

$5^{\text {th }}$ year

Shadowing in $5^{\text {th }}$ year

Not until PRHO

B: When did you first discuss a management plan with a patient?

$4^{\text {th }}$ year with simulated patient

$5^{\text {th }}$ year

As PRHO on first attachment (hospital or GP)

As PRHO on second attachment (GP)

As PRHO on third attachment (GP) 
'I think that it's really important to involve them in any decision that you make and to give them that option, if they are the kind of patient that is "you just decide doctor, I'll leave it with you, you're the doctor" then they don't want to partake in it then I guess you have to take on that responsibility as their doctor but I think you have to include them from the start about any decisions that you're going to make and ask them and inform them as much as you can...I'd want to give them the power to make the decision with me rather than just make it without them.' (PRHO 27)

They felt they had had little formal training to do this but, in particular, observing GPs in the first few days of their practice attachment was helpful in this respect.

'To be honest I think that is a weak area in medical school... when you get to the management plan... where as in general practice almost all the time I'm making up my own plans then following the, through week on week.' (PRHO 28)

'That's been the way I've learnt it really, just seeing seniors.' (PRHO 34)

\section{Observation and/or adoption of a shared decision making model more likely in general practice than in hospital}

While the PRHOs had seen some examples of doctors involving patients in management decisions in hospital this was less likely to happen than in the general practice setting.

'I can't...remember it happening so much with hospital patients. I think certainly surgeons and you know, the surgeons at the hospital when I was doing my previous job took a more paternalistic attitude, that this is what we need to do. I have this feeling that you know the medics were better at doing it, at presenting options more so you know to the outpatients rather than the inpatients.' (PRHO 33)

This difference in approach was felt to be partly due to the nature of general practice compared to hospital medicine.

(In general practice) 'it's more a negotiation, the doctor thinks the patient should be on that treatment, knows it's not very well tolerated you need a compliant patient to do it, and sort of having a discussion with the patient saying...'do you want to give it a try?' And I suppose there is more of that in general practice than in hospital medicine just because there's a lot more grey areas.' (PRHO 17)

PRHOs make value judgements about patients with regard to how much information should be shared

The PRHOs said they would try and include patients in decisions about their management. When asked if they would do this with all patients, they stated that in some situations this would not be advisable or would be unworkable. When challenged to state how they would decide which patients to involve, many found this difficult to explain. By 
intuition or instinct was a common answer, as was forming an opinion about the patient on how they reacted to telling the story or listening to the doctor's advice. The PRHOs did not ask the patients directly if they wanted to be involved in the decision making process. If they tried to involve the patient and the patient did not respond the PRHO would abandon the attempt.

Two typical responses to this line of questioning were:

'You go on things like the social class factors and the age of the patient, if they've got a job or not you know. You just, I suppose you shouldn't do but you do pre-judge and where they live and things. And whether you think they're intelligent or not. I suppose you think well is this patient intelligent enough to make their own decision or should I make it for him?' (PRHO 6)

'First of all I guess it would come from the consultation...you gained their level of understanding into their symptoms and underlying condition beforehand. So you probably get quite a good picture just from talking and relating to them and see how they interact. And their level of understanding about previous treatments or previous conditions.' (PRHO 24)

\section{Benefits of GP attachment}

Those PRHOs who had already done one or both of their hospital placements felt quite strongly that they had learnt a lot in general practice that they had not in hospital in relation to management issues and negotiation. This was one of the reasons they felt the GP rotation was so useful and should be undertaken by most if not all PRHOs.

'Here you're making a lot more decisions even as a house officer, you need to make a lot more decisions that I think has increased my confidence that will help me in the hospital environment.' (PRHO 14)

"I think I felt so much more empowered to talk to patients here and I think I will do as a house officer because I feel more like a GP registrar as in you can discuss things (sic) and discuss management plans. Whereas a house officer you're just there to do your lot of the jobs...the other thing of course is that most things here aren't so acute. So it's not kind of so difficult.' (PRHO 31)

The GP tutors also helped the PRHOs develop their consultation skills through tutorials, the use of video and role modelling.

'Here (we) do lots of communication skills work and we did some interviewing... and he (GP tutor) suggested that a better way would be to present the options and see which one's best and so after that I made an attempt to and I think I've steadily improved doing that.' (PRHO 33)

However there was some adjustment to be made at the start of the rotation.

'The downside of being a PRHO in general practice is the isolation you feel.' (PRHO 34) 


\section{Simulated patient consultation}

The main parameter under consideration was the PRHOs' behaviour as regards 'discussing options and reaching agreement'. The results of the eleven consultations are shown in Table 3. All the PRHOs suggested a range of options for the management of the patient's depression. These included blood tests (5 PRHOs), anti-depressants (10), counselling (9) and self-help/support from friends/hobbies (7). Nine of the doctors were keen that the patient should consider the options and return in a week to discuss them further. In summary the SP did feel that the PRHO involved him in the decision making process in line with what the doctors said about their consultation technique.

Table 3: Consultation behaviour as marked by simulated patient

Discussing options and reaching agreement

\begin{tabular}{|c|c|c|c|c|}
\hline Very poor & Poor & Satisfactory & Good & Very good \\
\hline & & & 2 & 9 \\
\hline
\end{tabular}

\begin{tabular}{|c|c|c|c|}
\hline Behaviour & $\begin{array}{l}\text { Not } \\
\text { achieved }\end{array}$ & & Fully achieved \\
\hline The doctor explained the available options to me & & 2 & 9 \\
\hline $\begin{array}{l}\text { I was involved in the decision-making about what was needed to be } \\
\text { done }\end{array}$ & & 2 & 9 \\
\hline $\begin{array}{l}\text { The advice I was given took account of my views and was relevant to } \\
\text { my situation }\end{array}$ & & & 11 \\
\hline I am happy with the decision (s) & & & 11 \\
\hline
\end{tabular}

\section{DISCUSSION}

The interviews with the PRHOs in the last two years support the conclusions from the first year of this study ${ }^{8}$, while adding further insights into the attitudes and consultation behaviour of the junior doctors, as well as the benefits of the GP PRHO posts. The junior doctors interviewed receive little training and practice in formulating management plans and have had virtually no skills training and practice in discussing these with patients. Yet these doctors are expected to take limited responsibility for management soon after starting their first house jobs. They are also put in the position of explaining treatment to patients without prior experience and practice and without observation and feedback 'on the job'. Moreover communication skills such as 'explaining to patients, liaising with patients and informing patients' have been identified as appropriate tasks for the pre-registration year ${ }^{13}$.

All the doctors interviewed had participated in communication skills courses as undergraduates; these are now a common feature of new curricula though they vary in content, timing and duration ${ }^{14}$. This type of training is usually with simulated rather than real patients and takes place in medical schools rather than in work-based situations. As 
such it only forms a small part of clinical experience and does not appear to prepare junior doctors to share management decisions with patients.

However junior doctors learn by observation and practice to try and involve patients in the decision-making process regarding management. They develop strategies for deciding how much information to give to patients and whether to involve them in decisions. But these strategies do not include asking patients themselves whether they wish to be involved but rather depend on a set of value judgements that the doctors make. This lack of explicitness about the adoption of a shared decision making process is at odds with Towle's list of competences ${ }^{7}$ but mirrors the behaviour of experienced clinicians $^{15}$. Using the PRHOs' experiences in training sessions at this stage could help focus their management skills further and facilitate other strategies to improve shared decision making. In particular, as real differences have been shown in what junior doctors and patients perceive as their decision-making roles in the doctor-patient relationship ${ }^{16}$, further emphasis needs to be placed during training on learning about patients' ideas and expectations in relation to decision-making.

As secondary care is only starting to embrace evidence-based patient choice due to several obstacles ${ }^{17}$, ISDM is more likely to occur and be more relevant in primary care settings than on the wards where PRHOs spend the majority of their time. Thus those PRHOs who do not undertake a GP attachment are less likely to begin to develop these skills at this stage. Indeed PRHOs often feel prevented from communicating well with patients in hospital due to lack of time and attitudes of more senior doctors ${ }^{18}$. According to the PRHOs in this study, they are also less likely to be given feedback about their interpersonal skills in hospital. The question thus arises as to when should junior hospital doctors be trained in these techniques including explanation of the evidence underlying different management strategies and negotiation with the patient ultimately to improve concordance.

This study involved interviewing 36 PRHOs over three years and by the end of this time no new themes were emerging suggesting that the results presented here are consistent with the views of PRHOs. The aim of discovering whether the PRHOs' consultation behaviour was compatible with their attitudes towards ISDM was achieved by using a simulated patient in a 'real' consultation. The doctors' attitudes towards shared decisionmaking and practical adoption of the model are borne out by their consultation with a simulated patient. The use of simulated patients to evaluate doctors' interpersonal skills and professional attributes is now well established as a reliable method of assessment in both simulated surgeries ${ }^{19}$ and real surgeries ${ }^{20}$.

The consultations with SPs and discussion of these afterwards shows that PRHOs in general practice learn to manage and share decisions with patients 'on the job', through observation of role models, formal teaching sessions, necessity and experience. Their self-acknowledged lack of training in medical school is compensated for by their acquisition of skills in the work environment. However, while this study shows that such skills are honed in primary care, it appears from what the junior doctors say that such skills are less likely to be fostered in hospital settings. 
The study suggests that medical educators should re-evaluate the ways in which students learn and practise consultation skills. More senior students should be encouraged to formulate management plans for all the patients they interview and these should be discussed with clinicians. If it is not feasible to observe and give feedback to students discussing plans with patients, then this should be done for PRHOs both in hospital and primary care. It would also be beneficial for all junior doctors to have at least one attachment in general practice during the proposed extended two year PRHO programme as such placements appear to help doctors observe and practise shared decision making. The proposed changes to PRHO posts and the introduction of an SHO foundation year should incorporate management skills training, observation and feedback sessions of junior doctors.

\section{References}

${ }^{1}$ Levenstein JH, McCracken EC, McWhinney IR et al. The patient-centred clinical method. 1. A model for the doctor-patient interaction in family medicine. Family Practice 1986; 3: 24-30.

${ }^{2}$ Elwyn G, Edwards A, Kinnersley P. Shared decision-making in primary care: the neglected second half of the consultation. British Journal of General Practice 1999; 49: 477-482.

${ }^{3}$ Royal Pharmaceutical Society of Great Britain. From compliance to concordance. Achieving shared goals in medicine taking. London: RPSGB; 1997.

${ }^{4}$ Coulter A. Paternalism or partnership. British Medical Journal 1999; 319: 719-720;

${ }^{5}$ Charles C, Gafni A, Whelan T. Shared decision-making in the medical encounter: what does it mean? (or it takes two to tango). Social Science and Medicine 1997; 44: 681-692;

${ }^{6}$ Elwyn G, Charles C. Shared decision making: the principles and the competences. In: Edwards A, Edwards G (Ed). Evidence-based patient choice. Oxford: Oxford University Press; 2001.p $118-143$.

${ }^{7}$ Towle A, Godolphin W. Framework for teaching and learning informed shared decision making. British Medical Journal 1999; 319: 766-9.

${ }^{8}$ Thistlethwaite JE. Making and sharing decisions about management with patients: the views and experiences of pre-registration house officers in general practice and hospital. Medical Education 2002; 36: 49-55.

${ }^{9}$ Miles HB, Hubermann AM. A sourcebook of new methods. California: Sage; 1984. 
${ }^{10}$ Strauss A, Corbin J. Basics of qualitative research. Second Edition. London: Sage; 1998.

"Silverman D. Doing qualitative research. A practical handbook. London: Sage; 2000.

${ }^{12}$ Thistlethwaite JE. The use of incognito simulated patients in general practice: a feasibility study. Education for primary care 2003; 14: 419-425.

${ }^{13}$ Stewart J, O'Halloran P, Spencer JA, Barton JR, Singleton SJ. Identifying appropriate tasks for the preregistration year: modified Delphi technique. British Medical Journal 1999; 319: 224-229.

${ }^{14}$ Hargie O, Dickson D, Boohan M, Hughes K. A survey of communication skills training in UK Schools of Medicine: present practices and prospective proposals. Medical Education 1998; 32: 25-34.

${ }^{15}$ Elwyn G, Edwards A, Kinnersley P, Grol R. Shared decision making and the concept of equipoise: the competences of involving patients in healthcare choices. British Journal of General Practice 2000; 50: 892-899.

${ }^{16}$ McKeown RE, Reininger BM, Martin M et al. Shared decision-making: views of first year residents and clinic patients. Academic Medicine 2002; 77: 438-445.

${ }^{17}$ Rosenberg W. Evidence-based patient choice in secondary care. In: Edwards A, Edwards G (Ed). Evidence-based patient choice. Oxford: Oxford University Press; 2001. p191-205.

17. Williams $C$, Cantillon $P$, Cochrane $M$. The doctor-patient relationship: from undergraduate assumptions to pre-registration reality. Medical Education 2001; 35: 743747.

${ }^{19}$ Allen J, Evans A, Foulkes J, French A. Simulated surgery in the summative assessment of general practice training: results of a trial in the Trent and Yorkshire regions. British Journal of General Practice 1998; 48: 1219-1223.

${ }^{20}$ Rethans J-J, Sturmans F, F Drop R, van der Vleuten C. Assessment of the performance of general practitioners by the use of standardized (simulated patients). British Journal of General Practice 1991; 41: 97-99. 
Chapter 10

Discussion: conclusions, implications and recommendations 


\section{Research questions and summary of conclusions}

The aim of the research and the main research question is: is the current medical undergraduate curriculum delivering the necessary training for the practice of the ISDM model within consultations? This answer to this question is explored through research relating to the subsidiary research questions and the answers to these will be considered in turn. In summary, however, on the whole the curriculum is not delivering the skills training required though it does introduce the concept, and students do have variable experiences during their education. There is lack of feedback during skills training though such feedback is important to students in order to instil confidence in the development of their skills. Primary care settings appear to provide better learning experiences and more role models than hospital based attachments. Once qualified and while working in suitable settings PRHOs have sufficient knowledge of the concept to be able to develop skills and strategies to share decisions with patients though their decision to do this is based on value judgements of patients.

\section{Do medical students observe the patient-centred approach during training and understand its relevance?}

As discussed in the literature review the patient-centred approach is an integral component of ISDM and teaching input focused on the patient-centred approach when medical students are learning the early clinical skills of history taking is important. Focus group interviews of junior medical students found that during hospital training students are rarely introduced, either through teaching or observation, to the idea of patient-centred consultations. However clinical skills teaching during general practice attachments demonstrate to the students the relevance of the approach both on the wards and in the community.

\section{Are medical students exposed to role models who demonstrate a patient-centred approach and ISDM?}

Medical students highlighted the observation of doctors in their dealings with patients as a vital component of training. Students want the opportunity to 'learn by example' so that ward doctors inevitably assume importance as role models, both positive and negative. Students stated they are less likely to observe doctors adopting a patientcentred approach during teaching sessions in hospital compared to general practice. However in hospital physician role models are more common on medical firms than surgical firms. The GP tutors who provide the input on primary care attachments stated that on the whole they try to encourage patients to share decisions about management. GPs are keen to help students learn consultation skills and are good role models for shared decision making strategies.

\section{Are students taught and encouraged to elicit a psychosocial history?}

At the end of their clinical skills course fewer than half the students felt confident in taking a psychosocial history, an essential component of the patient-centred approach. This was due to students not being encouraged by tutors to develop this component of their history taking and in some cases to them being actively discouraged from doing so. 
How may the attitudes of students to these concepts, specifically concordance, be assessed?

A 12-item Leeds Attitude Towards Concordance (LATCon) attitudinal scale was developed and was demonstrated to be a reliable and valid tool for assessing health care providers' attitudes to concordance.

Can the attitudes of students to these concepts be altered by a specific learning experience?

The LATCon scale was used to measure students' attitudes to concordance before and after a paper exercise focusing in part on IDSM. This exercise was shown to improve medical students' attitudes towards the concept. However this exercise needs to be followed up with skills training in order that the attitudes of the students translate into practice.

\section{Are PRHOs able and willing to practise the ISDM approach?}

PRHOs are the output of undergraduate medical education. The interviewed doctors confirmed that while their undergraduate training has to some extent introduced them to the concept of the patient-centred approach, it has given them little opportunity to practise sharing information and management decisions with patients. They have also had variable experience of this after graduation. However their time in general practice as PRHOs has helped them to understand the relevance and value of ISDM in consultations and they have begun to develop strategies to decide how much information to give to patients and to what extent to involve patients in management decisions. The development of these skills is prompted by the demands of the patients, many of whom expect information and involvement in treatment. Moreover the skills appear to be selflearnt through experience, though the process is also influenced by the amount the PRHO know and understand about the patient's condition.

Is the use of incognito simulated patients a satisfactory tool to assess whether ISDM skills are developing?

Incognito simulated patients were shown to be one method of assessing the performance of doctors in the workplace and thus may be used to look at the output of the education programme in terms of how doctors behave in consultations. However there are ethical and logistical considerations before introducing this method to assess doctors. Care must be given to the scenarios used and the identity of the patients. The method is more amenable to formative assessment at this stage, as the possibility of timely feedback is a positive attribute of the method.

\section{Do PRHOs practise the ISDM approach?}

The incognito simulated patients reported that the PRHOs did involve them in management decisions in the consultation that was assessed. This suggests that even though the PRHOs felt that they have a lack of experience in managing patients prior to qualification, they have developed to some extent the necessary skills required for the ISDM approach. But this development has mainly occurred during the time spent working in primary care rather than during their hospital attachments. 
Do students and junior doctors have different learning experiences relating to shared decision making in primary and secondary care settings?

There is a difference between the learning experiences relating to the patient-centred approach and ISDM delivered in primary and secondary care situations. The studies show that students are more likely to observe the processes and understand their relevance in community settings. GPs on the whole act as better role models in this respect.

\section{Methodological limitations}

A variety of research methods have been used in the chapters. Data has been collected by questionnaire and semistructured interviews with individuals and focus groups. Quantitative and qualitative analysis has been carried out on the data. Methods were chosen in order to best suit the aims of the research. Each method has advantages and disadvantages, which have been discussed in the individual chapters. However it is important to go into further depth about the methods before the implications of the research can be discussed, as the strength of the implications relies on the methods used.

Qualitative research methods underpin much of the work presented in this thesis, in contrast to the quantitative methods that are routinely used in clinical and biomedical research. There has been increasing interest in qualitative methodology over the last decade as researchers have stressed its importance in helping to gain insights into professional health beliefs amongst other things and it being a prerequisite of good quantitative research'. While the use of questionnaires, such as in chapters 5 and 6 , score high on reliability (consistency of retesting), qualitative methods score more highly on validity, by getting at what people, ie students and doctors, actually mean when they describe their experiences, attitudes and behaviours'. However there is a worry sometimes that interviewees, especially those in training positions, may answer questions in a way they think the interviewer wants. Thus as part of the validation process of research a triangulation ${ }^{2}$ of methods may be used, ie three or more methods should be undertaken in order to compare results and see if there is agreement. Responses in interviews should be wherever possible replicated by what students and doctors say and do in more 'naturally-occurring' situations', such as on wards and in consultations. In this thesis conclusions, implications and recommendations are drawn from the complete body of work, which does include different methods.

Analysis of qualitative data collected in interviews may be carried out in a number of ways. In the work presented here analysis is consistent with modified grounded theory, as expounded by Dewey ${ }^{4}$ and later in the works of Strauss and Corbin ${ }^{5}$. Grounded theory procedures are applied to text as data material in the form of interview transcripts and observers' notes in this case. Grounded theory does not deliver any incontrovertible theories but relies on looking for indicators of provisional concepts in the data. The coding procedure is an essential part of the process, though there is ongoing debate as to the best way to code data ${ }^{6}$. In the main, transcripts were analysed using an inductive approach whereby analysis of entire body of data, as opposed to analysis of isolated responses to individual questions, allowed for its organisation into dominant thematic categories. The categories were constructed on the basis of the identification of recurrent patterns in the overall responses of interviewees ${ }^{7}$. Reliability is aided by having two or more researchers code independently ${ }^{8}$. However some of the work relating to coding in 
this thesis was carried out by one person (Chapters 7 and 9) though all taped transcripts were checked by at least two people.

In chapter 2 data was collected by means of focus group interviews of junior medical students, to encourage discussion and debate amongst the interviewees in order to cover as many issues as possible ${ }^{9}$. Comparison of early experiences of patient contact on the wards and in primary care was enabled due to the participation of students from different clinical attachments. The focus group method gives security to participants as they are amongst others who share many of their feelings and experiences ${ }^{10}$ and this promotes discussion of issues that participants may be reluctant to share in one-to-one interviews with a senior figure.

In contrast to qualitative research, quantitative processes are dependent on a high response rate to questionnaires or surveys where relevant. The study in chapter 4 was hampered by a poor response rate by the students in keeping a logbook of their experiences. It was learnt from this study that medical students need to be highly motivated to participate in research of this kind, particularly if they cannot see immediate benefits for themselves. Regular meetings and feedback are necessary to improve response. However, while the poor response rate reduces the generalisability of this study, the conclusions informed further work. The focus group method used in chapter 2 was more successful as students interacted with each other and the interviewer over a much shorter period of time.

Methodological rigour is an issue in relation to the attitude questionnaire whose development is described in chapter 5. There is a high non-response rate and the subsequent validity coefficients were relatively low. The validity of the tool must therefore be treated with caution.

There was a high response rate to the questionnaire study reported in chapter 6 due to the method of date collection, an important factor to consider in work of this kind. However results may be misleading in that medical students may fill in such forms in a way they feel their tutors wish them to do so. The possibility of this is reduced if questionnaires are returned anonymously, as was the case here. However the fact that students may surmise how the researcher wants them to answer and respond accordingly, does suggest that they have understood the purpose of the educational intervention and realised what is good practice. Again this leads to the question, as posed in any assessment of attitudes, is what students think and feel backed up by the way they behave to patients?

Observed interactions with real and simulated patients may not give a true picture of how students and doctors interact with patients in the normal course of their working day. The use of incognito simulated patients is one way to overcome this problem as discussed above. In chapter 9 this method was used to correlate how the PRHOs say they behave, with their actual consultation behaviour. Obviously one consultation is not enough to make a firm judgement on this matter ${ }^{11}$ but does give some indication about consultation behaviour.

As regards the generalisability of the findings presented in this thesis a number of factors should be considered. The research was carried out at one medical school in the north of 
England, whose curriculum is similar to that of other British medical schools which follow the General Medical Council's recommendations ${ }^{12}$. A small number of the PRHOs who were interviewed in chapters 7 and 9 were from other British medical schools (and one was from the Netherlands). The views of all the PRHOs were similar in respect to their training and experience of managing patients. It is likely that the findings are consistent with what is happening in the UK. The recommendations drawn from this work are applicable to undergraduate medical education internationally for reasons discussed in the introduction. If medical students and junior doctors are already learning and practising ISDM within their institutions, this is a positive step towards improving patient partnership initiatives. If they are not then the following recommendations are applicable.

\section{Implications of the research}

Training in ISDM and its components is not being adequately delivered at present in the undergraduate medical curriculum. As medical students in the first stages of their development of clinical and communication skills are not often involved directly in the management of patients, educators would not expect them to learn by experience about shared decision making and to practise the necessary skills. However, while they are required to concentrate on history taking during interviews of patients, there are relevant components of ISDM to which they should be introduced. These include adopting a patient-centred approach, with an emphasis on exploring a patient's ideas and concerns and eliciting a full psychosocial history, which are relevant to management options. Communication skills training must be integrated with clinical skills teaching, so that students may make sense of what are sometimes seen as two approaches to historytaking: the medical/doctor-centred approach and the patient-centred approach ${ }^{13}$. Early communication skills training should include sessions on information giving as well as information gathering. Even junior students are able to formulate simple management plans for conditions they learn about in basic sciences courses. On clinical attachments students under supervision interact with patients. It is feasible that this interaction could include students discussing management plans with patients. The supervision should include observation of the student and feedback, as students indicate in these studies that this is an important part of their skills development. This could be done in both general practice and hospital settings with suitably trained and motivated clinical tutors. All students on qualification should be able to formulate management plans for a core group of conditions. They should also have had training in discussing such plans with patients, because, as shown, they will be expected to manage patients as PRHOs.

The addition of ISDM training to the undergraduate curriculum may not have the desired effect unless students and junior doctors in clinical settings are able to observe clinicians practising in a patient-centred way and within an ISDM framework. These studies show that role models are important to the students so that they may learn by example. However there is a lack of role models, particularly in hospital, and thus any theoretical training that students receive may be undermined if they are unable to observe a patientcentred approach and shared decision making in the workplace. The effects of the new curricula may be lost as training goes on, an effect that has already been noted with communication skills training in the past ${ }^{14}$. 
The importance of role models is well documented. By the time they graduate most medical students have identified physician role models ${ }^{15}$. While such role models most usually have an impact on students' and junior doctors' choice of speciality later in their careers $^{16.17}$, junior doctors also rate them in terms of their clinical skills and personality ${ }^{18}$. Students state that clinical skills such as educating patients about their illness and fully informing patients are important attributes they look for in role models ${ }^{19}$. Senior clinicians do not always practise an adequate doctor-patient relationship, though they preach about its importance to their students ${ }^{20}$. Such doctors can act as 'negative' role models. Students may emulate this behaviour or feel that they have been given tacit permission to interact with patients in this way ${ }^{21}$. The poor attitudes of senior doctors may cause confusion and distress to students under their supervision ${ }^{22}$, stressing the need for good staff training and development.

However there will be many patient-centred physicians and surgeons in hospital who do not have a major role in teaching. These doctors need to be identified and teaching scheduled so that they come into increased contact with students. Teaching ability and commitment to education must be awarded the same recognition as research activity to enhance the standing of academic teachers ${ }^{23}$. Doctors who teach students and PRHOs need to be aware of the consultation models that students are learning in the classroom and practising with simulated patients, and be able to reinforce the model by example and feedback. As future generations of doctors are trained, the model will hopefully become one of the norms and more role models will be available.

The testing of attitudes is controversial but is one way of evaluating a course and its impact on students. As demonstrated attitudinal scales may be used to evaluate whether a course is having the desired effect on students. Later clinical and communication skills and behaviour may be assessed by other means such as direct observation, the use of simulated patients and OSCEs. The introduction of new courses and exercises into the undergraduate curriculum may be tested by attitudinal questionnaires to evaluate their impact. However, the attitudes of students need to be crosschecked against their behaviour by other means such as direct observation and OSCEs, as it is their behaviour towards the patient that is important.

It could be argued that attempting to change student attitudes is a paternalistic process, mirroring in the teacher-student relationship the style of interaction that is found in doctor-centred consultations. However it is the way in which attitudes are fostered that should allay this worry about teacher-centred courses. Frank discussion with time for students to voice their opinions and consider options in patient management is important. If faculty believe that certain behaviours towards patients are important in their graduates, they need to encourage facilitation of such behaviours and the attitudes that underpin them. The General Medical Council in the UK has defined the attitudes of an independent practitioner demonstrating that it believes that certain attitudes are important in physicians ${ }^{24}$.

The covert method of using incognito simulated patients to assess consultation skills is important as it measures behaviours in the workplace rather than behaviours that may be performed solely for the purpose of an examination. Moreover the method allows feedback from the patient. A valid and reliable score sheet needs to be developed for the 
SP to use to assess the doctor. Ethical issues need to be considered carefully as objections to the use of SPs in this way in the feasibility study described in chapter 8 have been made ${ }^{25}$.

The research findings have implications for where the undergraduate curriculum is delivered. As Godolphin writes, it is still the case that 'formative medical training, when students are "professionalised" tends to be in acute care" ${ }^{26}$, a location where choices are few and patients' autonomy is limited. The fact that students and junior doctors are more likely to observe a patient-centred approach and ISDM in primary care settings suggests that more time should be spent in such settings, as well as identifying and encouraging suitable hospital-based physicians to teach. The number and length of primary care attachments in the UK at an undergraduate level is increasing. GP tutors certainly recommend longer attachments in order for students to be able to follow up patients and observe the effects of management decisions. How long the optimum attachment should be is open to debate and further study. GPs are encouraged to allow more senior students ( $4^{\text {th }}$ and $5^{\text {th }}$ year) to consult by themselves. Unfortunately the short attachments (two-tofour weeks) are not long enough to have experience of many solo consultations combined with such observation. However exposure to the model at this stage is helpful. The GPs suggest that to improve the training for students the general practice attachment should be increased in length in order that students are able to follow-up patients to see the effects of their management plans.

Bensing et al have acknowledged the need for a new agenda in communication research with one line of investigation being the context of time in relation to continuity of care ${ }^{27}$. They suggest that that it is important 'to consider the role and influence of previous and future consultations' in the communication process. As knowledge of patients is an important factor in ISDM, with communication of risk also being facilitated by relationships of trust between doctor and patient ${ }^{28}$, longer attachments would also facilitate this approach. Patients are staying for shorter times in hospital due to changes in practice and for students to have an insight into the natural history of illness and response to treatments primary care settings are preferable to hospital attachments. Thus a regular attachment to a general practice throughout the undergraduate clinical training may be preferable to a set number of consecutive weeks with a GP tutor. For example students might attend a practice one session a week during their speciality hospital-based training and be able to follow up patients for longer periods of time. Learning objectives for students need to be reviewed and decisions made as to the best setting for students to meet those objectives.

One might expect that students sitting in on consultations with GP tutors are exposed to the ISDM model. However analysis of consultations of GPs who profess support for shared decision making has shown that they do not always practise it due to time constraints and complexities of patients' agendas ${ }^{29}$. GP tutors need to recognise this and allow time for discussion with students to make sense of what they are observing.

\section{Recommendations and challenges arising}

The following recommendations are made with an acknowledgement that education at the medical school level and during the pre-registration year is changing in line with recommendations from registration bodies such as the GMC in the $\mathrm{UK}^{12}$ and the AAMC 
in the $\mathrm{USA}^{30}$. Innovations include an increasing proportion of curricula time spent on communications skills training. There is also a shift from the focus of medical undergraduate activity residing mainly in the hospital, to more learning being undertaken in community settings such as primary care. Some PRHO posts have been established in general practice. Such changes will take a while to have an effect. While there has been this shift in thinking relating to communication skills training and an increase in community-based learning experiences for medical students more work needs to be done to take these changes a step further.

Academic, teaching and clinical staff to sign up to the philosophy of patient-centred care and patient partnership.

All staff, academic or otherwise, who come into contact with students should be aware of the underlying philosophy of the undergraduate curriculum, what the students are being taught and how their courses are structured. In particular staff in clinical settings remote from the central teaching areas may not always be kept fully informed of changes to curricula and educational innovations. Communication between staff and the provision of training days where people can mingle and share ideas are vital to such large and complex organisations. It is important that everyone is conversant with national training requirements. Busy clinical staff will find it harder to keep abreast of what the students are learning but mixed messages about skills and attitudes from staff confuse students. Ultimately it should be realised that the philosophy proposed should improve patient outcomes and where possible such improvement should be demonstrated by the judicious use of evaluation and research.

Training of teaching staff to help facilitate students in adopting a patient-centred approach and ISDM where appropriate and relevant.

Such training should be developed with the help of the communication skills staff. A major challenge is the number of teaching staff responsible for the delivery of such complex curricula and the pressures on their time. Training programmes are being developed, however many staff require training at the doctor-patient interaction level themselves before they go onto be trained to teach students the models.

Exposure of students to role models who demonstrate the patient-centred approach and informed shared decision making with patients.

Students must be able to observe clinical staff consulting in the ways that they, the students, are being taught. A major problem for clinicians is time: time to adopt the ISDM model with suitable patients and time to teach about it.

Specific training related to management and the second half of the consultation to be introduced, starting at first with the encouragement of medical students to formulate management plans and discuss these with clinicians.

In the early years communication and consultation skills training will focus on eliciting information and planning investigations. As the students' knowledge expands and their bank of cases grows, they should be encouraged to formulate management and treatment plans. These plans should have an evidence-base but students should also recognise that there may be several options relating to management, each option having its own advantages and disadvantages and that these will vary from patient to patient. 
Longer clinical attachments particularly in primary care to allow students to followup patients to facilitate ISDM and demonstrate its effects.

Murray and Modell listed the challenges for increasing the amount of primary care based undergraduate medical education in the UK as: recruitment of additional training practices, time and space resources, impact on service general practice, quality control, burnout of practitioners and research/evaluation ${ }^{31}$.

It is important to remember that while general practitioners feel that they practise the ISDM model, as noted above, they do not always do so in practice. Thus there will be variability in student experience, which is inevitable with the number of tutors and locations involved in the delivery of the undergraduate curriculum. Monitoring of learning experiences and quality of teaching is something that medical schools need to address. To be sure that the ISDM model was being used in consultations, observations of GP consultations could be made. However at a time when student numbers are increasing and good quality GPs are becoming difficult to recruit and retain, starting a system of consultation review may be counterproductive. In the UK GPs who have passed the membership examination of the Royal College of General Practitioners (RCGP), have been assessed on their consultation skills, including shared decision making, listed as the performance criterion 'management options shared'32. However our undergraduate GP tutors are not required to have MRCGP as yet, unlike GP postgraduate trainers who are.

Questions about the quality of the learning experience in primary care compared to secondary care are being answered in a number of ways including the work reported in this thesis and by other researchers in the $\mathrm{UK}^{33,34}$, Australia ${ }^{33}$ and Europe ${ }^{36}$. The consensus appears to be that both settings have advantages and disadvantages but that the majority of students' time should no longer be spent in secondary care.

\section{Summative assessment of management and ISDM skills with simulated patients in final year.}

Summative assessment of ISDM will stress its importance to students and teachers. For valid and reliable assessment of students a suitable assessment scale is needed that is also easy to use given the numbers of students that are being assessed in their institutions each year. The move from long cases to the OSCE format ${ }^{37}$ for summative assessment has added to the reliability of examinations however standard six or ten minute stations may not be long enough to test students ISDM skills in an appropriate way.

\section{All PRHOs (or equivalent) to have attachment in primary care with help to develop ISDM skills.}

In the UK there are plans to change the pre-registration year into a two-year preregistration block with summative assessment prior to registration. Such a two year training period would include a mandatory period of time within general practice/primary care. The challenge to such an innovative and, from the point of view of this thesis, recommended change is the lack of sufficient practices at the moment prepared to take on PRHOs. With increased medical student numbers we are facing a problem recruiting enough practices for undergraduate attachments. For PRHOs the problems will be compounded by practices unlikely to choose to have more than one PRHO in post at a time. Unlike GP registrars who do have a service commitment as well as training needs 
and who are allowed to prescribe, PRHOs need high levels of supervision and the majority of their patients need to be reviewed by a GP before leaving the surgery. Given that the PRHO year(s) are predominantly for training purposes, GPs would need to be trained and commit to a high level of educational input, providing observation of and feedback to the junior doctors. While GPs are paid to provide such educational opportunities, in the UK the remuneration at present is the same as for registrar training but with greater supervision needed and without the benefits of the registrar patient workload $^{38}$. Payment levels, training and recruitment strategies will need to be thought through before this recommendation can be implemented.

\section{Formative assessment of management and ISDM skills with incognito simulated patients in PRHO year.}

Given that some of the learning objectives for primary care PRHO attachments are/will be further development of management and ISDM skills, thought must be given to the development of suitable and reliable methods of assessment. It is at this level that the use of incognito simulated patients may be appropriate for formative assessment. Formative assessment includes timely feedback, an important component to aid further skills development ${ }^{39}$. Educationalists will need to be clear about the level of skills required by the different seniorities of doctors and the cases upon which they should be tested.

Evaluation of any changes that are introduced, particularly in the Ionger term if possible and in relation to improved patient outcomes.

This is of course imperative during any innovation in curriculum design and delivery. A major difficulty in evaluating medical education initiatives are the longer term effects of change, particularly in relation to patient outcomes as there is usually more than one change introduced at any particular time. It also takes a while for junior doctors to have an impact on patient care, and this impact will vary depending on where and with whom they are working. However as these recommendations will affect training and resources, including cost, it is important that their implementation is evaluated as well as possible. The move towards best evidence medical education $(B E M E)^{40}$, in line with the evidence based practice initiative, means that medical educators will have to be accountable for change and be responsible for cost-effective quality education.

\section{References}

1 Pope C, Mays N. Qualitative research: Reaching the parts other methods cannot reach: an introduction to qualitative methods in health and health service research. BMJ 1995; 311: $42-45$.

${ }^{2}$ Denzin N. The Research Act in Sociology. London: Butterworth; 1970.

${ }^{3}$ Becker HS, Geer B. Participant observation: the analysis of qualitative field data. In: Adams R, Preiss J (eds), Human Organization Research: Filed Relations and Techniques. Illinois: Dorsey; 1960. 
${ }^{4}$ Dewey J. Logic. The Theory of Inquiry. New York: Wiley; 1937.

${ }^{5}$ Strauss A, Corbin J. Basics of qualitative research. Second edition. London: Sage; 1998.

${ }^{6}$ Tischer S, Meyer M, Wodak R, Vetter E. Methods of text and discourse analysis. London: Sage; 2000. p 74-89.

${ }^{7}$ Miles MB, Huberman AM. A sourcebook of new methods. London: Sage; 1984.

${ }^{8}$ Silverman D. Interpreting Qualitative Data. Methods for Analysing Talk, Text and Interaction. London: Sage; 1993. p 144-170.

${ }^{9}$ Kitzinger J. The methodology of focus groups: the importance of interaction between research participants. Sociology of Health and Illness 1994; 16: 103-121.

${ }^{10}$ Morgan DL, Krueger RA. When to use focus groups and why. In: Morgan DL (ed) Successful focus groups. Advancing the state of the art. London: Sage; 1993. p 3-19.

1 Van der Vleuten C, Swanson D. Assessment of clinical skills with standardized patients: state of the art. Teaching and Learning in Medicine 1990; 2: 58-76.

${ }^{12}$ General Medical Council. Tomorrow's doctors. London: GMC; 2002.

${ }^{13}$ Kurtz SM, Silverman JD, Benson J, Draper J. Marrying content and process in clinical method teaching: enhancing the Calgary-Cambridge guides. Academic Medicine 2003; 78: 802-809.

${ }^{14}$ Pfeiffer C, Madray H, Ardolino A et al. The rise and fall of students' skills in obtaining a medical history. Medical Education 1998; 32: 283-288.

${ }^{15}$ Basco WT Jr, Reigart JR. When do medical students identify career-influencing physician role models? Academic Medicine 2001; 76: 380-382.

${ }^{16}$ Campos-Outcalt D, Senf J, Watkins AJ, Bastacky S. The effects of medical school curricula, faculty role models and biomedical research support on choice of generalist physician carers: a review and quality assessment of the literature. Academic Medicine 1995; 70: 611-619.

${ }^{17}$ Wright S, Wong A, Newill C. The impact of role models in medical students. J Gen Internal Medicine 1997; 12: 53-56.

${ }^{18}$ Wright S. Examining what residents look for in their role models. Academic Medicine 1996; 71: 290-292. 
${ }^{19}$ Elzubeir MA, Rizk DEE. Identifying characteristics that students, interns and residents look for in their role models. Medical Education 2001; 35: 272-277.

${ }^{20}$ Cote L, Leclerc H. How clinical teachers perceive the doctor-patient relationship and themselves as role models. Academic Medicine 2000; 75: 1117-1124.

${ }^{21}$ Hutchinson L. ABC of learning and teaching. Educational environment. BMJ 2003; 326: $810-812$.

${ }^{22}$ Paice E, Heard S, Moss F. How important are role models in making good doctors? BMJ 2002; 325: 707-710.

${ }^{23}$ Greganti MA. Where are the clinical role models? Arch Intern Med 1990; 150: 25961 .

${ }^{24}$ General Medical Council. Duties of a doctor. London: GMC, 1995.

${ }^{25}$ Neighbour R. Reflections on the ethics of assessment. Education for Primary Care $2003 ; 14: 406-410$.

${ }^{26}$ Godolphin W. The role of risk communication in shared decision making. $B M J 2003$; 327: 692-693.

27 Bensing J, van Dulmen S, Tates K. Communication in context: new directions in communication research. Patient Education and Counseling 2003; 50: 27-32.

${ }^{28}$ Alaszewski A, Horlick-Jones T. How can doctors communicate information about risk more effectively? BMJ 2003; 327: 728-731.

${ }^{29}$ Stevenson FA. General practitioners' views on shared decision making: a qualitative analysis. Patient Education and Counseling 2003; 50: 291-293.

${ }^{30}$ Association of American Medical Colleges. Learning objective for medical student education. Guidelines for medical schools. Washington DC: AAMC; 1998.

${ }^{31}$ Murray E, Modell M. Community-based teaching: the challenges. British Journal of General Practice 1999; 49: 395-398.

${ }^{32}$ www.rcgp.org.uk/rcgp/exam/modules/video/nov00/index.asp

${ }^{33}$ Murray E. Teaching internal medicine in general practice: an evaluation. PhD thesis. Maastricht; 2001.

${ }^{34}$ Parle JV, Greenfield SM, Skelton J, Lester H, Hobbs FD. Acquisition of basic clinical skills in the general practice setting. Medical Education 1997; 31: 47-52. 
${ }^{35}$ Worley P, Silagy C, Prideaux D, Newble D, Jones A. The parallel rural community curriculum: an integrated clinical curriculum based in rural general practice. Medical Education 2000; 34: 558-565.

${ }^{36}$ Foldevi M, Trell E. Learning the basics of medicine in general practice in the Faculty of Health Sciences, Linkoping, Sweden. Annals of Community-Orientated Education 1993; 6: 97-113.

37 Harden RM, Gleeson F. Assessment of clinical competence using an objective structured clinical examination. Medical Education 1974; 13: 41-54.

${ }^{38}$ Carter YH, Parsons S. Pre-registration house officers in general practice: opportunities and pitfalls. Medical Education 2000; 34: 248-249.

${ }^{39}$ Eraut M. A wider perspective on assessment. Medical Education 2004; 38: 803-804.

${ }^{40}$ Hart IR, Harden RM. Best evidence medical education (BEME): a plan for action. Medical Teacher 2000; 22: 131-135. 
Summary 
The work presented in this thesis examines the nature of informed shared decision making and its relevance to the training of medical students and junior doctors. The studies were undertaken to find out whether informed shared decision making is being taught in undergraduate medical curricula and in the early period following qualification, and on the basis of the findings to make recommendations for medical training in the future.

Chapter 1 sets the scene for the research by considering the definition of informed shared decision making (what it is), why it is important in modern medical practice, and how and where it should be taught in medical education. Relevant literature was cited to consider these aspects including related concepts such as patient partnership, the psychosocial history, the patient-centred approach and concordance. A comparison was made between the main locations where medical students and junior doctors work and learn, ie primary and secondary care settings. The introduction concluded by stating the aim of the research and summarised the research questions:

- Is the current medical undergraduate curriculum delivering the necessary training for the practice of the ISDM model within consultations?

- Do medical students observe the patient-centred approach during training and understand its relevance?

- Are medical students exposed to role models who demonstrate a patient-centred approach and ISDM?

- Are students taught and encouraged to elicit a psychosocial history?

- How may the attitudes of students to these concepts, specifically concordance, be assessed?

- Can the attitudes of students to these concepts be altered by a specific learning experience?

- Are PRHOs able and willing to practise the ISDM approach?

- Is the use of incognito simulated patients a satisfactory tool to assess whether ISDM skills are developing?

- Do students and junior doctors have different learning experiences relating to shared decision making in primary and secondary care settings?

Chapter 2 presents a qualitative study based on focus group interviews, the aim of which was to explore students' perspectives on doctor-patient communication, with specific emphasis on their experiences of learning about the patient-centred approach in clinical contacts and perceived differences between clinical attachments in hospital and primary care settings. Third year medical students were interviewed before and after their placements. It was found that during hospital training students were rarely introduced, either through teaching or observation, to the idea of patient-centred consultations. In contrast, both the principles underpinning and/or the practice of such consultations were routinely encountered during the general practice placement. Students considered the community attachment to have helped them appreciate the value of exploring patients' concerns both in terms of enhancing the patients' overall healthcare experience and promoting effective clinical management. While they considered the nature and purpose of hospital care to be qualitatively different from that conducted in the community, the 
relevance of adopting a patient-centred approach on the wards was confirmed. Recommendations for clinical training were made and the importance of further evaluation of the best use of community and hospital-based attachments stressed.

In chapter 3 the views and experiences of GP tutors, who teach medical students consultation skills in their practices, were explored. The aim of this paper was to consider the views of GP tutors on how medical students may learn about patient management and shared decision making, taking into account the GPs' experiences of teaching and whether they act as role models by using a shared decision making model themselves The GPs' views will inform the planning of future primary care attachments. This is a study using qualitative analysis of semi-structured interviews with the eleven GP tutors who teach medical students in years two, three and four of a five-year undergraduate curriculum. We identified three main themes with subsidiaries. GPs enjoy teaching and have useful ideas about how to involve students in patient management. On the whole they try and encourage patients to share decisions about management and have developed strategies to decide how much information to share with patients. The GPs feel that over the years with changes in undergraduate curricula, the students' communication skills have improved. For students to become better skilled at shared decision making with patients, they need to have longer attachments in primary care with the ability to followup patients. We concluded that while GPs are being asked to take on increasing amounts of undergraduate teaching, they are keen to help students learn consultation skills and are good role models for shared decision making strategies. Longer attachments in primary care have implications for workload and curriculum planning but appear to be one method to help students manage patients.

Chapter 4 reports a study into whether the current medical undergraduate curriculum is delivering skills training relating to how to elicit a patient's psychosocial history, a prerequisite for adopting a patient-centred approach. The literature shows that medical students' communication skills and their ability to take a meaningful psychosocial history decline during their clinical training. It was postulated that psychosocial histories are given a low priority in busy clinical attachments. The aim of this study was to identify factors that affect how medical students gain skills in psychosocial assessment. A random sample of 37 medical students filled in a questionnaire before and after their introductory course and they were asked to keep a logbook of their experiences of teaching about psychosocial history taking. There were 504 teaching experiences recorded of which less than half were positive. Negative experiences often related to poor communication by clinicians. At the end of the course less than half the students felt confident in taking a psychosocial history. In conclusion it was suggested that to improve doctors' skills in this important area of patient assessment teaching in psychosocial history taking should be made explicit, as an integrated part of the overall assessment of a patient.

Chapter 5 describes the development and validation of a practical, valid and reliable tool to measure attitudes to concordance in medicine taking. A postal questionnaire was devised comprising of statements from the original concordance document of the Royal Pharmaceutical Society of Great Britain, along with statements reflecting the orthodox 
model of medicine taking. Respondents rated each statement on a 4-point Likert agreement scale. The questionnaire also included 3 scenarios of consultations involving medicine prescribing and taking, with associated statements for rating as true or false. A random sample of 207 medical, nursing and pharmacy graduates in the North of England at the time of qualification. 81 completed questionnaires $(39 \%)$ were returned. Item analysis reduced the 22 -item scale to a 12 -item scale with good reliability (Alpha $=.79$ ) and construct validity was demonstrated through correlation with responses to the scenarios. Although the typical respondent had a positive attitude towards concordance (mean $=2.3$ ), $25 \%$ of respondents had negative attitudes. Pharmacists showed the least favourable attitudes $(p<0.05)$. It was concluded that the 12-item Leeds Attitude Towards Concordance (LATCon) scale is a reliable and valid tool for assessing health care providers' attitudes to the new concept of concordance in medicine taking. Newly qualified doctors, nurses and pharmacists tended to hold favourable attitudes, although a significant minority - especially pharmacists - hold negative attitudes. The implications for undergraduate and continuing professional education were discussed, in line with the move towards patient partnership and informed shared decision making.

In Chapter 6 the LATCon scale was administered to undergraduate medical students to assess their attitudes to the concept of concordance as a base for further educational interventions. The scale was administered to first and second year medical students at the beginning of the academic year, and to the same second year students after they had completed a written exercise relating to concordance. The response rate was over $80 \%$ for each group. There was no difference in the attitudes towards concordance of the first years and the second years prior to the intervention. After they had completed the exercise, the second years' attitudes towards concordance improved by a small but significant amount. It was concluded that a paper-based exercise with questions focussing on concordance and based around cases appears to improve medical students' attitudes towards the concept. However this exercise needs to be followed up with skills training and observation of role models in order that the attitudes of the students translate into practice once they are qualified.

Chapter 7 explores whether newly qualified doctors are able to observe and practise the informed shared decision model by finding out their views and experiences in general practice and hospital settings regarding the concept of patient partnership and their experience of involving patients in management decisions. Twelve pre-registration house officers (PRHOs) were interviewed towards the end of their four-month general practice attachments. The interviews were semistructured and analysed qualitatively. Three major themes emerged. The PRHOs perceived differences in approach between consultations carried out in hospital and primary care settings, with general practitioners being more likely to share information and decisions with patients. As medical students the PRHOs had had little opportunity to practise sharing information and management decisions with patients and variable experience of this after graduation. On the whole they were favourable to the concept of patient partnership. It was concluded that medical students and PRHOs lack training and opportunity to decide on management and discuss this with patients and yet, particularly in general practice settings, they have to practise these skills. The PRHOs had begun to develop strategies to decide how much information to give to 
patients and to what extent to involve patients in management decisions. Thus this is an area that needs further consideration when planning both undergraduate and postgraduate medical education.

Chapter 8 describes a feasibility study regarding the use of incognito simulated patients as a method of assessing whether doctors, who state that they practise a patient-centred approach and share decisions with patients, do indeed do this in practice. The use of simulated patients in the training and assessment of medical students and doctors is now widespread. However in the UK simulated patients have not been used covertly in general practice though this practice has been introduced elsewhere. The aim of this study was to investigate the feasibility of introducing incognito simulated patients into general practices and to explore the experiences of the doctors and simulated patients involved. Covert simulated patients attended five general practice surgeries in West Yorkshire, England, for consultations with eleven pre-registration house officers, followed by semi-structured interviews of the doctors and reports from the patients. Six of the doctors deduced that the simulated patient was not a 'real' patient. There were various reasons for this. The doctors did not object to the experience, though some were worried about revealing a perceived lack of knowledge, and valued getting feedback on their consultations. In conclusion this was thought to be a valuable method, amongst others, of looking at GP consultations but involves difficult logistics. A code of practice needs to be adhered to so that the doctors and simulated patients do not feel threatened by the experience. Special care needs to be taken with the patient scenario.

Chapter 9 explores in more detail whether newly qualified doctors feel adequately trained to discuss management with patients, their attitudes to the concept of sharing decisions about treatment with patients and their strategies for coping with managing patients. In addition the doctors also carried out a consultation with a simulated patient in their practice to match their attitudes to their behaviour. Thirty-six pre-registration house officers (PRHOs) in general practice were interviewed over the course of three years.

Six themes arose from the interview data. Medical students infrequently formulate management plans and only one had discussed such a plan with a real patient before qualifying. Yet all the PRHOs had to manage patients once in post. They felt ill prepared to do this, however they had developed strategies to manage patients and believe that shared decision making is appropriate. The PRHOs felt that discussing options with patients is more likely in general practice than hospital and they have more opportunity to practise sharing decisions in primary care. There was evidence that the PRHOs do involve patients in the decision making process. In conclusion it was felt that medical students and PRHOs need further training and practice in sharing decisions with patients and feedback on their skills.

Chapter 10 presents conclusions, discusses the implications of the results of the research, and makes recommendations regarding medical undergraduate education and the early postgraduate training of junior doctors. The research questions are answered. On the whole there is a lack of training in the current medical undergraduate curriculum to help students in the early clinical years to develop the skills necessary for informed shared 
decision making, and a paucity of role models does not help foster the necessary attitudes. Student attitudes may be measured by an appropriate questionnaire/scale, such as the once to concordance, which was developed for this study. Specific educational inputs on concordance led to a change in attitudes that may be measured by the LATCon scale. Once into the post qualification period, there is variation between PRHOs as regards to observation and practice of informed shared decision making. The approach is more likely to be observed and practised in primary care than hospital. It was found that PRHOs have to manage patients despite little training to do this as students and develop their own strategies in practice. In order to find out whether PRHOs do indeed practise the ISDM approach as they state in interview, their behaviour in consultation was assessed by means of incognito simulated patients, following a feasibility study of their use. Incognito simulated patients in primary care are only one of several ways that junior doctors may be assessed. This is a feasible method but care must be taken in carrying out this method and attention must be paid to ethical issues. General practice attachments and GP tutors offer the opportunity for medical students to observe the approach. Longer periods spent in general practice for senior students would help the process and enable students to practise the approach with the benefit of following up patients whom they manage under supervision. There are different experiences for medical students and junior doctors in the two educational and work-based settings of primary and secondary care. There is a greater emphasis on a patient-centred approach and ISDM in primary compared to secondary care. Undergraduate and postgraduate medical education needs to recognise this fact and organise the optimum educational experience for students to observe and practise the approach.

Following a review of the methodology used in the thesis, I make nine recommendations relating to medical education based on the research. The challenges facing faculty in implementing these recommendation is discussed. 


\section{Samenvatting}

Het onderwerp van dit proefschrift is "informed shared decision making". Dit is een benadering van de arts-patiëntrelatie waarbij de patiënt uitdrukkelijk betrokken wordt bij de besluitvorming over beleid en behandeling en waarbij een open informatieuitwisseling tussen arts en patiënt van groot belang is. Deze benadering wordt hier aangeduid als 'participatieve besluitvorming'. Het doel van de onderzoeken die in dit proefschrift beschreven worden, was na te gaan of er in de artsopleiding en in het begin van de vervolgopleiding aandacht besteed wordt aan participatieve besluitvorming om te komen tot aanbevelingen voor het medisch onderwijs in de toekomst.

Hoofdstuk 1 schetst de achtergronden van het onderzoek, waarbij met name aandacht besteed wordt aan wat participatieve besluitvorming inhoudt, waarom het belangrijk is in de moderne geneeskundepraktijk en hoe en waar er in het medisch onderwijs aandacht aan besteed moet worden. Deze onderwerpen worden besproken op basis van relevante literatuur met daarnaast aandacht voor aanverwante concepten, zoals patiëntenpartnership, psychosociale anamnese, patiëntgerichte benadering en concordantie. Deze term dient ter vervanging van het misleidende 'therapietrouw'. Concordantic wordt gebruikt als: overeenstemming tussen arts en patiënt ten aanzien van voorschrijven en gebruik van medicijnen. In de onderzoeken is een vergelijking gemaakt tussen de voornaamste settings waarin het leren en werken van studenten en pas afgestudeerde artsen zich afspeelt, namelijk de eerste- en tweedelijnsgezondheidszorg. Aan het eind van hoofdstuk I wordt het doel van het onderzoek omschreven en worden de onderzoeksvragen als volgt samengevat:

- Krijgen studenten in het huidige geneeskundecurriculum voldoende training om het model van participatieve besluitvorming in de praktijk te kunnen toepassen?

- Krijgen pas afgestudeerde artsen in hun opleiding de gelegenheid om de participatieve aanpak te observeren en inzicht te krijgen in de relevantie van deze aanpak?

- Zien geneeskundestudenten rolmodellen die een patiëntgerichte benadering en participatieve besluitvorming hanteren?

- Leren studenten een psychosociale anamnese afnemen en worden zij gestimuleerd om dit in de praktijk toe te passen?

- Op welke manier kan de houding van studenten ten aanzien van een patiëntgerichte benadering en participatieve besluitvorming beoordeeld worden, met name de houding ten aanzien van concordantie?

- Kan de houding van studenten ten aanzien van deze concepten veranderd worden door middel van een specifieke leerervaring?

- Zijn pas afgestudeerde artsen bereid en in staat om participatieve besluitvorming toe te passen?

- Is de methode waarbij simulatiepatiënten incognito op het spreekuur komen een geschikt instrument om de ontwikkeling van vaardigheden ten aanzien van participatieve besluitvorming te beoordelen? 
- Zijn er verschillen in leerervaringen die studenten en pas afgestudeerde artsen opdoen ten aanzien van participatieve besluitvorming tussen eerste- en tweedelijnssettings?

Hoofdstuk 2 beschrijft een kwalitatief verkennend onderzoek met behulp van focusgroepen. In dit onderzoek staan de ideeën van studenten over artspatiëntcommunicatie centraal en wordt vooral aandacht besteed aan de leerervaringen van studenten met de patiëntgerichte benadering in de klinische praktijk en aan hun mening over de verschillen tussen co-assistentschappen in het ziekenhuis en in de huisartsenpraktijk. Derdejaars geneeskundestudenten namen voorafgaand aan en na afloop van de co-assistentschappen in dat jaar deel aan focusgroepen. Het bleek dat studenten in het onderwijs noch door middel van eigen waarneming patiëntgerichte consulten in het ziekenhuis tegenkwamen. In de huisartsenpraktijk daarentegen kwamen de studenten geregeld in aanraking met patiëntgerichte consultvoering, zowel met de onderliggende principes als met de toepassing ervan in de praktijk. De studenten gaven aan dat het co-assistentschap in de huisartsenpraktijk in belangrijke mate had bijgedragen aan hun inzicht dat het belangrijk is om aandacht te besteden aan de zorgen van de patiënt, omdat dit niet alleen bevorderlijk is voor een positieve ervaring van de patiënt met de gezondheidszorg maar ook voor een doeltreffend klinisch beleid. Hoewel de studenten inzagen dat er een kwalitatief verschil bestaat qua inhoud en doel tussen de zorg in het ziekenhuis en in de eerste lijn, werd bevestigd dat een patiëntgerichte benadering op een ziekenhuisafdeling ook zinvol is. Er werden aanbevelingen gedaan voor het klinisch onderwijs en er werd benadrukt dat het belangrijk is om na te gaan hoe co-assistentschappen in en buiten het ziekenhuis het beste ingevuld kunnen worden.

Het onderzoek dat beschreven wordt in hoofdstuk 3 betreft de meningen en ervaringen van huisarts-docenten die in hun praktijk geneeskundestudenten begeleiden bij het leren van consultvaardigheden. In dit onderzoek werd aan huisarts-docenten gevraagd hoe volgens hen geneeskundestudenten kunnen leren een behandelplan op te stellen en uit te voeren en de patiënt daarbij te betrekken, waarbij rekening werd gehouden met de ervaring van de huisarts als docent en ook of de huisarts zelf als rolmodel fungeerde voor een participatieve besluitvormingsstijl. De visie van de huisarts-docenten kan bijdragen aan de inrichting en organisatie van toekomstige stages in de huisartsenpraktijk. Er werden semi-gestructureerde interviews afgenomen bij elf huisarts-docenten en de verzamelde gegevens, werden kwalitatief geanalyseerd. De geïnterviewde huisartsdocenten begeleidden geneeskundestudenten in het tweede, derde en vierde jaar van een vijfjarige artsopleiding. Uit de analyse van de gegevens kwamen drie hoofdthema's met subthema's naar voren. De huisartsen waren enthousiast over het geven van onderwijs en zij hadden goede ideeën over hoe studenten bij de patiëntenbehandeling betrokken kunnen worden. Over het algemeen probeerden zij hun patiënten te betrekken bij beslissingen over de behandeling en hadden zij strategieën ontwikkeld om te bepalen hoeveel informatie een patiënt moet krijgen. De huisartsen vonden dat de communicatievaardigheden van studenten verbeterd waren tengevolge van de veranderingen die het geneeskundecurriculum in de loop der jaren heeft ondergaan. Om studenten meer vaardigheden voor participatieve besluitvorming bij te kunnen brengen moeten de co-assistentschappen in de huisartsenpraktijk verlengd worden, zodat 
studenten patiënten gedurende langere tijd kunnen volgen. De conclusie naar aanleiding van dit onderzoek was dat huisartsen enthousiast zijn over het begeleiden van studenten ondanks het steeds grotere beroep dat op hen gedaan wordt vanuit het onderwijs en dat zij bovendien goed als rolmodel voor participatieve besluitvorming kunnen fungeren. Langere stages in de huisartsenpraktijk hebben weliswaar consequenties voor werklast en curriculumplanning, maar lijken niettemin een manier om studenten te begeleiden bij het opstellen en uitvoeren van een behandelplan.

Hoofdstuk 4 behandelt een onderzoek waarin is nagegaan of er in het vaardigheidsonderwijs in de huidige geneeskundeopleiding aandacht besteed wordt aan de psychosociale anamnese als nodig onderdeel van een patiëntgerichte aanpak. Uit de literatuur is bekend dat studenten in de klinische fase een achteruitgang vertonen zowel in communicatievaardigheden als in de vaardigheid om een goede psychosociale anamnese af te nemen. In dit onderzoek werd ervan uitgegaan dat de psychosociale anamnese weinig prioriteit krijgt in de drukke klinische co-assistentschappen. Het doel van dit onderzoek was factoren aan te wijzen die van invloed zijn op de verwerving van vaardigheden die studenten moeten beheersen om psychosociale aspecten te kunnen beoordelen. Een willekeurige steekproef van 37 geneeskundestudenten vulde een schriftelijke vragenlijst in voór en na een inleidende cursus klinische vaardigheden. De studenten werd ook gevraagd een logboek bij te houden over hun ervaringen met onderwijs betreffende de psychosociale anamnese. Er werden 504 onderwijservaringen geregistreerd. Daarvan was minder dan de helft positief. Negatieve ervaringen hingen vaak samen met minder goede communicatie door clinici. Aan het eind van de cursus voelde minder dan de helft van de studenten zich in staat een psychosociale anamnese af te nemen. De conclusie uit dit onderzoek was dat de psychosociale anamnese als afzonderlijk onderdeel geïntegreerd moet worden in het geheel van het onderwijs omtrent het patiëntenonderzoek, teneinde de vaardigheden van artsen op dit belangrijke onderdeel te kunnen verbeteren.

In hoofdstuk 5 wordt een onderzoek beschreven waarin een uitvoerbaar, valide en betrouwbaar instrument werd ontwikkeld en gevalideerd voor het meten van attitudes ten aanzien van concordantie (overeenstemming tussen arts en patiënt over voorschrijven en gebruik van medicatie). Er werd een schriftelijke vragenlijst ontwikkeld die bestond uit stellingen ontleend aan het oorspronkelijke concordantiedocument van de Royal Pharmceutical Society of Great Britain en uit stellingen ontleend aan het traditionele geneeskundemodel. Op een vierpunts Likertschaal konden de deelnemers aangeven in hoeverre ze het met een stelling eens of oneens waren. Daarnaast werden drie scenario's in de vragenlijst opgenomen van consulten waarin het voorschrijven en gebruik van geneesmiddelen aan de orde kwamen. Bij deze scenario's behoorden stellingen waarvan aangegeven moest worden of ze juist of onjuist waren. De vragenlijst werd toegestuurd aan een gerandomiseerde steekproef van 207 pas afgestudeerde artsen, verpleegkundigen en apothekers. Er werden 81 vragenlijsten ingevuld teruggestuurd (39\%). De itemanalyse leidde ertoe dat de 22 items van de schaal teruggebracht werden tot 12 items. De schaal met twaalf items bleek een goede betrouwbaarheid te hebben (alfa $=.79$ ). De constructvaliditeit werd aangetoond door middel van correlatie met de antwoorden op de scenario's. Hoewel de doorsnee deelnemer een positieve houding had ten aanzien van 
concordantie (gemiddeld 2.3), bleek $25 \%$ van de deelnemers een negatieve houding te hebben. De apothekers hadden de minst gunstige houding $(p<0.05)$. Uit dit onderzoek werd geconcludeerd dat de Leeds Attitude Towards Concordance (LATCon) schaal met twaalf items een betrouwbaar en valide instrument is om de houding van gezondheidszorgverleners te meten ten aanzien van het nieuwe concept concordantie bij medicijngebruik. Pas afgestudeerde artsen, verpleegkundigen en apothekers hadden over het algemeen een positieve houding, maar een aanzienlijke minderheid - hoofdzakelijk bestaand uit apothekers - had een negatieve houding. De implicaties van deze bevinding voor basisopleiding en nascholing worden besproken in het licht van de tendens om meer aandacht te besteden aan patiëntenpartnership en participatieve besluitvorming.

Hoofdstuk 6 betreft een onderzoek, ten behoeve van onderwijsontwikkeling, waarin de attitude van geneeskundestudenten ten aanzien van concordantie beoordeeld werd met behulp van de LATCon-schaal. De vragenlijst werd aan het begin van het academisch jaar ingevuld door eerste- en tweedejaars geneeskundestudenten en nogmaals door dezelfde tweedejaarsstudenten nadat ze een schriftelijke oefening over concordantie hadden gemaakt. In alle groepen was de respons hoger dan $80 \%$. Voorafgaand aan de interventie waren er geen verschillen tussen de houding van de eerste- en de tweedejaarsstudenten. $\mathrm{Na}$ de oefening bleek de houding van de tweedejaarsstudenten ten aanzien van concordantie een geringe maar significante verbetering te vertonen. Hieruit werd geconcludeerd dat een schriftelijke oefening met gerichte vragen over concordantie naar aanleiding van een aantal casus de houding van geneeskundestudenten ten aanzien van dit concept kan verbeteren. De oefening dient evenwel gevolgd te worden door vaardigheidstraining en observatie van goede voorbeelden opdat de houding na het afstuderen vertaald kan worden naar toepassing in de praktijk.

In hoofdstuk 7 wordt een onderzoek gepresenteerd waarin werd nagegaan of pas afgestudeerde artsen in de gelegenheid waren participatieve besluitvorming te observeren en toe te passen. Hiertoe werd pas afgestudeerde artsen gevraagd naar hun mening en ervaringen in huisartsenpraktijk en ziekenhuis van ten aanzien van het concept patiëntenpartnership en naar hun praktijkervaringen met participatieve besluitvorming. $\mathrm{Bij}$ twaalf pas afgestudeerde artsen werd een semi-gestructureerd interview afgenomen na afloop van vier maanden stage in de huisartsenpraktijk. De interviews werden kwalitatief geanalyseerd. Uit de analyse van de gegevens kwamen drie hoofdthema's naar voren. Als verschil in benadering tussen ziekenhuis en huisartsenpraktijk noemden de artsen dat huisartsen meer geneigd waren patiënten te informeren en bij beslissingen te betrekken. De artsen gaven aan dat ze tijdens hun geneeskundestudie weinig ervaring op hadden kunnen doen met participatieve informatieverstrekking en besluitvorming. De ervaringen van de artsen na de basisopleiding waren wisselend. Over het algemeen stonden de artsen positief tegenover het concept patiëntenpartnership. De conclusie die uit dit onderzoek naar voren kwam was dat er, ten aanzien van besluitvorming over beleid en bespreking daarvan met patiënten, te weinig training en gelegenheid tot toepassing geboden wordt aan geneeskundestudenten en pas afgestudeerde artsen, terwijl zij wel geacht worden deze vaardigheden toe te kunnen passen, met name in de huisartsenpraktijk. De artsen waren beslissingsstrategieën gaan ontwikkelen ten aanzien van de hoeveelheid informatie voor patiënten en de mate waarin patiënten bij beslissingen over hun behandeling 
betrokken kunnen worden. Hieruit blijkt dat dit een aandachtsgebied moet zijn bij curriculumontwikkeling in basis- en vervolgopleiding.

In hoofdstuk 8 wordt een haalbaarheidsonderzoek beschreven betreffende een methode waarbij simulatiepatiënten incognito op het spreekuur komen om te beoordelen of artsen die zeggen dat zij een patiëntgerichte en participatieve benadering toepassen dit in de praktijk ook werkelijk doen. Op veel plaatsen spelen simulatiepatiënten een rol bij training en beoordeling van geneeskundestudenten en artsen. De beoordelingsmethode waarbij simulatiepatiënten incognito op het spreekuur in een artsenpraktijk komen, is elders al wel toegepast, maar nog niet bij beoordelingen in de huisartsenpraktijk in GrootBrittannië. Dit onderzoek had tot doel om te bepalen of het haalbaar was om simulatiepatiënten incognito op het spreekuur van de huisarts te laten komen en om de ervaringen van de betrokken artsen en simulatiepatiënten met deze methode te evalueren. Simulatiepatiënten bezochten incognito vijf huisartsenpraktijken in West Yorkshire, Engeland, waar zij op het spreekuur kwamen van 11 pas afgestudeerde artsen. Na het consult werd een semi-gestructureerd interview afgenomen bij de arts en rapporteerde de simulatiepatiënt over het consult. Zes huisartsen ontdekten dat de simulatiepatiënt geen echte patiënt was. Hiervoor waren verschillende oorzaken aan te wijzen. Hoewel sommige artsen bezorgdheid uitten over de mogelijkheid dat een door henzelf ervaren gebrek aan kennis aan het licht zou komen, hadden de artsen geen bezwaar tegen deze aanpak en waardeerden zij het dat ze feedback kregen over hun consultvoering. De conclusie uit dit onderzoek was dat de onderzochte methode een waardevolle bijdrage kan leveren als een van de methoden om consulten in de huisartsenpraktijk te observeren, maar dat de logistiek van de methode gecompliceerd is. $\mathrm{Er}$ is een gedragscode nodig om ervoor te zorgen dat artsen en simulatiepatiënten de methode niet als bedreigend ervaren. De patiëntenrol dient met grote zorgvuldigheid opgesteld te worden.

Hoofdstuk 9 beschrijft een onderzoek dat nader ingaat op de vraag of pas afgestudeerde artsen zich door hun opleiding goed voorbereid voelen wat betreft het bespreken van behandelplannen met patiënten en strategieën voor het opstellen en uitvoeren daarvan. Simulatiepatiënten consulteerden de artsen incognito, met als doel na te gaan of gedrag en attitude van de artsen met elkaar in overeenstemming waren. In 3 jaar tijd werden 36 pas afgestudeerde artsen geïnterviewd in de huisartsenpraktijk. De analyse van de gegevens leverde zes thema's op. Geneeskundestudenten stellen maar zelden een behandelplan op en slechts één student had vóór het afstuderen een behandelplan besproken met een echte patiënt. Niettemin behoorde patiëntenbehandeling tot het takenpakket van alle pas afgestudeerde artsen. $\mathrm{Zij}$ hadden het gevoel dat hun voorbereiding hierop te wensen overliet, maar zij hadden zelf strategieën hiervoor ontwikkeld en zij zagen participatieve besluitvorming als een goede aanpak. Ook waren zij van mening dat in de huisartsenpraktijk behandelmogelijkheden vaker met patiënten besproken worden dan in het ziekenhuis en dat zij in de huisartsenpraktijk meer mogelijkheden hadden om participatieve besluitvorming in de praktijk toe te passen. $\mathrm{Er}$ werd bewijs gevonden dat de artsen hun patiënten inderdaad betrokken bij het nemen van beslissingen over de behandeling. Op basis van dit onderzoek werd geconcludeerd dat geneeskundestudenten en pas afgestudeerde artsen meer training en ervaring en ook meer feedback moeten krijgen met betrekking tot participatieve besluitvorming. 
In hoofdstuk 10 worden conclusies gepresenteerd, wordt de betekenis van de onderzoeksresultaten besproken en worden aanbevelingen gedaan voor de geneeskundeopleiding en de opleiding van junior assistenten. De onderzoeksvragen worden beantwoord. Over het algemeen krijgen studenten in het huidige geneeskundecurriculum onvoldoende training om hen in de eerste jaren in de kliniek te helpen vaardigheden voor participatieve besluitvorming te ontwikkelen en levert het gebrek aan goede voorbeelden geen positieve bijdrage aan de ontwikkeling van een gewenste attitude. De attitude van studenten kan gemeten worden met behulp van een goede vragenlijst, zoals de vragenlijst over concordantie die in het kader van dit onderzoek ontwikkeld is. Deelname aan een onderwijsonderdeel over concordantie resulteerde in een attitudewijziging die gemeten kon worden met behulp van de LATConschaal. Pas afgestudeerde artsen hebben verschillende ervaringen met betrekking tot het observeren en toepassen van participatieve besluitvorming. De benadering wordt vaker gezien en toegepast in de huisartsenpraktijk dan in het ziekenhuis. De resultaten van het onderzoek laten zien dat pas afgestudeerde artsen verantwoordelijk zijn voor de behandeling van patiënten, ook al hebben zij hierin tijdens de studie weinig training gehad, en ontwikkelen ze in de praktijk hun eigen behandelstrategieën. Om te bepalen of de pas afgestudeerde artsen participatieve besluitvorming echt toepassen, zoals zij in een interview zeggen te doen, is hun consultvoering beoordeeld door simulatiepatiënten die incognito de praktijk bezochten, nadat de haalbaarheid van een dergelijke onderzoeksmethode was onderzocht. Deze onderzoeksmethode met simulatiepatiënten die incognito een huisartsenpraktijk bezoeken is slechts een van de vele manieren om het functioneren van pas afgestudeerde artsen te beoordelen. De methode is bruikbaar, maar vereist grote zorgvuldigheid en aandacht voor ethische aspecten. Co-assistentschappen in de huisartsenpraktijk en huisarts-docenten bieden geneeskundestudenten gelegenheid tot observatie van participatieve besluitvorming. Langere co-assistentschappen in de huisartsenpraktijk in de latere jaren van de studie zouden studenten meer mogelijkheden geven om deze benadering te oefenen en bieden tevens het voordeel dat studenten onder supervisie patiënten die bij hen in behandeling zijn, kunnen volgen. Ziekenhuis en huisartsenpraktijk verschillen in de onderwijs- en werkervaringen van geneeskundestudenten en pas afgestudeerde artsen. In de huisartsenpraktijk wordt meer aandacht besteed aan een patiëntgerichte benadering en participatieve besluitvorming dan in het ziekenhuis. De basisopleiding en de vervolgopleiding moeten erkennen dat dit zo is en ervoor zorgen dat studenten in de gelegenheid gesteld worden om tijdens hun studie deze benadering te observeren en toe te passen.

$\mathrm{Na}$ een overzicht van de methodes die in dit proefschrift zijn toegepast worden op basis van het onderzoek 15 aanbevelingen gedaan voor het medisch onderwijs. Er wordt ingegaan op de uitdaging die de uitvoering van deze aanbevelingen aan docenten biedt. 


\section{Curriculum Vitae}

Jill Elizabeth Thistlethwaite was born in Manchester, England on 27 June, 1957. She studied medicine at University College London, during which time she gained a BSc in the history of medicine. She graduated MB BS in 1981 from University College Hospital, London. After house officer posts in Stoke Mandeville and London, she undertook her vocational training for general practice in Aylesbury, Buckinghamshire. She passed her MRCGP with distinction in 1985.

For sixteen years she was a general practitioner in Hebden Bridge, West Yorkshire. Her interest in medical education began when she became a GP trainer and subsequently course organiser in Calderdale. In 1996 she became senior lecturer in community-based education at the School of Medicine, Leeds University. She gained a Masters in Medical Education from the University of Dundee in 1998. In 2003 she moved to the new medical school at James Cook University in North Queensland, Australia where she is currently associate professor in general practice and rural medicine. She has fellowships from the Royal College of General Practitioners (UK) and the Royal Australian College of General Practitioners, and has been elected a fellow of the Society of Medical Writers.

Her interests in education and patient care are communication, consultation skills and shared decision making, as well as professionalism and interprofessional education. She also writes widely for the medical press and is associate editor of the Journal of Interprofessional Care. 
